\title{
School improvement from the central office: A view of the five year school system strategic planning process in selected West Virginia counties
}

\author{
Victor V. Fisher \\ West Virginia University
}

Follow this and additional works at: https://researchrepository.wvu.edu/etd

\section{Recommended Citation \\ Fisher, Victor V., "School improvement from the central office: A view of the five year school system strategic planning process in selected West Virginia counties" (2010). Graduate Theses, Dissertations, and Problem Reports. 3516. \\ https://researchrepository.wvu.edu/etd/3516}

This Dissertation is protected by copyright and/or related rights. It has been brought to you by the The Research Repository @ WVU with permission from the rights-holder(s). You are free to use this Dissertation in any way that is permitted by the copyright and related rights legislation that applies to your use. For other uses you must obtain permission from the rights-holder(s) directly, unless additional rights are indicated by a Creative Commons license in the record and/ or on the work itself. This Dissertation has been accepted for inclusion in WVU Graduate Theses, Dissertations, and Problem Reports collection by an authorized administrator of The Research Repository @ WVU. For more information, please contact researchrepository@mail.wvu.edu. 
School Improvement from the Central Office:

A View of the Five Year School System Strategic Planning Process in Selected West Virginia Counties

\author{
Victor V. Fisher \\ Dissertation submitted to the \\ College of Human Resources \& Education \\ at West Virginia University \\ in partial fulfillment of the requirements \\ for the degree of \\ Doctor of Education \\ In \\ Educational Leadership Studies \\ Helen M. Hazi, Ph.D., Chair \\ Paul Chapman, Ph.D. \\ Martha Dean, Ed.D. \\ Daniel Hursh, Ph.D. \\ Adriane Williams, Ph.D. \\ Department of Educational Leadership Studies \\ Morgantown, West Virginia \\ 2010
}

Keywords: Strategic Planning, School Improvement 


\begin{abstract}
School Improvement from the Central Office:

A View of the Five Year School System Strategic Planning Process in Selected West Virginia Counties
\end{abstract}

Victor V. Fisher

This study's purpose was to describe and develop understandings of the West Virginia Five Year School System Strategic Plan development process in selected counties. A qualitative design of a multiple site case study was chosen because of its ability to interpret and understand process. Strategic planning is intended to be a state mandated process for school districts that results in improved student, school, and school system performance. These four nominated districts used a common style and process of consensus building and decisionmaking. Facilitators and barriers to the process were identified. Facilitators are described in a context of teaming and consensual decision-making. The districts in this research overcame barriers, such as the compliance nature of the document, to achieve plans aimed at school improvement. Four theories are used to help understand the planning process: systems as the overarching process, distributed leadership to describe the shared leadership roles, stasis theory as a generative heuristic to model the social discourse and knowledge building that occurred, and social decision scheme to consider the characteristics of consensual decisionmaking. 


\section{Acknowledgement}

This dissertation could not have been completed without the support of many individuals both personally and professionally.

First I extend my deepest thanks to Dr. Helen Hazi, my chairperson, mentor, cheerleader, and taskmaster throughout this endeavor. She is one of those very few teachers, in each of our lives, which have had a profound and lasting impact.

Thanks to each of my committee members, Dr. Chapman, Dr. Dean, Dr. Hursh, and, most recently, Dr. Williams for their support, advice, and wisdom throughout this process. A special thank you to the cohort's primary instructors, Dr. Chapman, Dr. Harnett, Dr. Hazi, and Dr. Heinen. Their time and effort made the cohort model the success it has been at WVU. Each of us appreciated their ability to blend research and theory with practice. As a cohort we have shared many special moments. It's been a pleasure to go through the program with so many talented individuals. In particular it is the camaraderie of Dr. Hazi’s group of David Agnew, Karen Davies, Kathy Kidder-Wilkerson, Robin Lewis, David Tupper, and Diane Watt that got us moving on the dissertation adventure.

I also thank the WVDE representative, school districts, and administrators that were willing to give their time and share their knowledge to make this research possible.

In closing I thank my wife, Jami, for her patience and encouragement through this

long and demanding journey. To my daughter, Michelle, and my parents Edwinnia and Vincent, for understanding my absence and supporting me unconditionally. 


\section{Table of Contents}

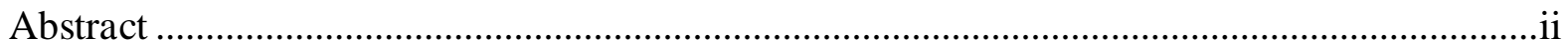

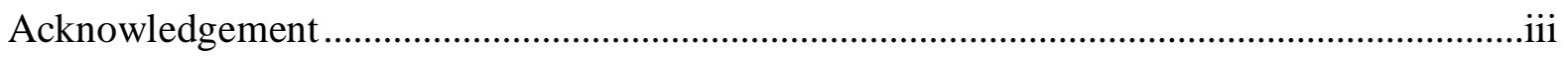

Chapter One: Statement of Problem................................................................................ 1

School Improvement and the Central Office .............................................................. 1

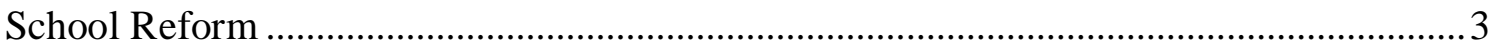

Organization Theory Considerations ....................................................................

Strategic Planning and West Virginia Improvement Efforts ........................................5

Purpose of Study, Research Questions, and Design ....................................................... 8

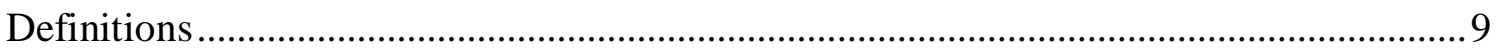

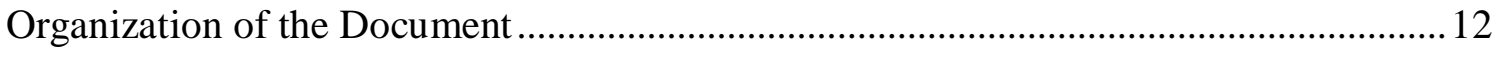

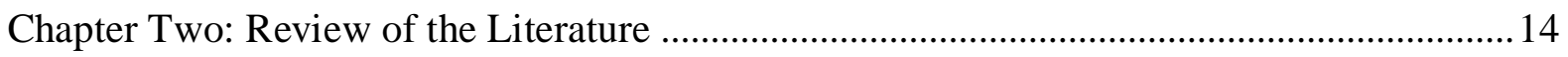

School Improvement and Strategic Planning ........................................................... 14

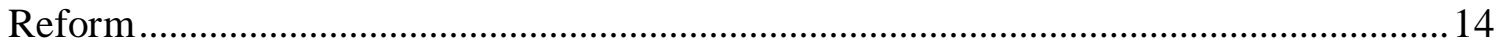

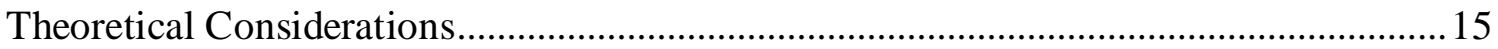

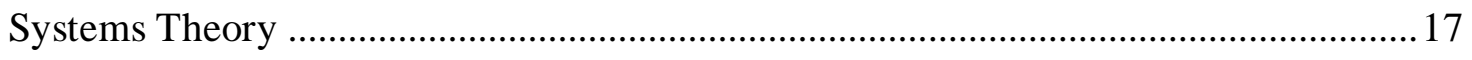

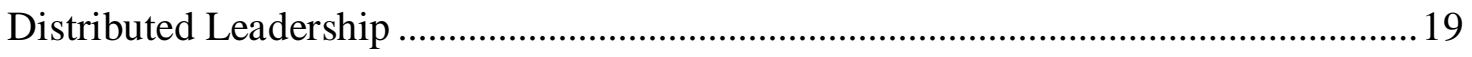

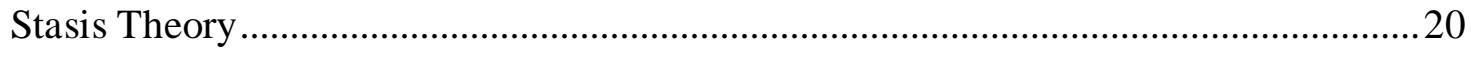

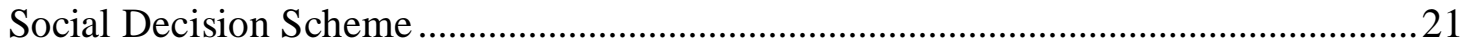

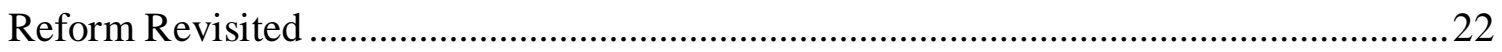




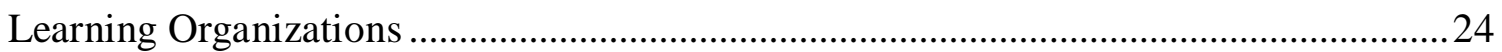

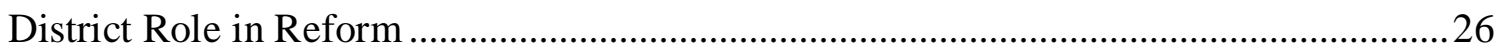

Historical Context of Strategic Planning .......................................................................29

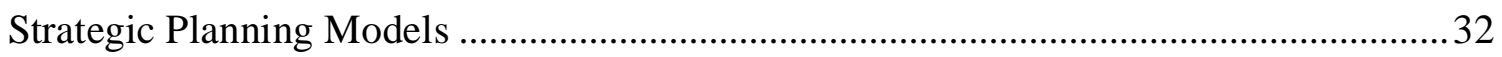

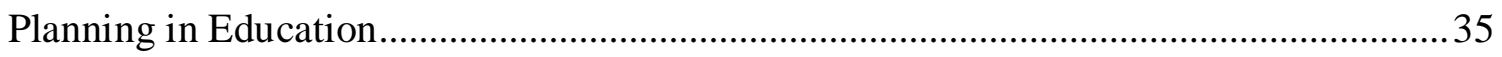

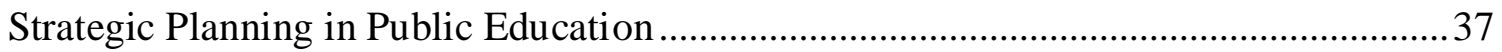

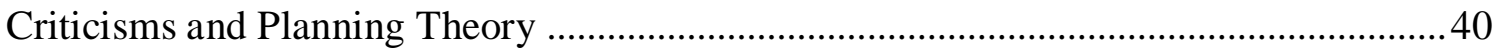

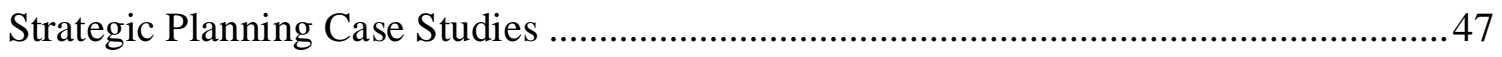

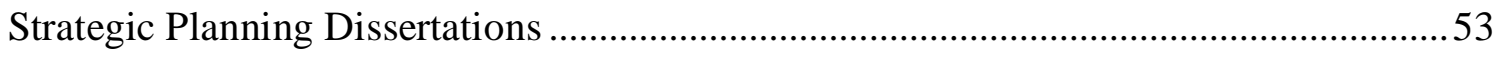

Planning in West Virginia Public Schools ................................................................57

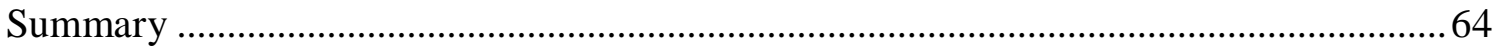

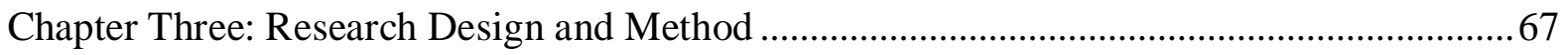

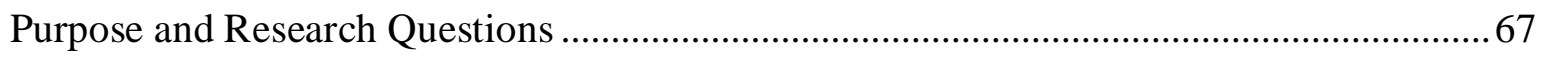

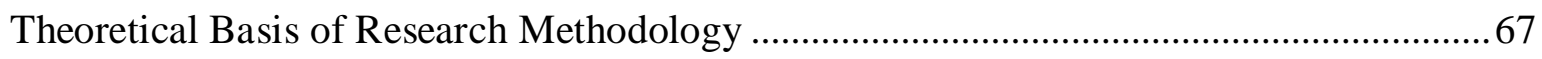

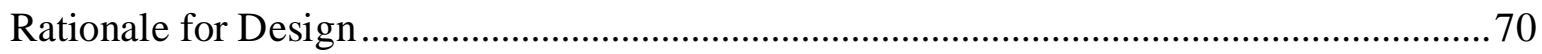

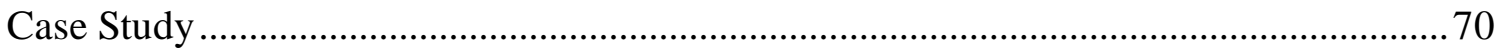

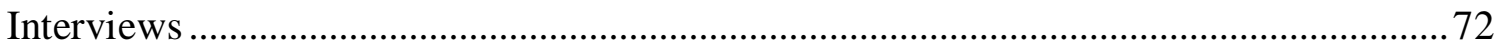

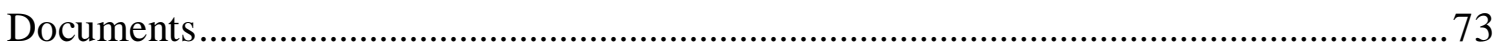

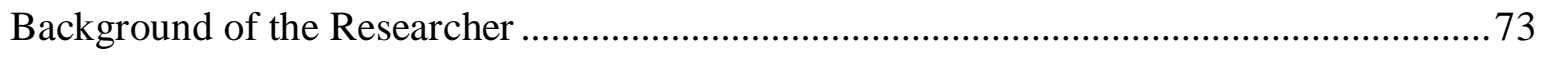

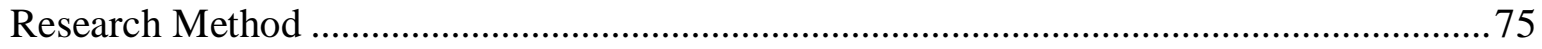




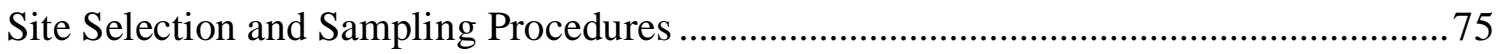

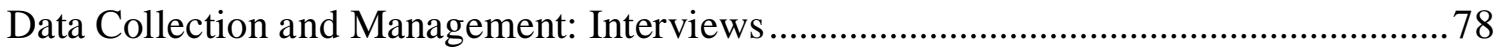

Data Collection and Management: Document Cache ........................................................ 80

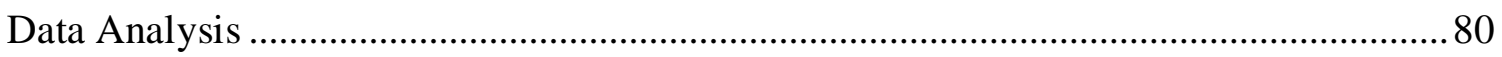

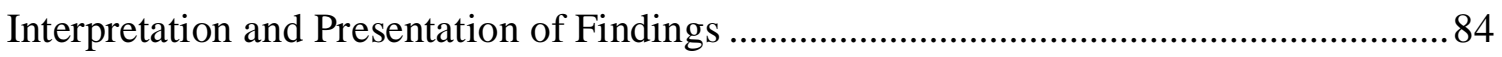

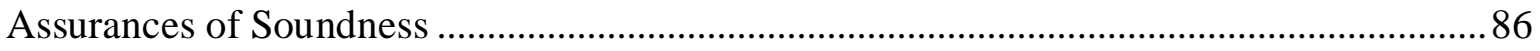

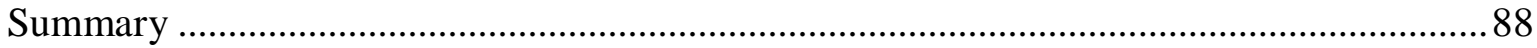

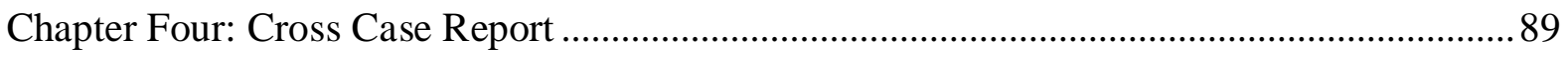

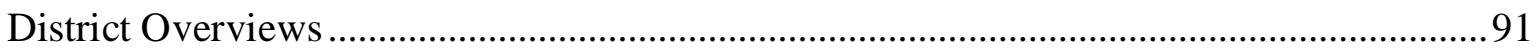

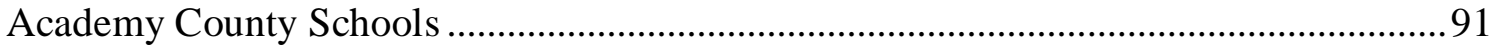

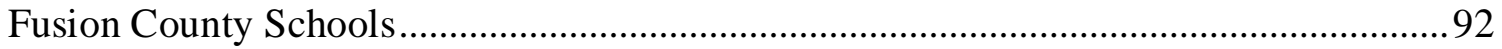

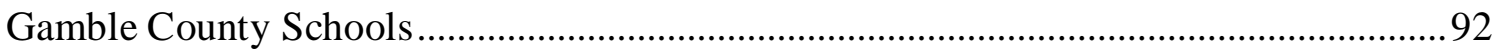

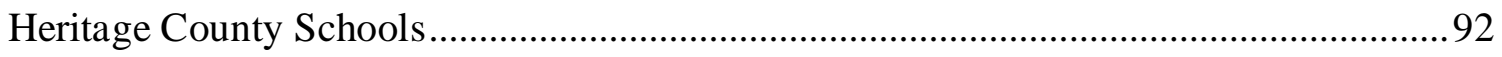

The Strategic Plan Development Process........................................................................93

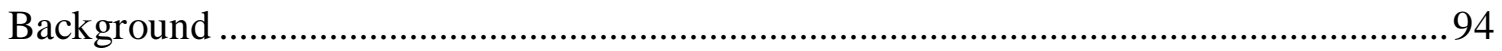

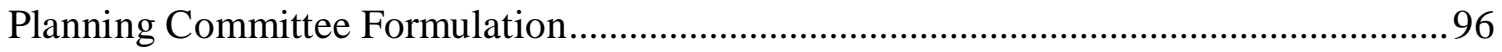

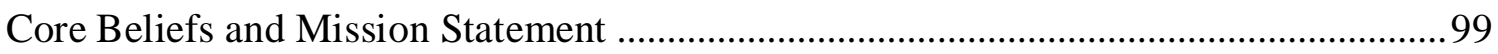

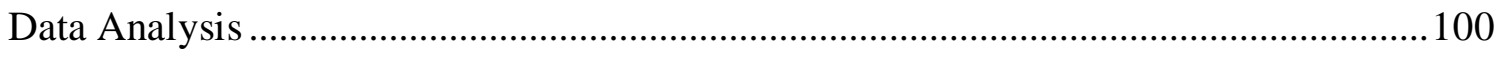

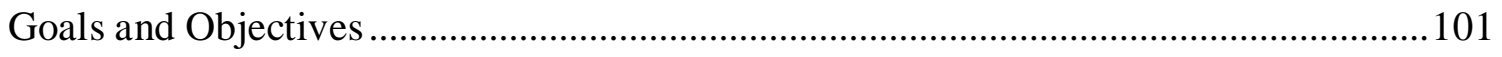

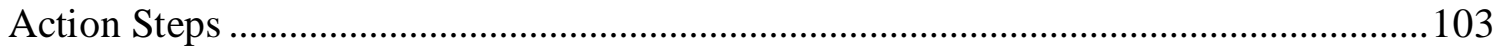




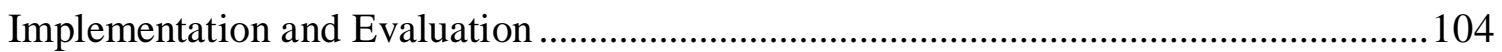

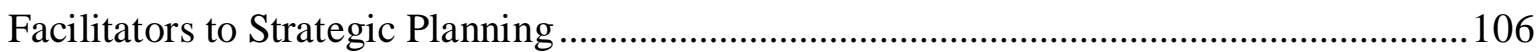

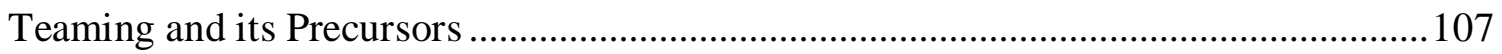

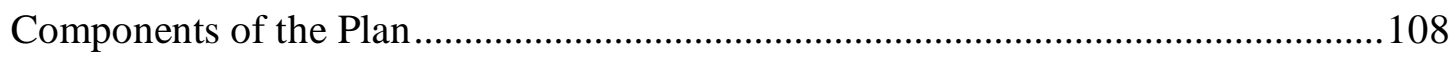

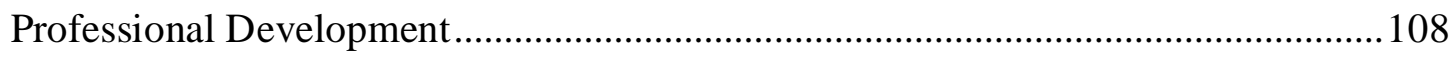

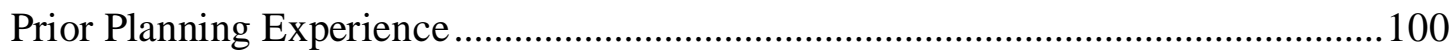

Public Educator/Administrator Experience ............................................................ 109

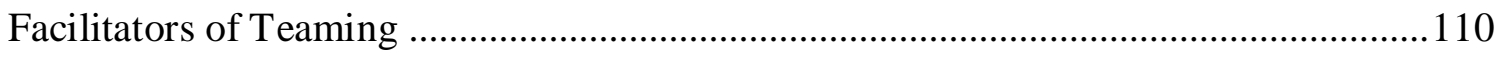

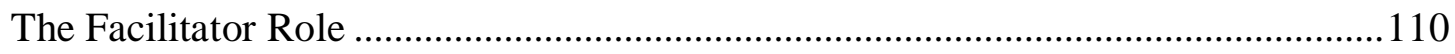

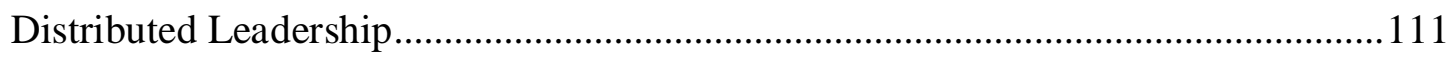

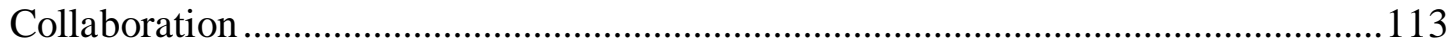

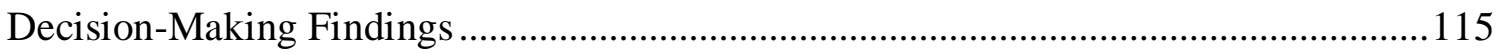

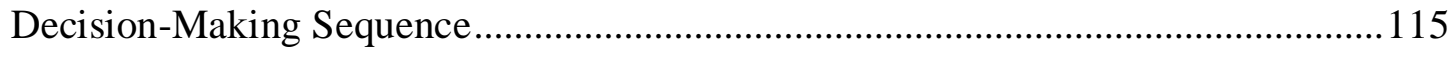

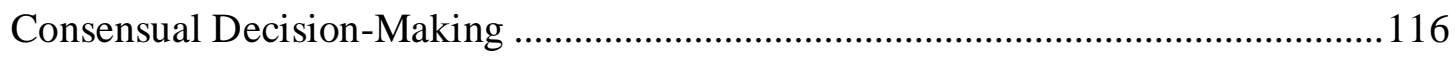

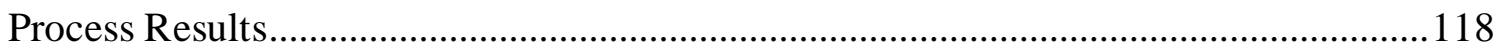

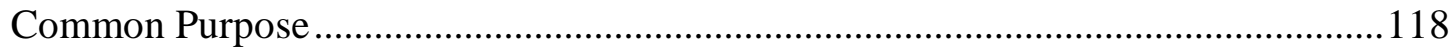

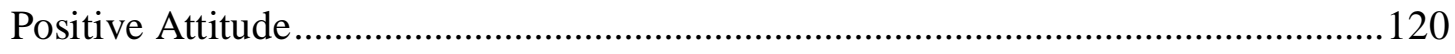

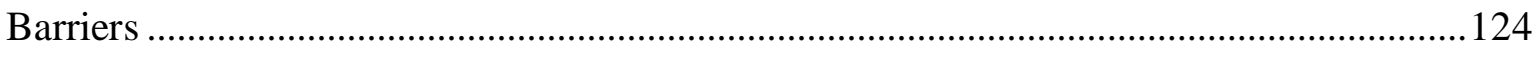

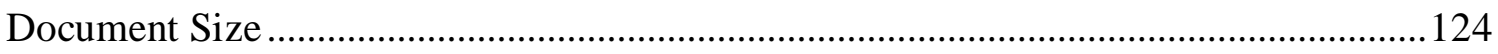

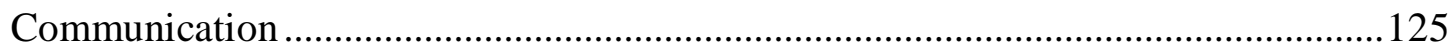


Coordination

Time Required

Deadlines

Technology

Plan Updates

Related Findings: Perceptions of the Process

Summary

Conclusions

Discussion

Strategic Planning

Strategic Planning Limitations.....

A Process Model.

A Critical View of Strategic Planning

Strategic Planning Pros and Cons: Leadership and Decision-Making

Recommendations for Theory in Use

Recommendations for Policy

Federal

State 165

Recommendations for Practitioners. 
Recommendations for Future Research

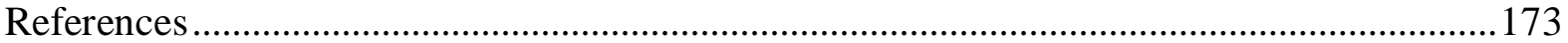

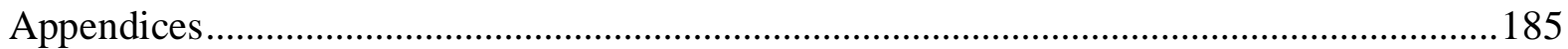

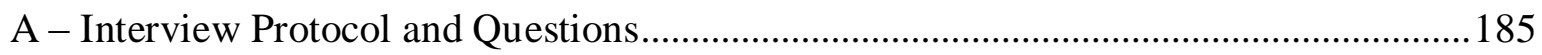

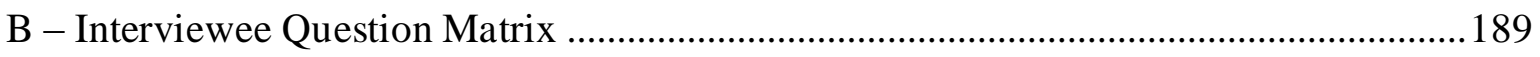

C -Investigative, Coding, and Analytic Approaches to Research Questions .................... 192

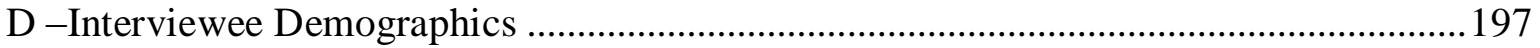

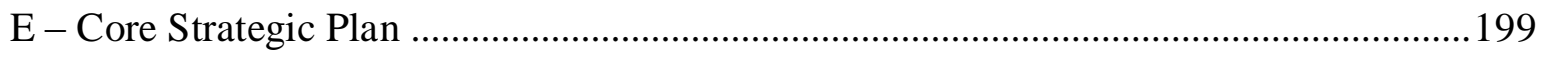

F - WVDE Online Strategic Plan Text Box ............................................................225 


\section{List of Figures}

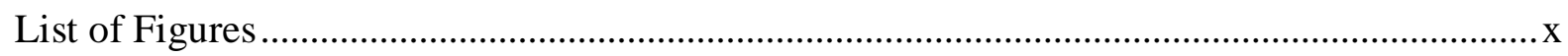

1. West Virginia School District Strategic Planning Steps .............................................96

2. The Five Step Consensual Decision-Making Sequence in Strategic Planning ..............115

3. Facilitators of the Strategic Plan Development Process ............................................. 123

4. Stasis Theory as a Model of the Strategic Planning Process ........................................ 149 


\section{Chapter One}

\section{Statement of Problem}

School improvement and the central office. Many state and federal education policies have focused on the individual school, instead of the district, as the most important setting for school improvement. School improvement can be broadly defined as school-wide or districtwide efforts intended to strengthen and reform the prevailing practices of teaching and learning resulting in increased student achievement and positive impacts on other student outcomes. School improvement efforts have also increasingly targeted the school level as being the most important location for change. Some of these efforts have rendered local school districts "virtual non-actors" (Marsh, 2000, p. 1) in the process of school improvement.

Marsh (2000) found that recent education reform had paid little attention to school districts as the organizational unit that can achieve school improvement. McLaughlin and Talbert (2003) suggested this lack of attention was because: "Districts' dismal track record in carrying out or sustaining school reform leads some policymakers and reformers to conclude that while the district is part of the reform problem it should not be part of the solution" (p. 4). Districts may intentionally ignore or knowingly change state policy. They may also unknowingly change the intent of state policy by misinterpreting the policy's message and content (Marsh, 2000). On a more positive side, districts can also be very active agents of change. They may also be adept at anticipating new policy initiatives and using them to their advantage.

McLaughlin and Talbert (2003) concluded from their research that "for better or worse, districts matter fundamentally to what goes on in schools and classrooms and that without effective district engagement, school-by-school reform efforts are bound to disappoint” (p. 5). From their case studies and surveys they found five key conditions for successful reform: 
1. A system approach to reform.

2. Learning community at the central office level.

3. Coherent focus on teaching and learning.

4. A stance of supporting professional learning and instructional improvement.

5. Data-based inquiry and accountability.

McLaughlin and Talbert (2003) stressed their most fundamental finding to be a focus on the school district as the unit of change. "These districts engender shared norms of practice across schools through system-wide communication and strategic planning” (McLaughlin \& Talbert, 2003, p. 10). School districts' central offices may be key instruments in school improvement. More specifically, and as the title of this document indicates, a strategic planning process may be essential to successful school improvement from the central office.

Chapter one builds toward the purpose of this study, its research questions and design, by discussing school improvement, school reform, organization theory, strategic planning, and West Virginia improvement initiatives. Terms relevant to this study are defined and the organization of the document is provided.

School reform. Within the last several decades public schools have seen reform efforts initiated by governments in response to public sentiment, such as columnists and politicians, as well as efforts brought about internally by professionals. Reports such as A Nation at Risk brought about parental and political demands for the reform of public schools. The Goals 2000 : Educate America Act of 1994 attempted to provide resources to support state and local efforts toward systemic reform. Most recently, the No Child Left Behind Act (NCLB) of 2001 enacted standards-based reform by increasing accountability and attempting to provide parents with some 
degree of school choice. Although the effectiveness of these reform efforts may be challenged, they have raised emotions both inside and outside of public education.

Marking the $25^{\text {th }}$ anniversary of the 1983 report $A$ Nation at Risk, columnist Morton Kondracke (2008) called us a nation still at risk. "How many wake-up calls does America need before we make our failing public schools fit for the competitive challenges of the $21^{\text {st }}$ century" (p. A4). Reflecting on the 25 years that have passed since A Nation at Risk, former U.S. Secretary of Education Richard Riley and advisor Terry Peterson (2008) described the American education reform effort as "noble but only partially successful, and too often it has been defined by an either-or dichotomy that has led to publicly defined wars over reading and math instruction" (p.1). Public schools have frequently been caught in the middle of these grandiose visions. "All too often people have reached for the next silver-bullet solution, from open classrooms to new math to a four-day school week, only to discover the reality that improving American education does not happen that quickly" (Riley \& Peterson, 2008, p. 1).

With the new millennium came calls for public education to prepare students with the skills they would need to be successful in the $21^{\text {st }}$ century. As the world became flatter there was concern about America's ability to remain competitive in an international environment. The first major federal reform effort in the $21^{\text {st }}$ century was the No Child Left Behind Act of 2001.

NCLB has been denounced by democratic candidates and teachers' unions (Kondracke, 2008). Others, such as Kondracke, described it as "a pioneering, bipartisan step on the road to improving American education - requiring states to adopt measurable performance standards, test children regularly, report results based on race and income groups and take remedial action when schools fall short" (p. A4). Then president Bush said he would veto a reauthorization of NCLB that did not include the accountability rules and school choice measures (Hoff, 2007). It 
remains to be seen what type of education reforms President Obama and his education secretary Duncan will initiate.

Whether these reform efforts focus on the district or school level, they bring with them ever more demanding requirements and expectations. How states, districts, and schools interpret and implement these reform efforts aimed at school improvement may be understood by examining organization theory.

Organization theory considerations. Three concepts will be discussed briefly in this section; systems theory, dynamic complexity, and organizational learning. Of significance to this research is the systems theory view of the organization as "a social device for efficiently accomplishing through group means some stated purpose” (Katz \& Kahn, 1966, p. 481). Chapter two will provide a closer examination of the changes that have occurred within organization theory as it has advanced from classical models to the more current open systems models.

An understanding of dynamic complexity, the ability to see the structures that underlie complex situations, is what Senge (1990) referred to as the fifth discipline. Dynamic complexity for the purpose of this study is the understandings, relationships, and decision-making that occurs within a group during the plan development process.

Historically, most large-scale reform efforts have failed to penetrate the culture of teaching. The superficial changes in the structure and management of school systems and the sometimes significant changes in educational policy have rarely resulted in fundamental changes in the conditions of teaching and learning (Supovitz, 2006). Recognizing the ineffectiveness of traditional and even more current reform approaches, several authors have promoted the process of organizational learning (Fullan, 2008; Honig, 2007; Resnick, 1998; Schmoker, 2004; Supovitz, 2006). Learning organizations have the potential to take advantage of the human 
relations and group interaction aspects of a systems theory approach to school improvement. This approach may also implement improvement efforts at a level necessary to impact the culture of an organization. "Learning is not workshops and courses and strategic retreats. It is not school improvement plans or individual leadership development. These are inputs. Rather, learning is developing the organization, day after day, within the culture” (Fullan, 2008, p. 28). Learning organizations will be described further in chapter two.

Strategic planning and West Virginia improvement initiatives. Although strategic planning has been criticized for, among other things, its long term view based on a predicted future, it still has proponents. For example, Reeves (2008) remained a supporter of strategic planning. After analyzing hundreds of plans he concluded that to be effective, strategic plans need to have focused expectations, be brief, and provide consistent monitoring and evaluation. "There is evidence that schools are well served by one-page plans that are clearly focused and simple enough that every participant in the process understands his or her role in executing the plan” (Reeves, 2008, p. 87). Reeves cautioned school leaders to remember that the strategic planning process is a tool to improve student achievement - not an end in itself.

School improvement efforts in West Virginia, the focus of this research, rely, in part, on the development and implementation of school system and individual school strategic plans. The West Virginia Department of Education requires each county school system and school to annually develop and/or revise a Five Year Strategic Plan. Chapter two's review of the literature will show strategic planning, as a reform or improvement method, has had mixed reviews. Discussion in chapter two will suggest that an overreliance on a rational, structured approach to the planning process may result in a plan that lacks impact. In contrast, a plan and planning 
process that is focused and demonstrates organizational learning may bring about change within an organization.

In West Virginia, the focus state for this research, public school improvement efforts have been driven by a variety of initiatives including large scale reform efforts such as the Master Plan for Public Education (West Virginia Board of Education, 1983). This plan, the result of a sweeping court case on public school financing, was perhaps the most comprehensive plan in the history of West Virginia public schools. Its intent was revisited in 1998 by the Commission on Educational Quality and Equity in Providing a Thorough and Efficient System of Schools: Quality and Equity (Commission on Educational Quality and Equity, 1998). Other significant education legislation in West Virginia includes the Jobs through Education Act of 1996. Each of these reform initiatives included as one of its requirements a type of school system improvement plan.

The Providing a Thorough and Efficient System of Schools: Quality and Equity (1998) document listed 10 important elements to improve the teaching and learning process. These were:

1. Effective leadership.

2. Agreed upon goals that target areas for strategic investment by the state.

3. A clear cohesive set of performance and process standards.

4. Equitable distribution of funding.

5. Adequate physical/structural facilities.

6. Objective processes to assess student, school and school system performance and to identify the strengths of schools and school systems.

7. An accountability system. 
8. Sufficient state infrastructure and contingency resources to target assistance to specific areas for building capacity.

9. Local program evaluation and strategic planning processes at both the county and school levels.

10. Effective leadership and management at both the county and school levels. (p. 13)

These elements were considered to be the keys to the process for improving education. The ninth element of the plan specifically addressed strategic planning. The document required strategic planning to be based on the identified needs of students in order to meet academic standards. Along with other state determined measures of performance the strategic plans were to form a basis for assessing the capacity of schools and school systems for delivering a high quality education.

The West Virginia Department of Education planning requirement has been revised and renamed over the years until reaching its current form, the West Virginia Five-Year School and School System Strategic Plan. Chapter two shows how planning and, more specifically, strategic planning have come to be relied on by public educators as the foundation for reform efforts aimed at school improvement. West Virginia Department of Education policy considers the strategic plan to be a key component in the capacity building necessary to achieve school improvement. "School and county electronic strategic improvement plan development is intended, in part, to provide mechanisms to target resources strategically to the teaching and learning process to improve student, school, and school system performance" (WVDE, 2007, section 18.1).

There are many structures and levels of focus for school improvement and school reform efforts. West Virginia has continued to place significant emphasis on planning as a basis for 
school improvement efforts. The research presented in this document is important because it describes and develops understandings of this planning process. This study examined the strategic plan development processes of county school systems in West Virginia that were recognized as having a well developed process and plan.

Purpose of study, research questions, and design. This study's purpose was to describe and develop understandings of the West Virginia Five Year School System Strategic Plan development process in selected counties. A qualitative design was chosen because of its ability to interpret and understand process. As briefly mentioned in this introduction, process may be an important aspect of planning efforts in support of school improvement. The study was approached from an interpretive paradigm in order to investigate the complex issues and processes involved in the development of the West Virginia Five Year School System Strategic Plan.

The study was guided by three research questions:

1. How do county office personnel develop the West Virginia Five Year School System Strategic Plan?

2. What styles of development do they use?

3. What are the facilitators and barriers to development?

Four county school systems, as identified by nomination by a West Virginia Department of Education official, were used in this multi-site case study. Two data collection methods were used. The first data collection method was semi-structured, topical interviews with key team members from the respective county school systems. Three to five team members were interviewed. The second data collection method was a cache of documents such as the respective district's plan. Within-case and cross-case analyses of the data lead to a presentation of the 
study's descriptions, portrayals, and interpretations. A meaningful portrayal and interpretation of the strategic planning process could advantage practitioners, policy makers, and future researchers.

\section{Definitions.}

Action Steps - "a detailed description of the specific actions required to achieve specific results necessary for the implementation of the plan" (Cook, 2001, p. 73).

Case Study - "an exploration of a bounded system or a case (or multiple cases) over time through detailed, in-depth data collection involving multiple sources of information rich in context" (Creswell, 1998, p. 61).

Coding - a procedure used to categorize data based on the conceptual nature of research questions and according to themes that emerge during analysis.

Comprehensive Planning - improvement of existing aspects of the organization by assessing components in terms of performance, needs, future projections, or expectations based on preconfigured standards assumed to be exclusive, essential, and permanent (Cook, 2004). Consensual Decision-Making - "every person has an opportunity to have a voice in the process and that there is agreement that decisions are reached by and supported by all" (Calderman, 1999, p. 398).

Constant Comparison Method - taking information from data collection and continually comparing it to emerging categories and themes.

Distributed Leadership - "a distributed perspective on leadership argues that school leadership practice is distributed in the interactions of school leaders, followers, and their situation" (Spillane, 2004, p. 2). 
Interview - a conversation between two or more people where the interviewer poses questions that may be structured, semi-structured, open, or probing in order to obtain information about interviewees' understandings about a selected topic.

Organizational Learning - "organizations improving their performance by creating new ways of working and developing the new capabilities needed for that work" (Resnick, 1998, p. 101). Operational Planning - deals with the everyday activities of an organization, maintains programs, and is driven by budgets (Hayden, 1993).

Planning - "a formalized procedure to produce an articulated result, in the form of an integrated system of decision" (Mintzberg, 1994, p. 12).

Saturation - "no additional data are being found whereby the sociologist can develop properties of the category" (Glaser \& Strauss, 1967, p. 61). Theoretical saturation of a category is reached when: “(1) no new or relevant data seem to emerge regarding a category; (2) the category development is dense, insofar as all of the paradigm elements are accounted for, along with variation and process; (3) the relationships between categories are well established and validated" (Strauss, 1990, p. 188).

School Improvement - school or district wide efforts intended to strengthen and reform prevailing practices of teaching and learning resulting in increased student achievement and positive impacts on other student outcomes.

School Reform - "planned efforts to change schools in order to correct perceived social and educational problems" (Tyack \& Cuban, 1995, p. 4).

Snowball Sampling - "an approach for locating information-rich key informants or critical cases .. . by asking well situated people: Who knows a lot about ? Whom should I talk to?"

(Patton, 1990, p. 237). 
Strategy - "a complex web of thoughts, ideas, insights, experiences, goals, expertise, memories, perceptions, and expectations that provides general guidance for specific actions in pursuit of particular ends" (Nichols, 2000, p. 5).

Strategic Intent - "management process that includes: focusing the organization's attention on the essence of winning; motivating people by communicating the value of the target; leaving room for individual and team contributions; sustaining enthusiasm by providing new operational definitions as circumstances change; and using intent consistently to guide resource allocations" (Hamel \& Prahalad, 1989, p. 39-40).

Strategic Management - "the analysis of internal and external environments of a firm to maximize the utilization of resources in relation to objectives" (Bracker, 1980, p. 221). Strategic Planning - the systematic analysis of the organization and its environment and the formulation of a set of key strategic objectives to enable the organization to realize its vision, within the context of its values and its resource potential (Davies \& Ellison, 1998).

Systemic Reform - approaches advanced as a means of providing top-down system-wide support for bottom-up instructional improvement strategies (Goertz, Floden \& O’Day, 1995).

Systems Theory - "views the organization as a complex set of dynamically intertwined and interconnected elements, including its inputs, processes, outputs, and feedback loops, and the environment in which it operates and with which it continuously interacts" (Shafritz, Ott, \& Yang, 2005, p. 476).

Theme - "an overarching concept or theoretical formulation that has emerged from the data analysis" (Merriam, 1994, p. 190).

Triangulation - the combination of multiple methods, observers, or data sources in order to overcome bias (Patton, 2002). 
Organization of the document. Chapter two of this document discusses school reform and strategic planning in more detail. Approaches to school improvement and organization improvement are traced from their roots in the business sector to their eventual application in public school systems. Planning theory and planning in schools are reviewed leading to a more detailed discussion of strategic planning. Chapter two also reviews the criticism directed at strategic planning. Selected case study research, found in a search of journals and unpublished dissertations, investigating strategic planning in public schools is highlighted. The chapter concludes by historically tracing the planning requirement for West Virginia public schools. This study's research design and method are presented in chapter three. This chapter begins with a rationale for selecting a qualitative approach to describe and develop understandings of the strategic plan development process. The rationale for a case study design using the methods of interviews and collection of a cache of documents is presented next. The background of the researcher is discussed prior to the research method section. The research method section presents site selection and sampling procedures, data collection, management, and analyses, and concludes discussing interpretation and presentation of findings. Chapter three's final section reviews assurances of soundness relevant to the study.

Chapter four presents the results of this research in a cross-case report format. The findings are presented as answers to the research questions. The cross-case report begins with a description of the style and process the school districts used to develop the five-year strategic plan. Facilitators and barriers to the process are then described. To conclude chapter four related findings are presented. These findings are descriptions of the administrators' opinions of their planning process and strategic planning as an instrument for school system improvement. 
The final chapter presents conclusions based on the research findings. The discussion section focuses on strategic planning, teaming, and decision-making. Recommendations are offered for theory, policy, practice, and future research. 


\section{Chapter Two}

\section{Review of the Literature}

School improvement and strategic planning. The purpose of this chapter is to provide a background of and context for strategic planning. It contains the following sections: reform, reform revisited, learning organizations, district role in reform, historical context of strategic planning, strategic planning models, planning in education, strategic planning in public education, criticisms and planning theory, theoretical considerations, strategic planning case studies, strategic planning dissertations, and a summary.

Reform. Public schools have long been the focus of a variety of reform efforts. Sometimes reforms are initiated by governments in response to public sentiment, while others have been brought about internally by professionals. Tyack and Cuban (1995) define educational reform as the "planned efforts to change schools in order to correct perceived social and educational problems" (p. 4).

Broad based initiatives such as the No Child Left Behind legislation have attempted to force reform through accountability measures. Reports such as the 1983 A Nation at Risk brought parental and political demands for the reform of public schools. External pressures like these tended to result in top-down reform strategies. Within this time frame there were also internal calls for reform from professionals and their organizations. These initiatives resulted in bottomup approaches such as site-based management. The dichotomous approaches to reform, topdown versus bottom-up, often resulted in fragmentation within and between policy, governance, professional development, curriculum, and instructional practice.

Attempting to reconcile the two divergent models and produce coherence instead of fragmentation, the 1990s saw the development of systemic reform approaches. These were 
developed in response to criticism of the top-down and bottom-up reform strategies of the 1980s. The Goals 2000: Educate America Act of 1994 attempted to provide resources to support state and local efforts toward systemic reform. To receive funding, states had to submit improvement plans addressing the act's goals and pledge to initiate systemic reform activities.

Systemic reform approaches were advanced as a means of providing top-down systemwide support for bottom-up instructional improvement strategies (Goertz, Floden \& O’Day, 1995). Balancing top-down and bottom-up approaches is described by Supovitz (2006) as a leadership dilemma. Top-down mandates force coherence but weaken commitment, while the freedom of bottom-up choices create ownership, but result in a programmatic hodgepodge.

Goertz, Floden, and O’Day (1995) described systemic reform as containing three integral components: “(1) the promotion of ambitious student outcomes for all students; (2) alignment of policy approaches and the actions of various policy institutions to promote such outcomes; and (3) restructuring the governance system to support improved achievement" (p. 1). One of the concluding recommendations from the Goertz et al. study was an emphasis on capacity building. They described and stressed the importance of capacity building at both the individual teacher and organizational levels.

More recently the professional literature (Fullan, 2008; Honig, 2007; Resnick \& Hall, 1998; Schmoker, 2004; Supovitz, 2006) has promoted organizational learning as the key ingredient for successful systemic reform. The use of learning organizations to build capacity will be addressed in a later section.

Theoretical considerations. To further an understanding of the strategic planning process it may be helpful to consider relevant theories from several fields. As mentioned in the previous section, the four major traditions of planning have been categorized by Friedman and Hudson 
(1974) as rationalism, organizational development, empiricism, and philosophical synthesis. There are similarities between the progression of organization theory in general and the four major traditions of planning. For example, classical organization theory typically emphasized structure. Similarly a rational approach to planning emphasized a sequential series of steps and processes that focused on adherence to its structure while excluding other variables. This section will review the more recent evolution of organization theory, its relation to the progression of planning theory, and the application of relevant theories to this research and the strategic planning process. Specifically it will discuss four theories relevant to this research: from organization theory, a systems approach; from leadership, a distributed viewpoint; from social processes, stasis theory; and from decision-making theory, social decision scheme's description of group consensus.

As a result of an overreliance on structure and form, early criticism of organization and planning theory was built around their failure to consider culture, human relations, social and political factors. Classical organization theory typically emphasized structure. Neoclassical theorists, critical of the overreliance on structure, begin to introduce the importance of human relations, group interactions, and the interplay between the organization and its environments. Planning traditions also began to consider these factors. Organization development was particularly cognizant of human relations and interactions. Empiricism included such concepts as systems theory while the philosophical synthesis view attempted to construct a more integrated approach and included social processes.

The changes in classical organization theory can be traced back over half a century ago . For example, Selznick, in his Foundations of the Theory of Organization (1948), spoke of the concept of organizations as cooperative systems. He described them as "adaptive social 
structures, made up of interacting individuals, subgroups, and informal plus formal relationships" (Selznick, 1948, p. 130). For Selznick a theory of organization should be able to construct generalizations concerning transformations within and among cooperative systems.

In 1963 Cyert and March's, A Behavioral Theory of the Firm, described the organizational decision-making process. Because an organization is made up of individuals and groups with their own aspirations and conflicting interests, they believed a predictive theory should describe the process of coalition building (Cyert \& March, 1959). Accordingly, an organization's behavior and decisions are determined by the interaction of these individuals and groups as they form these coalitions. This political aspect of organizations was advanced further by March (1966) and Mintzberg (1983). This political aspect to organization theory is important within this research because strategic plans are developed by a team of individuals that may have similar or dissimilar interests and objectives.

Systems theory. Systems theory developed as a means to represent the interaction of individuals and groups within an organization and the interplay between the organization and its environment. A systems approach to organization theory requires, among other components, consideration of the organization's culture. Recognition of the importance of an organization's culture can be traced to Deming's effort in Japan and the Total Quality Management (TQM) movement that followed. This method achieved remarkable success and popularity because of its ability to improve product quality within a positive corporate environment. The cultural aspect of TQM was its promotion of a management approach that allowed employees across the organization to participate in quality improvement activities. This culture empowered employees and work teams by giving them autonomy and discretion to make decisions. The major 
components of TQM were leadership, customer focus, continuous improvement, employee empowerment, and management by fact (Shafritz, Ott, \& Yang, 2005).

Taken to extremes by emphasizing structure and content over culture, this method also lead to Management by Objectives (MBO), the Program Planning and Budgeting System (PPBS), and Zero Based Budgeting (ZBB). Tyack and Cuban (1995) reported that by 1970 about three-fourths of the states either had mandated or were considering requiring school districts to report in some type of program budget format. These processes were described as costing a great deal of time and money, creating new layers of bureaucracy, and resulting in piles of paper. The over-burdensome nature of these processes and limited cost effectiveness led to their demise. For example, California initiated PPBS in 1966, but after significant opposition dropped it by 1972 .

Organizational culture continues to be recognized in the literature as a significant component of organization improvement efforts (Schein, 2004). An open systems approach to organization improvement combines the elements of structure, human resources, politics, and culture. "Systems theory views an organization as a complex set of dynamically intertwined and interconnected elements, including its inputs, processes, outputs, and feedback loops, and the environment in which it operates and with which it continuously interacts" (Shafritz, Ott, \& Yang, 2005, p. 476).

Katz and Kahn's The Social Psychology of Organizations, published in 1966, is credited as being one of the most influential modern works in organization theory (Shafritz, Ott, \& Yang, 2005). Katz and Kahn (1966) credit von Bertalanffy's 1951 work with the model upon which their systems theory is based. These theorists described the organization as "a social device for efficiently accomplishing through group means some stated purpose" (Katz \& Kahn, 1966, p. 481). 
Systems thinking has been more recently popularized by Senge's The Fifth Discipline: The Art and Practice of the Learning Organization. Published in 1990 it described systems thinking as the ability to see interrelationships rather than isolated elements of an organization. The five disciplines were labeled team learning, shared organizational vision, individual mastery, mental modeling, and systems thinking. The fifth discipline, systems thinking, is the ability to see the structures that underlie complex situations. Senge characterized organizations as having two types of complexity: dynamic and detail. "The real leverage in most management situations lies in understanding dynamic complexity, not detail complexity" (Senge, 1990, p. 71).

Systems theory remains a useful lens to view the complex, dynamic organizational processes of public schools. Reform initiatives that fail may take too narrow a view of the organization by emphasizing one aspect, such as an overreliance on the structure of policy and mandates. An open systems theory considers the broader range of variables that come into play as espoused reform policy is translated into policy in use.

Distributed leadership. As an organizational process strategic planning requires leadership. Hoy and Miskel (2005) defined leadership as "a social process in which a member or members of a group or organization influence the interpretation of internal and external events, the choice of goals or desired outcomes, and shared orientations" (p. 377). Because strategic planning is a group process that involves the interactions of many different members, a recent leadership concept, distributed leadership, may be helpful in understanding the dynamics of the leadership that occur during strategic planning.

Distributed leadership means shared leadership, participatory leadership and democratic leadership (Spillane, 2004). The term is appropriate for this research because distributed leadership attempts to describe the interactions of people rather than the actions of leaders. "A 
distributed perspective on leadership argues that school leadership practice is distributed in the interactions of school leaders, followers, and their situation" (Spillane, 2004, p. 2). Spillane (2004) also described distributed leadership as situational because as tasks are carried out, leadership practices emerge through the collaboration and interactions of individuals.

Stasis theory. Because the process of strategic planning is a group activity that includes teaming and decision-making it is important to consider its social aspects. Stasis theory is a four step social knowledge building process developed in ancient Greece and refined by Roman rhetoricians (Brizee, 2008). Stasis theory suggests there are four common, underlying stases: (a) facts as derived from data (conjecture), (b) the meaning of the issue in terms of goals or objectives (definition), (c) the prioritization or seriousness of the issues (quality), and (d) a determination of what should be done (policy).

Stasis theory as it relates to this research is built more on the Greek's use of stasis as a system for inquiry and philosophy than it is on the Roman's use as a technique for argument. This viewpoint uses stasis "to build bridges rather than dig trenches" (p. 375). The stases should "act like a puzzle where the parties involved in discussion work together to build facts, agree on definition and quality, so they can develop policies that emerge as multi-sided, shared processes" (p. 376).

Stasis theory may be used to advance an understanding of the complex social process and discourse that occurs during the planning process. Stasis theory is relevant because it describes a social inquiry and knowledge building process. Brizee (2008) recommended stasis theory as a theoretical model for teaming and decision-making because of its ability to foster critical thinking and assist teams in making better decisions. This author described it as a "rigorous yet flexible analytic process" (p. 383). 
Social decision scheme. Because the decisions that occur through strategic planning may be significant factors in the school improvement process it is important to understand the decision-making process. Strategic planning advocates a consensual approach to decisionmaking. One theory that has been developed to describe the consensual decision-making phenomenon is social decision scheme theory. This theory views group interaction as "a combinational process wherein preferences for decision alternatives across group members must be combined in such a way as to allow the group to reach consensus on a single group choice" (Kameda, Tindale, \& Davis, 2003, p. 460). Social decision scheme theory examines the likelihood of a group favoring a particular decision alternative. Going strictly by proportionality would suggest that the probability that a group will choose a particular alternative is the proportion of members favoring that alternative. For example, if two out of six members prefer an alternative it has a 33 percent chance of being selected. Conversely, majority probability, as described by social decision scheme theory, predicts that whenever a majority of group members favor a particular decision alternative that alternative will be chosen by the group. Therefore, if two out of six members prefer an alternative it has a zero percent chance of being selected.

Theories such as social decision scheme may be instructive to teams relying on consensual decision-making. Research has shown that these groups tend to adopt the majority's preference at the expense of members whose views are discrepant. "Majorities may contain only one more member than a competing minority, yet they define the group consensus nearly $100 \%$ of the time. This is particularly true when no demonstrable correct alternative exists" (p. 464). In these instances the quality of a group decision depends more on what kinds of preferences are shared at the outset in a group, than it does on any data or alternatives presented during the 
decision-making process. This could have serious ramifications for school districts' strategic planning.

Social decision scheme is an example of how theory can further an understanding of the strategic planning process. Describing public school systems' strategic planning with this type of theory may increase practitioners' understanding and awareness of the advantages and limitations of consensual decision-making.

Summary. This section discussed four theories relevant to this research: systems, distributed leadership, stasis, and social decision scheme. Each of these four theories may be helpful to furthering an understanding of the strategic planning process. Systems theory may be used as a means to represent the interaction of the team members within the planning process as well as within their organization and its environment. Distributed leadership describes a type of leadership that could occurr during the planning process. Stasis theory describes the underlying social discourse, knowledge building, and decisions that may occur during a process such as team planning. Finally, social decision scheme describes the decision-making tendency of groups relying on consensus.

Reform revisited. Richard Elmore is known for stating hard questions about public school practice. In a 2002 article with that title, Hard Question About Public School Practice, the author observed that most educators in the schools he has visited believed they were engaged in enlightened reform. The reality, in Elmore's (2002) opinion, was that these "reforms are largely symbolic activities engaged in to demonstrate visible concern for student performance" (p. 24). Tyack and Cuban (1995) would agree. They summarized that reformers, for years, have promised to reinvent schooling and replace the antiquated schools and methods of our past and present. "But in practice their reforms have often resembled shooting stars that spurted across the 
pedagogical heavens, leaving a meteoric trail in the media but burning up and disappearing in the everyday atmosphere of schools" (Tyack \& Cuban, 1995, p. 111). These authors noted that the symbolic gestures and grandiose promises that come with reform initiatives sometimes interest policy makers more than any actual change in classroom practice that may accompany them. Tyack and Cuban (1995) suggested in order to assess the actual impact of reforms on schools it may take careful detective work. Similar to Elmore (2002), they concluded that grandiose policy talk has frequently led to minimal, but symbolically important implementation. To explain this phenomenon, they distinguished between policy talk, policy action, and implementation. Policy talk is the recognition of problems and the politics behind the advocacy for proposed solutions. Policy action is the adoption of a particular reform approach and its accompanying policy mandates. These may be adopted by federal or state legislation, federal or state policy, or local policy and regulations. Actual implementation, putting the reforms into action, is another stage, "often much slower and more complex than the first two" (Tyack \& Cuban, 1995, p. 40).

In order to understand the impact of reforms on practice Tyack and Cuban (1995) suggested asking the question: How do schools change reforms? Rarely do reforms perform and persist exactly according to plan, when faced with the realities of schooling. Kennedy's (2005) study demonstrated how the realities of classroom life can undermine reform efforts. Therefore, reformers that rely on a top-down, prescriptive approach that measures success by predetermined goals and criteria may be disappointed or blame districts, schools, and teachers for their resistance and the reform's apparent failure.

Strict mandates do not account for the various ways schools shape reforms as administrators and "teachers employ their wisdom of practice to produce pedagogical hybrids" 
(Tyack \& Cuban, 1995, p. 83). Tyack and Cuban suggested that instead of insisting that reforms are ready-made plans, they should be expressed as principles that can be "modified in the light of experience, and embodied in practices that vary by school or even by classroom” (p. 83).

The effectiveness of reforms has been questioned for reasons such as those stated above. More importantly, the purposes or goals of these reform efforts have also been questioned. Resnick (1998) found that the history of educational reform had largely amounted to tinkering with organizational characteristics. These include the "practices of grouping, reporting, accountability, governance, and management - that have little impact on established patterns of teaching and learning. Reform has rarely penetrated the educational core of how knowledge is defined" (Resnick, 1998, p. 91).

Kolderie (2008) even suggested that systemic reform cannot directly improve achievement. This author contended that, because so much attention is focused on system reform, the typical organization has left little resources available to significantly change traditional schooling. Kolderie described most of what passes for change and improvement as inside the box thinking. In a later section of this chapter strategic planning is promoted as the method to think outside the box. Kolderie challenged leaders to develop innovative alternatives to the batch processing of traditional schooling. The author proposed that the assumption that change can be imposed politically, through universal reforms, is why so little actually changes. Instead, innovative early adopters that cultivate change at the school and classroom levels are more likely to lead to meaningful changes in practice.

Learning organizations. In their review of a century of public school reform, Tyack and Cuban (1995) concluded that bringing about improvement at the level of classroom instruction has proven to be the most difficult type of reform. Their prediction is that this type of change is 
more likely to occur as a result of internal changes created by the knowledge and expertise of teachers than from the decisions of outside policymakers. Schmoker (2004) also supported the need for internal improvement efforts in his article titled Learning Communities at the Crossroads: Toward the Best Schools We've Ever Had. The author referred to studies that revealed that teachers actually learn most effectively - not from outsiders - but from one another. To this end, Schmoker recommended professional learning communities as the most promising strategy for sustaining substantial, school improvement efforts.

Resnick (1998) defined learning organizations as: “organizations capable of improving their performance by creating new ways of working and developing the new capabilities needed for that work" (p. 101). The author recommended that teachers and administrators form communities of learners who are focused on improving their practices and at becoming expert conductors of the learning community process at the classroom, school, and district levels. More specifically, this researcher described these as nested learning communities. The primary purpose of these communities is the enhancement of knowledge and instructional expertise. This occurs by making student learning the daily, dominant focus of teachers and administrators. Resnick stated that these nested learning communities should be "built around the core belief that ability is learnable through effort and that an active, self-regulated approach to professional growth produces high levels of achievement over time” (Resnick, 1998, p. 102).

Learning organizations have the potential to take advantage of the human relation and group interaction aspects of a systems theory approach to organizational development. They also implement improvement efforts at the level necessary to impact the culture of the organization. Sustainable improvement must change the daily practices to the extent that they become the new, way we do things around here. 
By fostering school improvement efforts at the classroom level, teachers and administrators are allowed the discretion and autonomy to continually improve their instructional practices. Learning organizations may also achieve the balance between top-down command and control versus bottom-up independence. To achieve this balance school districts can facilitate school level learning communities through a supportive, capacity building role. Broad based goals, derived consensually, allow for achievement through a variety of approaches.

Honig (2007) recommended that school districts transform themselves from top-down regulatory agencies to ones that partner with schools in order to build capacity for continuous improvement. The author offered the premise that "calls for district central offices to operate as learning organizations hold great promise for advancing central office reforms that might enable implementation" (Honig, 2007, p. 5).

District role in reform. What is the role of school districts in reform efforts attempting to achieve school improvement? If top-down reform mandates are ineffective and school level initiatives are the source for meaningful change, what is the role of school districts? This section will review the role of the district in reform efforts and lead to the role of strategic planning in support of organizational learning efforts.

Historically, large-scale reform efforts have failed to penetrate the culture of teaching. The superficial changes in the structure and management of school systems and the sometimes significant changes in educational policy have rarely resulted in fundamental changes in the conditions of teaching and learning for students and teachers (Supovitz, 2006). "In order to effectively sustain reform it needs to be embedded into the values, regular practices, and cultural fabric of the organization" (Supovitz, 2006, p. 160). Supovitz described sustainability as the holy grail of educational reform and organizational learning as the engine of sustainability. To achieve 
levels of deep learning Supovitz distinguished three views of the concept of organizational learning. These are: “(1) fostering individual learning for the purposes of the organization; (2) using social interactions as a means of fostering and sharing learning across individuals and groups; and (3) embedding learning in the rules and routines of the organization" (Supovitz, 2006, p. 161). This researcher described the first concept as a form of nested community learning. This is similar to the language Resnick used in 1998. The second is built on Deming's work that showed teams achieve quality through communication, feedback, and constant incremental improvement. Supovitz also related the second concept to Senge's five disciplines. The third concept is based on a more structural view of the organization. As a basis for this concept the author goes back to Cyert and March's work that showed how organizational learning is imprinted onto the rules, procedures, and routines of an organization.

Supovitz (2006) concluded, from his research on district practices, that few of the districts studied gave serious attention toward their own learning and growth. He hypothesized "this is because mature bureaucratic organizations tend to become set in their ways" (Supovitz, 2006, p. 186). The author recommended that school districts who can sustain system-wide support and enhancement of an organization's learning practices can realize widespread educational improvement. To accomplish this, districts should move from being managerial organizations, common to the twentieth century, to teaching organizations and preferably, learning for teaching organizations. In order to achieve system-wide instructional improvement Supovitz (2006) listed the following as central lessons:

1. Develop a clear vision of instructional quality in the major content areas ... 2. Balance persuasive and coercive methods of influence to build system-wide commitment to the instructional vision ... 
3. Build capacity through employee development at all levels of the organization ...

4. Marshal external resources ...

5. Use data formatively to inform both individual decisions about students and programmatic decisions ...

6. Develop strategies to sustain reform efforts over longer periods of time. (p. 27-29)

McLaughlin and Talbert (2003) also acknowledged the dismal track record that most reform efforts have realized. These researchers noted that some policymakers and reformers have concluded that while the district is part of the problem it might not be part of the solution. From McLaughlin and Talbert's review of case studies and surveys of district administrators, however, they have reached a different conclusion. In their view "a weak central office in fact limits schools' reform progress, while a strong district role is effective and welcomed when it uses a strategic conception of responsibilities and leadership between levels" (p. 3).

McLaughlin and Talbert (2003) found several key conditions that were typical of successfully reforming school districts:

1. A system approach to reform,

2. Learning community at the central office level,

3. Coherent focus on teaching and learning,

4. A stance of supporting professional learning and instructional improvement, and

5. Data-based inquiry and accountability. (p.10)

These researchers also noted that reforming districts developed shared goals and focused their efforts through a system-wide planning process. This strategic planning process was considered fundamental to sharing accountability at all levels of the system. McLaughlin and Talbert's review of the research identified several advantages obtained from a strategic planning process 
and its consensual goal formation. First, the planning process allowed districts to be proactive in responding to state accountability pressures. Second, clear and consensual goals allowed districts to grant significant authority to schools. Third, reform was sustainable through changes in leadership. Finally, the strategic planning process was used to maintain strong school board and political support.

The first sections of this chapter reviewed reform in public schools. A section also briefly reviewed the concept of organizational learning as a means to implement and support systemic reform and school improvement efforts. The remainder of this chapter will look specifically at strategic planning as a tool and process to implement school reform and support school improvement efforts.

Historical context of strategic planning. The next sections, historical context of strategic planning, strategic planning models, planning in education, and strategic planning in public education, begin with a review of the history of organizational strategy in the private sector and move toward the application of these planning processes to public agencies, specifically, this country's public schools. The history of strategy in business in the United States can be traced back to at least the 1940s. Bracker (1980) chronicled 14 definitions of business strategy that developed between 1947 and 1977. Generally these definitions included the characteristics of an environmental or situational analysis followed by the application of resources in an appropriate manner to attain major goals. The definitions vary in terms of the breadth of the concept of strategy, the individual components of strategy, and inclusion of the strategy formulation process.

Nickols (2000), in his article titled Strategy: Definitions and Meaning, reviewed the concept of strategy from the viewpoint of several leading authors on the subject. These included 
George Steiner, Henry Mintzberg, Kenneth Andrews, and Michael Porter, among others. Nickols (2000) offered these definitions of strategy, in consideration of the viewpoints of the most prominent authorities on the topic:

Strategy is the bridge between policy or high-order goals on the one hand and tactics or concrete actions on the other... In short strategy is a term that refers to a complex web of thoughts, ideas, insights, experiences, goals, expertise, memories, perceptions, and expectations that provides general guidance for specific actions in pursuit of particular ends. (p. 5)

Strategic management is the broader description of the organization's use of strategy. Bracker's (1980) definition was: "Strategic management entails the analysis of internal and external environments of a firm to maximize the utilization of resources in relation to objectives" (p. 221). In Bracker's The Historical Development of the Strategic Management Concept the author listed 11 different approaches, developed between 1967 and 1978, to operationalize strategic management. These operational approaches led to the frequently more prescriptive process of strategic planning.

Strategic planning developed primarily from the third of the common components of the definition of strategic management: the application of the strategy formulation process to planning. The remainder of this chapter will focus on the application of strategy in the more specific sense, strategic planning, rather than the broader concepts of organizational strategy or strategic management.

In the 1960s and 1970s strategic planning was viewed by businesses as the best way to ensure productivity and profit. Woods and Woods (1981) reported that based on their survey of 500 large US corporations, $94 \%$ had used some form of strategic planning by 1979 . The 
development of, and advocacy for, strategic planning can be attributed to several sources during the early years. The Harvard Business School is credited with advancing the belief that strategy could be a powerful tool for businesses (Mendenhall, 2006). In 1963 the Boston Consulting Group developed popular approaches to strategic planning that centered on the concepts of experience curves and a growth and market-share matrix. Another popular consulting group, McKinsey and Company, successfully employed strategic planning during these early years on a very large scale with General Electric.

After the corporate environment, strategic planning was applied in large governmental agencies such as the Department of Defense (Conley, 1992). It moved further into the public arena through city and county government and higher education. George Keller's 1983 book Academic Strategy is credited with promoting the practice of strategic planning in higher education (Dooris, 2002-2003). This book was named the most influential higher education book of the decade by both Change magazine and the New York Times. Through the 1980s and the 1990s strategic planning was rapidly adopted by colleges and universities. Higher education, and soon thereafter public schools, adopted the private sector strategic planning techniques in order to implement reform, restructure their respective forms of education, and revitalize their institutions.

Strategic planning, management models, and their respective processes have evolved over the years within business, public, and non-profit sectors. When strategic planning first began in the 1950 s, it was used primarily for the purposes of budgetary planning and organizational control. More recently it has been used as a means to implement reform policy that requires organizational innovation. "Relatively recent conceptions of strategic planning focus more than earlier approaches on dynamism, the future, flexibility, organizational 
intelligence, and creativity and about actually moving from strategy to transformation" (Dooris, 2002-2003, p. 29). Organizational learning and creativity are now more important than the seemingly rigid and prescriptive objectives and action steps strategic plans were known for in the early years.

Although strategic planning has many advocates, it has also received considerable criticism. For example, some critics suggest it should be modified to emphasize strategic intent instead of formal, comprehensive planning. Others question its worth entirely. The arguments for and against strategic planning will be explored in greater detail in a later section. Preceding that discussion will be a review of business and public education strategic planning.

Strategic planning models. This section includes a review of strategic planning models that are most commonly, though not exclusively, seen in the business sector. Although business models are typically concerned with profit, productivity, growth, and market share, there are some commonalities between business and educational models. Each of these early models may be categorized as rational. Therefore, noticeably absent is the consideration of strategic planning as an interactive, social, and political event. As the models evolved they increasingly included external or environmental factors. Although systems theory does begin to emerge, there is little mention of human relations in the early models. This absence becomes one of the criticisms of strategic planning.

In the late 1960s the Boston Consulting Group (BCG) developed a four cell matrix known as the BCG Growth/Share Matrix (Mayo, 2006). This tool was designed to help companies measure their market growth rate and market share. Product lines in the high market growth rate/high market share cell were known as stars. This cell was viewed as the area of greatest opportunity for a company. Conversely, product lines in the low market growth rate/low 
market share cell were titled dogs. Efforts in this sector of business had limited potential. The remaining cells were known as cash cows and question marks. Cash cows were product lines where a company had considerable market share through an established product line. Growth potential was limited however. Question marks were growing markets where a company had either limited experience or few products. Through analysis companies placed product lines in one of the four cells of the matrix. The characteristics of the cell were then considered to make planning decisions.

The McKinsey and Company Consulting group, along with General Electric, developed a nine cell matrix in the 1980s (Mayo, 2006). Market attractiveness was placed on one side of the grid and ranked low, medium, or high. Business strength occupied the other axis and was graded as weak, average, or strong. This matrix was considered to be an advance over the BCG matrix because market attractiveness considered factors including market growth rate, barriers to entry, profitability, suppliers, customers, distribution issues, and other opportunities and threats.

One of the most widely used strategic planning tools was the SWOT (Strengths, Weaknesses, Opportunities, Threats) analysis. Most companies in the 1980s and 1990s used SWOT, in one form or another, as their basic guide for strategic planning (Mayo, 2006). This model required companies to view internal positions, strengths and weaknesses, and their external circumstances, opportunities and threats. Strengths could be a group of highly skilled employees, high-quality products, or superior technology. Weaknesses might be high production costs or an aging product. Opportunities may be a growing market, favorable legislation, or a loss of competition. In contrast, threats could be a shifting market, unfavorable legislation, or increasing competition. Carefully determining and classifying each of these positions allowed a company to evaluate its current and future situation. 
A leading theorist in strategic planning in the 1980s and 1990s was Michael Porter (Mayo, 2006). He developed Porter's Generic Competition matrix which placed competitive advantage (lower cost or differentiation) on one axis and competitive scope (broad target or narrow target) on the other. He also developed the Five Forces Model that is used to evaluate the competitive nature of a market. Porter suggested that five forces collectively determine the intensity of competition in an industry: "threat of potential entrants, threat of potential substitutes, bargaining power of suppliers, bargaining power of buyers, and rivalry of existing firms in the industry" (Mayo, 2006, p. 8).

The model that most closely resembles current educational models may be Hoshin Planning. Hoshin kanri, as it is known in Japan, was developed in the 1970s and adopted by U.S. firms in the 1980s (Distelzweig \& Clark, 2006). It has also been called policy deployment and management by policy. Major U.S. companies that have utilized this method include HewlettPackard and Xerox. Hoshin Planning includes five major steps:

1. Development at the executive level of a long-term vision.

2. Selection of a small number of annual targets that will move the organization toward the vision.

3. Development of plans at all levels of the organization that will together achieve the annual targets.

4. Execution of the plans.

5. Regular audits of the plans. (Distelzweig \& Clark, 2006, p. 7)

The origins of the Hoshin Planning method can be traced back to the work of W. Edwards Deming, Joseph Juran, and the Japanese Union of Scientists and Engineers. Hoshin Planning was developed in the context of total quality management (TQM). Significant 
components of TQM include a vision built by consensus, lateral and vertical coordination, and recognition of individual initiative and responsibility.

During its evolution strategic planning shifted from the narrower focus on market growth rate and share to a more comprehensive process that engaged the organization. Strategic planning's popular appeal and more generally applicable principles helped lead to its adoption by public agencies.

Planning in education. Preceding a discussion of strategic planning in education this section will review planning, in general, in education. For while strategic planning has become increasingly popular in education, it was not the first type of planning used within schools, nor is it the only model currently in use. Planning has been listed as an administrative function by almost all of the early authorities on administrative processes and functions including Fayol in 1916 (Conley, 1992).

Planning types may be categorized according to several different perspectives such as time, hierarchical orientation, purpose, and conceptual basis. Planning described by titles such as five-year plan, long-range plan, and short-term plan is based on a time dimension. Other plan styles emphasize a particular hierarchical orientation; bottom-up, site-based decision making, top-down, and executive planning. Planning may occur for specific purposes such as problemsolving planning, operational planning, and development planning. Planning types may also be based on a particular conceptual approach such as strategic planning and tactical planning.

Although various forms of planning have been present in public schools, strategic planning is a relative newcomer. Strategic planning was not used to any significant degree by public school systems until the early 1980s. The term strategic planning rarely appeared in educational literature before 1985 (Conley, 1992). However, since that time it has become more 
commonplace as a tool to implement reform policies and as a general planning model for public schools.

Planning existed in public schools in various forms prior to the popularity of strategic planning in the 1980s. For instance, one of the earliest examples of long range planning in public schools is the District of Columbia's Division of Planning created in 1976 (Anderson, 1991). Beginning in the 1980s several models and consultants emerged and began work on strategic planning within public schools (Conley, 1992). For example, Broward County Public Schools, the eighth largest school system in the country, began its five-year planning process in 1986 with The Broward Compact (Kalan \& Kinzer, 1991). States continued to adopt strategic planning in the 1990s. New Jersey adopted its first strategic plan in 1995 and titled it the Strategic Plan for Systemic Improvement of Education in New Jersey (2003). New Jersey used its plan to advance its curriculum content standards, implement an aligned assessment system, introduce charter schools, and place a greater emphasis on early childhood education. Public education strategic planning models will be described in greater detail in a later section.

Proponents of strategic planning for public schools (Moldof, 1993) are careful to differentiate it from other forms of planning. William Cook (2001) in his book Strategic Planning for America's Schools is quick to point out what strategic planning is not and stated "there is a distressing overabundance of ideas about what strategic planning really is" (p. 45). To help distinguish it from and contrast it with other popular types of planning, Cook described four common non-strategic planning methods:

1. Comprehensive planning is typically restricted to what already is. Most self-studies required by accreditation fit this category. 
2. Long range planning usually develops the anticipated operation of existing components such as curriculum, staff development, facilities, and budgeting.

3. Program planning takes a single idea or program, tests its potential implementation, and describes a plan to make it work.

4. Project planning is the development of a logical, sequential process to accomplish a specific purpose.

Hayden (1993) contrasted strategic planning with two other types of planning; operational and long-range. Operational planning was described as dealing with everyday activities, maintaining programs, and is driven by budgets. Long-range planning uses past history, facts, and figures to determine future direction.

Knight (1997) in his book Strategic Planning for School Managers encouraged strategic planners to not confuse the process with development planning. He described development planning as the work typically carried out in most schools. Although effective in its own right, the author contended that this type of planning should not be called strategic. "Consideration of strategy involves something more than the incremental moves forward that characterize the vast majority of school development plans” (Knight, 1997, p. 4). Knight suggested current school planning is more of a tactical process than strategic. The author concluded that many plans are preoccupied with the immediate and consequently there is little analysis of the alternative futures and possible options.

Strategic planning in public education. Davies and Ellison (1998) offered one of the more comprehensive definitions of strategic planning for public schools: "the systematic analysis of the school and its environment and the formulation of a set of key strategic objectives to enable the school to realise $[s i c]$ its vision, within the context of its values and its resource 
potential" (p. 2). This section will review a few strategic planning models that have been used by public school districts.

One of the most popular strategic planning processes for public schools was developed by William Cook and the Cambridge Group. Through its early affiliation with the National Center for Strategic Planning, a bureau within the American Association of School Administrators, and subsequent private ventures, they have facilitated over 950 school district plans and trained over 6,000 school district facilitators. Their procedure for strategic planning has become popular and known simply as the Cambridge process. There are ten components to the Cambridge process (Cook, 2001):

1. Belief statements,

2. Mission statement,

3. Parameters,

4. Internal analysis,

5. External analysis,

6. Competition,

7. Critical issues,

8. Objectives,

9. Strategies, and

10. Action plans.

Cook (2001) described strategic planning methods as "an effective combination of both a process and discipline which, if faithfully adhered to, produces a plan characterized by originality, vision, and realism" (p. 52). In addition to the components of the plan, Cook stressed the importance of the process. He suggested the one cardinal rule for every facilitator and 
participant should be to trust the process. The facilitator is viewed as a key to the process because the quality of the plan depends on this person's personality, group management skills, and technical knowledge.

Cook (2001) noted that the best strategic plans come out of aspiration not desperation. Decision-making is based on adequate, though not necessarily extensive, information. Strategy is based more on the collective intuition of the planning team than it is on hard data. He also downplayed evaluation by quantitative means and management by objectives: "So far, no one has been able to explain how quantitative improvement translates into qualitative gains" (Cook, 2001, p. 148). Strategic issues should deal with what the purpose of the organization is and why it exists, such as student learning. "The how is left to operational planning within the strategic context" (Cook, 2001, p. 143). Knight (1997) suggested an even more hypothetical approach by noting strategy requires the "willingness to suspend belief in present practice (however good that is) in the search for a possibly more meaningful future" (p. 4).

Another educational strategic planning model was developed in 1980 by Charles Adams and Thomas Mecca (1990). They titled their model ED QUEST and described it as integrating "futures research techniques and divergent thinking modes into a participatory group process that provides visions of alternative futures" (p. 1). Adams and Mecca's model emphasized environmental scanning because they believed conventional strategic planning practices did not adequately address the uncertainty created by continuous change. Through Delphi techniques they attempted to anticipate the changing educational environment. "The essence of the ED QUEST process is the development of strategic plans that take into account the future state of the environment in which the district will operate" (Adams \& Mecca, 1990, p. 6). 
Although the specific components and processes of strategic planning may vary based on the theorist, consultant, state, or school district, there are common features. In a comprehensive review of strategic planning in public education, Conley (1992) reviewed 120 plans from school districts in 30 states. His review of planning models showed the following to be the general categories present in some form or another: "a vision statement or mission statement; guiding principles or core beliefs; external scan; internal scan; strategic issues or direction; action plans" (Conley, 1992, p. 18).

Criticisms and planning theory. Whether within the business sector, nonprofit, governmental, higher education or public education domains, strategic planning has been defined through a variety of approaches. Mintzberg (1994) categorized these schools of thought on strategy formation into ten categories: Design, planning, positioning, cognitive, entrepreneurial, learning, political, cultural, environmental, and configurational. The first three are considered to be prescriptive, while the remainder is more descriptive. The consequences of strict adherence to the prescriptive approaches have become the focus of some of the debate about the utility of strategic planning.

In order to understand the basis for some of the criticism directed at strategic planning, it may be helpful to briefly review planning theory. It may be the over-reliance on a particular major intellectual tradition in planning theory that causes concern with some models.

Mintzberg (1994) described the field of planning as elusive conceptually and therefore somewhat difficult to define. However, the author appeared to settle on the following definition: "Planning is a formalized procedure to produce an articulated result, in the form of an integrated system of decision" (Mintzberg, 1994, p. 12). 
Friedman and Hudson (1974) categorized the four major traditions of planning as: philosophical synthesis, rationalism, organizational development, and empiricism. The dominant approach for planning models is rationalism. "Rational models of planning . . . assume a sequential, observable cycle that includes setting goals, determining objectives, making plans, implementing the plans, and reviewing the results" (Friedman \& Hudson, 1974, p. 12). The second major tradition, organizational development, is concerned with bringing about change within the organization. It is particularly cognizant of human relations and interactions. Empiricism uses a positivistic approach and applies concepts such as systems theory. Philosophical synthesis views planning as a social process and attempts to construct an integrated view. It emphasizes a broad approach that includes social, economic, ethical, and environmental factors.

Although strategic planning was vigorously adopted by many institutions it has not been without its detractors. At least as early as 1989 criticism was appearing within the business literature (Hamel \& Prahalad, 1989). More recently this criticism has extended to its use in public education. Phi Delta Kappan hosted a debate in 2004 about strategic planning involving Mike Schmoker, William Cook, and Bruce Joyce (Cook, 2004; Schmoker, 2004). Cook and Joyce supported strategic planning, while Schmoker advanced the concept of organizational learning as a preferred alternative.

According to Cook (2004) strategic planning, when applied correctly, has the potential to create capacity for constant emergence through intuitive imagination. For Cook this evolving, creative process has the best chance at developing effective reform methods. While advancing the utility of strategic planning, the author also acknowledged limiting factors for public schools. Schools must still struggle against an "oppressive accumulation of mandates, policies, rules, and 
regulations that have, through ineffectual bureaucracies, already displaced teaching and learning" (Cook, 2004, p. 75). Cook also cautioned that what most schools describe as strategic planning is in reality comprehensive planning.

Schmoker (2004) suggested strategic planning is too long term for the constantly changing environment of public schools. Instead, he believed that learning communities are the best way to develop short-term efforts that respond to emergent opportunities and problems.

To understand these contrasting current views I will return to an earlier criticism and advance forward. One of the earliest criticisms of strategic planning was written by Hamel and Prahalad (1989). These authors' comments were directed primarily at the corporate community. However, several of their points can also translate into advice for public schools. The crux of their argument is that strategic intent is more important than strategic planning. Hamel and Prahalad (1989) described strategic intent as a:

Management process that includes: focusing the organization's attention on the essence of winning; motivating people by communicating the value of the target; leaving room for individual and team contributions; sustaining enthusiasm by providing new operational definitions as circumstances change; and using intent consistently to guide resource allocations. (p. 39 - 40)

This description may not appear to contrast with strategic planning. The difference that can be deduced from their article is that strategic intent is much less formal, does not develop a definitive prediction of the future, and does not necessarily create a detailed plan. Strategic intent attempts to provide guidance for short-term action, while allowing for flexible reinterpretation as new opportunities emerge. Hamal and Prahalad (1989) used the following metaphor: 
In this respect, strategic intent is like a marathon run in 400-meter sprints. No one knows what the terrain will look like at mile 26 , so the role of top management is to focus the organization's attention on the ground to be covered in the next 400 meters. (p. 43). Beyond their effort to contrast strategic intent with strategic planning, Hamel and Prahalad (1989) offered, through the following list, sound advice for effective implementation:

\section{Create a sense of urgency,}

2. Develop a competitor focus at every level through widespread use of competitive intelligence,

3. Provide employees with the skills they need to work effectively,

4. Give the organization time to digest one challenge before launching another, and 5. Establish clear milestones and review mechanisms. (p. 45)

This emphasis on strategic intent was picked up a decade later by Davies and Ellison (1998) and applied to public schools. These authors were critical of public schools' strategic plans because most of them resemble operational plans lacking anything strategic. Davies and Ellison categorized operational plans as having endless lists, subdivided into numerous action plans, which are delivered in a top down fashion. According to Davies and Ellison (1998): “The thicker the plan the less it affects classroom practice!” (p. 2).

Cook (2004) also cautioned that strategic planning should not be confused with other types such as comprehensive planning. In the author's opinion the later is the type of planning required and practiced almost universally in public education. Cook (2004) stated it a little less delicately:

Comprehensive planning is the singular, selfish obsession of an institutionalized mentality held by those dedicated to the status quo. That is the reason this kind of 
planning always begins with information that is "research based" and ends with decisions that are "data driven." What better way to justify the continuation of a system than to judge it and define any proposed changes to it within the context of that very system? (p. 75)

In contrast, Cook recommended that strategic planning should consider a new reality and do whatever it can to push the system toward that reality.

Public schools' strategic plans have also been criticized for being too incremental. Incrementalism occurs when each subsequent plan becomes a minor revision of its predecessor. For example, goals may be set slightly higher but there is a lack of creativity and originality. If these plans assume a predictable and controllable environment they are developed in a linear, detailed manner. Davies and Ellison (1998) contended that such incrementalism inhibits school systems from taking the fresh view needed to be creative. Instead, each plan tends to become a revision of a previous plan, continuing the same practices with minor adjustment.

Another weakness of strategic planning is said to be its reliance on a predictable future (Davies \& Ellison, 1998). Because of the rapid changes that occur in education, it is questionable whether long term strategic plans can effectively consider the various potential futures.

Developing detailed plans that are rapidly overcome in the turbulent educational environment may not be the best use of schools' time and resources according to Davis and Ellison (1998). These authors recommended schools devote their energy to "focusing on building, over the medium-term, capability in key areas of the school's activity without the paranoia of trying to produce detailed plans that are rapidly overcome in a turbulent environment" (Davis \& Ellison, 1998, p. 5). Again they advocated for strategic intent. Instead of detailed plans strategic intent is concerned with building capacity, maintaining flexibility, and encouraging creativity. 
Bell (2004) expressed a concern with traditional strategic planning's effect on creativity. Although strategy itself is creative, there is concern that a formalized strategic plan may inhibit creativity in the broad sense. This author believed strategic planning in education is overly prescriptive and based on the assumption there is one best way to do things. The result is an inhibition of creativity and imaginative thinking.

As mentioned by Davies and Ellison (1998) strategic planning has been criticized because it is based on a belief that the future is predictable. Mintzberg (1994) and Bell (2004) both included the fallacy of prediction as one of the three fundamental flaws found within strategic planning models. As a second flaw, Mintzberg included the fallacy of detachment, brought about because they are developed by management rather than the workers. Mintzberg's third fallacy is formalization. Formal systems might be able to analyze large amounts of data but synthesis is something that may occur inside or outside of the strategic planning process. Experimenting, integrating, and creating are processes that gradually converge into viable strategies (Mendenhall, 2006). Prescriptive, formalized planning processes may impede the emergence of these strategies.

Bell (2004) included prediction as the first of his three fallacies but varies somewhat from Mintzberg (1994) on the other two. The fallacy of leadership is described by Bell as the second. Although similar to detachment because of its lack of involvement for workers, Bell directed attention to implementation instead of formulation. The point is similar however. Without dispersed leadership, such as the involvement of teachers in the implementation process, the improvement plans will be ineffective. The third fallacy for Bell is focused on effectiveness. Again this is similar to Mintzberg's formalization. Bell suggested: "Strategic planning is predicated, therefore, on a world view that presents the environment as a place of order, 
simplicity and conformity, where everything operates according to specific, knowable and predetermined rules" (Bell, 2004, p. 35).

It is unlikely that the proponents of strategic planning would agree to all of the above characterizations of the formulation process, resulting plan, and implementation. Some of the debate is about semantics because, as mentioned earlier, the definition of planning in general, and strategic planning, in particular, is elusive. For example, although there may be differences conceptually between strategic planning and strategic intent, this significance will vary according to which definitions or models a school district accepts. The ensuing debate about strategic planning is probably less helpful than the implication that organizations must be viewed with a variety of lenses to consider their complex dynamics. Context is significant when determining what models or processes to employ.

Johnson (1990) made this last point in his article about managing strategic change. In order to implement strategic change effectively we must first understand organizations. Johnson (1990) urged us to consider "explanatory models which integrate organizational, cognitive and cultural dimensions of the change process with the symbolic activities of change agents" (p. 183). This author, in particular, stressed the importance of symbolism and its relevance to the organization's existing culture. Radical innovation, the kind that may be proposed as a result of strategic planning, can only be effectively implemented through consideration of the organization's social, cultural, and political attributes.

In place of strategic planning some authors recommended strategic intent. In this researcher's opinion, strategic intent has more in common with strategic planning than it has differences. However, it is a modification with sound conceptual intent. 
Proponents of strategic planning suggest much of the criticism directed at the model is in reality directed toward the operational and comprehensive planning models that schools utilize under the name of strategic planning. This researcher will not attempt to settle the matter. Instead, the following is posed: Rather than being viewed and delivered as a rationalistic or prescriptive process, the formulation and implementation of strategy is more effective and better understood as a relatively unstructured, iterative, social, creative, and political process.

Strategic planning case studies. In order to conduct a review of current research on the topic of strategic planning in public schools, an electronic search of educational databases was conducted using the Elton B. Stephens Company's online system (EBSCOhost). Databases searched included: Academic Search Premier, Education Research Complete, and the Educational Research Information Center (ERIC). Key search terms included, strategy, strategic plans, strategic planning, strategic planning and schools, educational planning, and improvement planning.

This next section will review three case studies of strategic planning in public schools found by this search. The first study looks at Florida's Orange County Public Schools. The second reviews the state of Utah's process. The third is a comprehensive study that reviews 120 plans from 30 states.

Orange County Public Schools have used many planning techniques over the years. In the 1980s they labeled their comprehensive planning process the Educational Planning and Resource Management System. It included four major components, an annual district plan, individual school plans, district level departmental plans, and individual objectives for management. In 1985 Orange County Public Schools incorporated strategic planning concepts and processes into 
the development of the district plan. Jackson, Blamick, and Morrison (1989) conducted a case study of this strategic planning and external analysis process.

Not surprisingly Orange County Schools’ process emphasized external analysis. Florida public schools had been faced with rapidly changing physical environments, enrollments and demographics. Orange County emphasized external analysis to develop an early warning system, hoping to generate additional lead time, provide data for sound decision-making, and form a shared perception of the big picture. External analysis included events, issues, and trends in six general areas: "economic, educational, political, technological, demographic, and social" (Jackson, et al., 1989, p. 12). In the researcher's view this is what distinguishes strategic planning from traditional long-range planning. "Environmental scanning is a key feature of the strategic planning process. It enables strategic planning to be dynamic, responsive, futuredirected, and improvement oriented" (Jackson, et al., 1989, p. 9). The Orange County model featured nine steps:

1. Conduct external analysis

2. Conduct internal analysis

3. Formulate assumptions about the future

4. Develop/update the mission statement and general goals

5. Generate and select alternative approaches

6. Develop strategic objectives

7. Develop annual operating objectives

8. Develop action plans

9. Compile, adopt, and disseminate the strategic plan. (p. 6) 
Jackson et al.'s (1989) case study focused on a description of the model and its processes. It concluded with a strong endorsement of strategic planning. "A more focused understanding of an organization's current position and future possibilities is provided by the future-driven nature of strategic planning and its external analysis component" (Jackson, et al., 1989, p. 21). These researchers also recommended school-based planning to decentralize the improvement process. They believed that the school level is the location where improvement effects are most likely to have a noticeable effect on student outcomes. Jackson et al. (1989) suggested the use of district strategic plans as guides for individual school plans and to encourage schools to "work out much of their own destiny within that general framework" (p. 21).

The second case study is Utah's process. In 1992 the Utah State Legislature required strategic planning in its public school system. The Utah State Strategic Plan (USSP) included four broad objectives and 11 strategies. The Utah State Office of Education contracted with the Western Institute for Research and Evaluation (WIRE) (1993) to conduct a study to determine the status of strategic planning in Utah's public school system. This study was guided by 12 research questions. While the entire list will not be included here, several of its questions are noteworthy:

1. What types of strategic planning activities currently exist within Utah's districts and schools?

2. How do Utah's district and school personnel perceive strategic planning efforts at the school, district, and state level, and the impact they will have on educational programs at these levels?

3. What impediments have slowed or prevented schools from effectively launching the strategic planning processes outlined in the USSP? 
4. What specific operational steps do schools and school districts perceive as necessary to implement the USSP?

5. What are the stakeholders' recommendations or concerns about strategic planning at the school, district, and state level? (WIRE, 1993, p. 6)

To answer these research questions WIRE (1993) combined telephone interviews, a questionnaire, and on-site visits. Each of Utah's 40 school district superintendents was interviewed by telephone. A questionnaire was sent to a random sample of Utah school principals. On-site visits were conducted at five schools. These sites were selected by purposive sampling by the Utah State Office of Education and WIRE for having significant involvement in strategic planning.

WIRE (1993) found that the majority of strategic planning efforts followed the Cambridge model. A key step in this process was the creation of a task force which developed actions plans for accomplishing the identified mission and objectives. From their analysis of the data, WIRE (1993) concluded the stakeholder groups had three consistent recommendations for Utah's strategic planning process: (a) provide funding for strategic planning; (b) strategic planning efforts need to unfold and be supported over time; and (c) strategic planning should be a bottom-up process to encourage buy-in prior to implementation. In conclusion, WIRE found that many stakeholders viewed strategic planning very positively and the process showed progress as a vehicle for improvement.

The third case study is a comprehensive study of strategic planning in public school districts in the United States. Conley (1992) reviewed 120 plans from 30 states. The method included a review and analysis of the plans and a survey. The plans showed the following general categories to be present in most of those reviewed: "vision statement or mission 
statement; guiding principles or core beliefs; external scan; internal scan; strategic issues or directions; action plans" (Conley, 1992, p. 18). The survey included items on a Likert scale and questions requiring a short narrative.

Conley's (1992) findings addressed many of the areas in which strategic planning has been criticized. Overall the results of the survey found an overwhelmingly positive response to strategic planning. There were eight major conclusions and implications. A few of these will be highlighted as well as more specific responses to survey questions.

The survey results suggested strategic planning enhanced the movement to a more open systems form of governance and goal setting. "Strategic planning may be the glue that is needed for decentralized decision-making to succeed" (Conley, 1992, p. 52). The district plan was viewed as the umbrella under which individual schools created their own strategies and action plans.

Strategic planning also seemed to be effective as a tool to limit incrementalism. Incrementalism, as used to describe an unintentional rather than a deliberate approach, is considered to be a consequence of strategic planning models. Conley's (1992) survey contained questions directed at both incrementalism and restructuring. Respondents felt strategic planning would lead to both, although they had stronger feelings that restructuring would be the primary outcome. The districts in the study appeared to support the idea that systematic planning can, at the same time, address broad issues and more focused implementation strategies.

A significant issue in the debate on strategic planning addresses the overemphasis on rationality, or the prescriptive quality of the process, versus its interactive qualities. Conley (1992) addressed this issue by stating: 
If strategic planning is to be valued primarily as an interactive planning model, rather than for its rational dimensions, then it should lead to greater focus on issues of general importance to the organization. If, however, it is basically a rational model, where the implementation of the action plans is more important than the process of making meaning, then it would not be unlikely that the process would not focus administrators as a group on key issues for the district's future, since their role would be primarily to implement the action plans that result from the planning process. (p. 23)

Respondents in this study agreed that planning helped focus administrators on important issues in the district's future. Strategic planning was also viewed as a public forum as much as a rational planning model. There was an overwhelmingly positive response to an item suggesting strategic planning is an arena "where teachers and administrators can communicate and find common cause and purpose with one another" (Conley, 1992, p. 31).

Most importantly 72 percent of respondents agreed that the plan would lead to improved learning outcomes. This suggested that the focus of the plans was on student learning and that the goals and outcomes were stated in terms of students' learning gains. Although positive, such an outcome should be viewed cautiously because it is an unproven prediction.

Finally, Conley's (1992) review of the 120 plans showed that the process of strategic planning had been revised extensively by educators. It bore little resemblance to corporate models even though the elements and format may be similar. The researcher's evidence suggested that educators combine a number of planning techniques when they perform strategic planning. They appear to adopt the rational aspect for a framework while also using a political and interactive approach to the planning process. This questions the applicability of specific 
strategic planning criticism. "While these models are neatly separated by theorists, it appears practitioners find no such need to separate or distinguish between them" (Conley, 1992, p. 52).

Strategic planning dissertations. Much has been written about strategic planning in public schools. Hambright and Diamantes (2004) reviewed 66 books, 29 journal articles, 28 research presentations, 6 doctoral dissertations, and miscellaneous other sources in their analysis of prevailing models. Their review included literature from the mid 1980s forward. While the literature is replete with how to books and opinion pieces, this researcher's search of databases using EBSCO Host (Academic Search Premier, Education Research Complete, and ERIC) found limited case study research.

To obtain additional studies on the topic, searches were performed using the Dissertation Abstract Online Database. An initial search using the keywords planning public schools yielded 1447 records. The search was also limited to those available in English. The search was then narrowed to strategic planning public schools. These keywords yielded 95 records. The titles of these 95 studies were reviewed. This list was reduced to the 20 most recent and relevant studies. The abstracts of these 20 were studied to assess their relevance to the purpose and research questions of this study.

The most recent and relevant studies employed both quantitative and qualitative methodologies. The most common methods of data collection were interviews, document reviews, and surveys. Several dissertations paired the study of strategic planning with its influence on, or coexistence with, related concepts such as systems theory (Jackson, 2006), organizational learning (Sloane, 2003), environmental scanning (Feek, 1999), restructuring (Oram, 1997), public support (Bingham, 1996), and decision-making (Busler, 1992). 
The studies selected for inclusion in this literature review had purposes most similar and relevant to the proposed research questions. In particular, they investigated the models, styles, or processes used during strategic planning. The selected studies also identified facilitators and barriers to the development and implementation of strategic plans.

The three dissertations selected for inclusion in this literature review employed qualitative methodology similar to the methods used for this research. The most common methods for data collection were interviews and document reviews. Each dissertation selected used a case study approach. Two of the studies focused on a single school district. These will be reviewed first.

The first study examined the strategic planning process as it was employed in the Des Moines, Iowa public school district (Vincent, 1992). This study combined interviews of 20 strategic planning participants with observations to describe Des Moines’ planning process. Research questions from this study focused on investigating the role of the superintendent, the desired results of the plan, decision-making activities used, and employee's knowledge of the strategic planning process.

The results of Vincent's (1992) study, in general, supported the strategic planning process. The Des Moines School District adopted the Cambridge Model paired with a human action model to facilitate the process. The researcher concluded the superintendent's active role in strategic planning was essential for successful implementation. The district also held frequent staff development activities to support the strategic planning process. The strategic planning process required the participation of a wide range of stakeholders. 
One of the major outcomes of Des Moines' (Vincent, 1992) use of strategic planning was its shift to site-based management. This resulted in increased shared decision-making similar to that which occurred during the strategic planning process itself.

The second study selected also investigated the strategic planning process in a single school district. Johnson's (2004) study described strategic planning in the Millard, Nebraska public school district. Interestingly, the researcher was also a member of the school board in this district. This study combined 16 interviews of planning participants with document reviews to describe the process and outcomes of Millard School District's strategic planning process. The document review included Millard's strategic plans from 1989 - 2003, accompanying planning sessions, and related meetings' documentation.

Johnson (2004) concluded that strategic planning, as implemented by Millard School District over the previous 14 years, had contributed to a number of positive district attributes. These included the development of numerous policies, programs, and procedures within the school district. The planning process was also credited with encouraging "innovative thinking and allowing entrepreneurial spirits to flourish" (Johnson, 2004, p. 136). Other outcomes included:

1. A program based budget process,

2. Site-based planning at the building level,

3. The development of new evaluative measurements,

4. The development of individual mini-magnet programs, and

5. The development of essential learner outcomes.

The final dissertation selected for review in this section provides a view of strategic planning in selected Wisconsin public schools (Busler, 1992). The stated purpose of Busler's 
(1992) study was the examination of the role of strategic planning and its effect on decisionmaking in Wisconsin public schools. This study combined an initial survey with case studies. The initial survey was distributed randomly to Wisconsin school districts to compare districts using a strategic planning model with those using long-term planning or other forms of planning. Strategic planning was not a requirement for Wisconsin school districts when this study was conducted. Case studies were conducted in six Wisconsin schools. Three school districts were selected that were using the strategic planning process while the other three districts were using some other form of planning. Eight planning participants were interviewed from each of the six districts.

Busler (1992) reached several conclusions from the research. First, there were signs of organizational weaknesses in the non-strategic planning schools. These included:

1) lack of employee/organizational commitment and ownership of goals and priorities, which is caused by leaders dictating goals and priorities; 2) planning activities were of a crisis nature and had little or no long-term focus and a limited degree of correlation to each other; and 3) many of the participants said their district's long-term goals were not clearly stated and played no role when program and financial decisions were made. (Busler, 1992, p. 203)

For those districts using the strategic planning process, Busler (1992) reached more positive conclusions. First, for those using a strategic planning process, school districts' decisions can't be made in isolation of their effect on the internal or external environments. This was described as signaling a major paradigm shift for these public schools. Second, and similar to the first conclusion, the strategic planning process requires an organization to view itself as a system. Finally, the survey and case studies suggested that a strategic planning process improves 
decision-making. This last conclusion should be qualified however because it was based on self report.

Planning in West Virginia public schools. Planning occurs at many levels within public schools, in general, and West Virginia public schools, in particular. For example, there are individual student plans of study and student transition plans. There are also various plans associated with budgets, facilities, staffing, curriculum, and instruction. This section will focus on the broad plans that schools and school systems within West Virginia have been required to produce within the last several decades. This section will also show that the accreditation process, school improvement efforts such as the Master Plan for Public Education (West Virginia Board of Education [WVBOE], 1983), and county/school plans are closely tied together.

Perhaps the most comprehensive plan in the history of West Virginia public schools resulted from a class action civil suit filed in 1975 by the parents of five children who attended the public schools of Lincoln County. When the suit reached the West Virginia Supreme Court in 1979 it was known as Pauley v. Bailey (1984). The Supreme Court of Appeals remanded, with directions, this case to the Kanawha County Circuit Court. In 1982 Special Judge Arthur Recht issued his comprehensive opinion that the system of financing public schools in West Virginia was unconstitutional and directed that a master plan for a thorough and efficient system of education be prepared under the direction of a commissioner. The commissioner and advisory committee released A Master Plan for Public Education in 1983 (WVBOE, 1983). The plan included a detailed set of programmatic standards that were considered at the time to provide a high quality system of education. 
During approximately this same time period, 1981, the WVBOE established an accreditation process policy, Policy 2320: Standards for Educational Quality. "The implementation of a county accreditation process requires new assessment, planning, and developmental efforts by county boards of education, plus an increased commitment to evaluation, planning, and technical assistance by the West Virginia Board of Education (WVBOE, 1981, p. 1). The original Standards for Educational Quality (WVBOE, 1981) policy required county school systems to determine their compliance with certain minimum standards: "This benchmark information will be used as the foundation upon which to develop an annual county plan for educational excellence" (p. 1). The county plan was also required to include improvements which addressed locally identified needs and priorities above the minimum standards.

In the early 1980s this plan was titled the County Plan for Educational Excellence. This four-year county plan was to be amended and renewed annually. It was required to be submitted to the state department of education by July 1 of each year. The first priority of this county plan was to address standards that had not been met by the respective county districts and it was to include improvement components which address locally identified needs and priorities. It also required districts to address efforts to advance programs above the minimum standards. This county plan was to incorporate several other plans including Chapters I and II, continuing education, instructional improvement, and special education. Each county plan was reviewed by the West Virginia Department of Education (WVDE) to verify compliance with standards and to verify that the improvement components addressed locally identified needs and priorities.

In 1988 the West Virginia Legislature passed education reform legislation that established a school/school district Performance Based Accreditation System (W. Va. Code, §18- 
2E-5, 1988). This replaced the accreditation system that had been in place since 1981. Under this system, schools and school districts were required to "submit an annual performance plan based upon their needs as identified by the annual performance measures and high quality standards (WVDE, 1990, p. 1). The Office of Accreditation was charged with reviewing each of these plans and issuing an accreditation status and approval level.

Subsequent revisions to Policy 2320 further defined the requirements of school and school district annual improvement plans. The plan's purpose was defined as providing an indication of the district's and individual school's intent to comply with the high quality standards and annual performance measures established by the WVBOE. Schools and districts were required to base the plan on locally identified needs. Additionally, each school and district was required to include performance data and both qualitative and quantitative assessments of the school's and district's compliance with high quality standards. Again the plans were to be reviewed by the WVDE after which an approval status and accreditation status would be assigned. This status was to be determined by the annual performance measures and the results of an on-site review, if one occurred (WVDE, 1992).

Additional, significant education legislation was enacted by the West Virginia Legislature through its Jobs through Education Act of 1996, more commonly referred to as Senate Bill 300. This legislation described an education improvement plan that included, among other items, school report cards and technology plans. In regard to the technology plans, it also required the state board of education to develop a plan which specified the resources to be used to provide services to students based on the plans developed by each individual school team.

Senate Bill 300 again tied school district plans and accreditation together as it required a system for the review of school district education plans. This legislation required that: 
"Whenever a school is given probationary accreditation status, the county board shall implement an improvement plan which is designed to increase the performance of the school to a full accreditation status level within one year" (West Virginia Legislature, 1996, p. 15).

The County Plan for Educational Excellence was redefined and renamed the Unified County/School Improvement Plan by the WVDE in 1997. This was the first time these improvement plans were recommended to be developed through a strategic planning process. The goal of these plans was:

To provide for identified county-wide needs while unifying county level resources to deliver a strong educational program ... The plan should be designed to bring together the best knowledge and practices to meet the needs of the county schools and students while combining resources in an efficient and effective manner. (WVDE, 1997, p. iv) The Unified County/School Improvement Plan was meant to be a cooperative effort that involved county staff, a steering committee, staff development councils, the technology team, parents, and members of the community. The plan was meant to be a single document that could bring together all the programs and resources related to improving instruction and learning. The overriding purpose of these plans was the need to improve student achievement. The second priority was described as the "better use of time, people, and resources to maximize the effectiveness and efficiency of the instructional program" (WVDE, 1997, p. iv). The Unified County Improvement Plan was required to have the following components:

1. County School District Vision and Mission

2. County School District Goals

3. Needs Assessment and Conclusions

4. Improvement Objectives 


\section{High Quality Activities}

6. Monitoring Implementation

7. Assessment

8. Using Evaluative Information

9. Technical Assistance

10. Staff Development

11. Budget (p. iv-v)

A report by the Commission on Educational Quality and Equity in 1998, Providing a Thorough and Efficient System of Schools: Quality and Equity, also called for strategic approaches in West Virginia's public schools. The report's process for improving education was described as "strategically targeting resources to improve the capacity of schools and school systems to improve the teaching and learning process" (Commission on Educational Quality and Equity, 1998, p. 13). It called for strategic investment by the state in agreed upon goals and target areas. One of the important elements that schools systems were to use to improve the teaching and learning process was a "local program evaluation and strategic planning process at both the county and school levels capable of assessing weaknesses and targeting resources to improve the teaching and learning process to achieve the performance and process standards" (Commission on Educational Quality and Equity, 1998, p. 14). This document also referenced the Unified County and School Improvement Plans. It stated that these plans require strategic planning based on the identified needs of students in order to meet the state's standards. The report recommended that a checklist indicating compliance with the standards should accompany the plans. The report also stated that the plans should specify strategies for meeting performance and process standards that have not been meet. "Along with other state determined measures of 
student and school performance, these plans form a basis for assessing the capacity of schools and school systems for delivering a high quality education" (Commission on Educational Quality and Equity, 1998, p. 14).

The improvement planning process currently required of West Virginia public schools was made effective by legislation and policy the beginning of the 2005-2006 school year. West Virginia statute 18-2E-5 (2007) required the development of electronic county and school strategic improvement plans: "Each respective plan shall be a five-year plan that includes the mission and goals of the school or school system to improve student, school or school system performance and progress, as applicable" (p. 65).

Similar to the language within state code, WVDE Policy 2320 (2007) required each county board to develop a five-year electronic county strategic improvement plan. The plan was to be annually revised in each area that the school or school system was below standard on the annual performance measures. The WVDE was responsible for the provision of the electronic template for the plan. This template was to include all required aspects and improvement requirements of No Child Left Behind (NCLB) and the state's annual performance measures for school system approval status and school accreditation status.

The five-year plan was also linked to the state's approval level process. The WVBOE issues one of four approval levels to each county board: Full approval, conditional approval, temporary approval, or nonapproval. Each of the approval levels involves the improvement plan. For example, conditional approval is issued when a school system is below the level required for full approval but whose improvement plan meets certain criteria. Similar to previous requirements, whenever a school system is issued temporary accreditation status the improvement plan must be revised to increase the performance to full accreditation status. The 
WVBOE must approve this revised plan. If it is not approved the school system may be placed on low performing status.

Policy 2320 also considered the electronic strategic improvement plan to be a key component in capacity building. "School and county electronic strategic improvement plan development is intended, in part, to provide mechanisms to target resources strategically to the teaching and learning process to improve student, school, and school system performance" (WVDE, 2007, section 18.1).

In addition to references in state code and accreditation policy, the five-year plan was included in the state's comprehensive policy that establishes regulations for all education programs. WVBOE Policy 2510, Assuring the Quality of Education: Regulations for Education Programs (2007) referenced improvement planning at both the school and system levels. This policy identified the Five-Year School/School System Strategic Plan as containing the procedures and activities necessary "to strengthen the county education program in order to increase student achievement and positively impact other student outcomes" (WVBOE, 2007, section 12.1.1). The plan required nine components:

1. Core beliefs and mission

2. Data analysis

3. Improvement goals

4. Improvement objectives and benchmarks

5. A work plan that includes action steps and professional development

6. A system for monitoring and supporting the implementation and effectiveness of the work plan

7. An evaluation process 


\section{A budget}

9. Annual planning updates for federal and state programs that meet the specific requirements of each program and support the goals and objectives of the plan. (section

\subsection{1)}

The 2008-2009 school year was the fourth year that each West Virginia school and district completed or revised the five-year plan. While West Virginia schools and school systems have been doing planning since the 1980s, the current version of this requirement has only been in place since the 2005-2006 school year. The plan is a comprehensive document intended to identify the action plans, objectives, and benchmarks that will lead to achievement of stated goals in fulfillment of each school's and each school district's mission. The planning process is designed to be a collaborative effort involving a variety of stakeholders. The planning process itself models the sustained professional development necessary to build capacity. This increased capacity is necessary to continually improve the teaching and learning processes required to improve student, school, and school system performance.

Summary. This chapter began with a discussion of reform and our nation's public schools. The approaches to organization improvement and their foundations in organization theory were traced from their historical roots in the business sector to the eventual application within public school systems. These approaches evolved along with the conceptual changes that occurred within organizational theory. Theory and practice moved from an emphasis on the rational and structural characteristics to an acknowledgement of the complexities and dynamics represented by systems theory. Culture, environmental considerations, social, and political dynamics had been excluded from previous models. 
Planning theory and planning in schools were reviewed. More specifically, strategic planning was introduced as a preferred method for many businesses and subsequently school districts. Strategic planning achieved increasing popularity within businesses and school systems. Models were developed and applied in a variety of public school settings. Strategic planning was promoted as a way to think outside of the box while considering both internal and external factors. The school district's future was anticipated and a strategic plan created to achieve the organization's vision, mission, and goals.

This chapter also reviewed the criticism directed at strategic planning. Some of this criticism is a result of models and processes being too rational or prescriptive. When this happens creative, visionary, emergent strategies that develop outside of the planning process may be ignored. The fundamentals of strategic planning have been questioned for their reported reliance on predictability, detachment, and formalization. Strategic plans have also been characterized as being too incremental. This can amount to, at best, maintenance of the status quo, and, at worst, lost opportunity if more innovative, "break the mold" types of strategies are not embraced.

Systems theory may also have been the source for some of the criticism of strategic planning. Viewing public schools from an open systems approach suggests these organizations must be flexible and responsive to a rapidly changing environment. Instead of strategic planning, learning organizations have been promoted as a preferable vehicle to achieve school reform. Learning organizations are described as the best way to develop short-term efforts that respond to emergent opportunities and problems.

Strategic planning models were then reviewed. The most popular of these was the Cambridge model. Case studies from refereed journals and dissertations were reviewed. 
Planning in WV public schools was traced from the 1980s forward. The requirement for the current on-line five-year school system strategic plan, in place since the 2005/2006 school year was reviewed.

In conclusion, the following is drawn from this review of the literature. Successful school improvement plans and implementation efforts also need to maintain organizational coherence through a process that considers its dynamic complexity. Local contexts and a constantly changing educational landscape make it difficult for any one theory or model to describe and predict which school improvement efforts will result in the meaningful enhancement of learning and teaching. 


\section{Chapter Three}

\section{Research Design and Method}

Purpose and research questions. The purpose of this study was to describe and develop understandings of the West Virginia Five Year School System Strategic Plan development process. Its research questions were: How do county office personnel develop the West Virginia Five Year School System Strategic Plan? What styles of development do they use? and What are the facilitators and barriers to development? This was a qualitative design that included multisite case studies. Two data collection methods were used: interviews and the assembly of a cache of documents relevant to strategic planning.

This chapter begins by discussing the rationale for selecting the interpretive paradigm to answer this study's research questions. The attributes of qualitative research in this regard are reviewed. The rationale for this qualitative case study's two data collection methods, interviews and documents, is then provided. The background of the researcher is discussed prior to a more detailed description of the research methods. The research methods section includes site selection, participant selection, and data collection, management, analysis, and interpretation. The final section reviews assurance criteria relevant to this study's design.

Theoretical basis of research methodology. While positivists may search for the empirically demonstrated best practices in instructional methodology and the causal attributes of successful curricula, interpretivists acknowledge the importance of intersubjective meaning in educational contexts and processes (Soltis, 1984). Although everyone interprets a phenomenon, there is not one subjective meaning shared between all individuals.

This study was approached from an interpretive or constructivist paradigm. "The basic tenet of constructivism includes the notion that we construct our realities, for the most part, in 
interpretive communities" (Garman, 1994, p. 5). Revealing these constructed realities and researching complex issues and processes requires the in-depth analysis offered by the qualitative approach (Glesne, 2003; Peshkin, 1988; Stake, 1995). This study investigated the complex issues and processes involved in the development of the West Virginia Five Year School System Strategic Plan.

The selection of method for this study was based on neither rigid paradigm adherence nor methodological eclecticism. "If a method were not based on certain assumptions about the phenomena to be investigated, it would not possess the unique characteristics required to study them" (Yanchar \& Williams, 2006, p. 4).

Yanchar and Williams (2006) proposed five guidelines for method use. One of these five is conceptual awareness. The acknowledgement of certain assumptions and their influence on the choice of methods is a form of conceptual awareness. "In this sense methods would be viewed as practical (though theoretically informed) extensions of the investigators' assumptive framework that may facilitate inquiry" (Yanchar \& Williams, 2006, p. 9).

The selection of method for this study was based on several assumptions about the strategic planning process. First, it is a planning process. It also demonstrates compliance with state policy. As noted in chapter two, strategic planning processes are frequently means for organizational communication and control. While considering these assumptions, this study was particularly interested in the teaming and decision-making that occurred during the development process as decisions were made about goals and their prioritization. As a social experience it is important to understand the communication, collaboration, and understandings that occurred and were constructed during the process. As a political phenomenon, strategic planning may also reveal examples of power, coalition building, negotiations, and trade-offs. 
Glesne (2003) described qualitative research methods as those used to understand some social phenomenon from the perspective of the individuals involved and "to contextualize issues in their particular socio-cultural-political milieu" (p. 4). A description of the strategic planning process can be enriched by the inclusion of subjective personal and interpersonal responses. Soltis (1984) suggested that "researchers of this bent seek to bring to our collective consciousness and critical awareness a demystification of our educational institutions and practices that will serve our emancipatory interests" (p. 8).

Garman (1994) described some of the most important purposes of qualitative design. "The essential mode of inquiry of qualitative research is for portraying deeper understanding. Qualitative statements are supposed to be used to illuminate, to explain, to interpret, and not to verify" (Garman, 1994, p. 13).

A number of attributes of qualitative design make it the appropriate approach for this proposed research. The following list of attributes has been combined from the writing of Glesne (2003) and Krathwohl (1998):

1. The purposes of the qualitative approach are understanding, interpretation, and contextualization. The purpose of this research is to describe and develop understandings of the strategic plan development process.

2. Qualitative research is concerned with processes that are complex, interwoven, and difficult to measure. They describe complex personal and interpersonal phenomena. The teaming and decision-making that occur during planning are complex processes.

3. Qualitative research is interested in how participants perceive, construct, and react within their social environments. The interview questions are designed to investigate participants' perceptions of the process. 
4. It is inductive in nature. It uses analysis to attempt to find commonalities in the data which lead first to description and then to explanation. Themes are based on the review of the literature as well as an inductive process.

5. The qualitative researcher is the primary instrument for the collection of data, which usually occurs in a natural setting, and its analysis. I am the primary researcher and will interview and gather documentation in the respective districts' offices.

6. The design of qualitative studies allows them to be responsive to the changing conditions and findings of the study. It is emergent and flexible. The selection of interviewees and the semistructured interview style allows for this flexibility.

This study was approached from this interpretive tradition while touching on some normative aspects of the process. A normative or critical component may also be of significant interest when interpreting mandated policy or processes. Rather than being purely descriptive a normative component can delve further into the attitudes and reactions of the participants. Soltis (1984) argued that "the normative is an essential and integral part of what constitutes human pedagogy and as such must be included in whatever form the science of pedagogy takes" (p. 8).

Rationale for design. This section discusses the rationale for choosing a qualitative case study approach as the means to answer this study's three research questions. It also briefly provides a rationale for the two methods proposed: interview and document analysis and interpretation.

Case study. This research used case studies to describe and develop understandings of the strategic plan development process. Merriam (1998) appeared to give an endorsement applicable 
to this choice. "Case study is a particularly suitable design if you are interested in process" (Merriam, 1998, p. 33).

Creswell (1998) defined case study as "an exploration of a bounded system or a case (or multiple cases) over time through detailed, in-depth data collection involving multiple sources of information rich in context" (p. 61). Yin (2003) described a case study as "an empirical inquiry that investigates a contemporary phenomenon within its real-life context, especially when the boundaries between phenomenon and context are not clearly evident” (p. 13).

Case study can also be defined by a description of its key qualities. Merriam (1998) characterized qualitative case studies as being particularistic, descriptive, and heuristic:

Particularistic means that case studies focus on a particular situation event, program, or phenomenon ... Descriptive means that the end product of a case study is a rich, thick description of the phenomenon under study ... Heuristic means that case studies illuminate the reader's understanding of the phenomenon under study. (p. 29-30) Merriam (1994) also described the positive attributes of case study. Its strengths include the ability to investigate complex social phenomena that contain many variables. Because it is anchored in real-life situations case study also results in a "rich and holistic account of a phenomenon" (p. 41). Case study research offers insights to processes and expands the reader's understanding. These insights may lead to tentative hypothesis that generate grounded theory and suggest avenues for future research.

A case study that studies more than one case is a multi-case or collective case study (Stake, 1995). When "choosing what cases to study an array of possibilities for purposive sampling is available" (Merriam, 1998, p. 62). 
Stake (1995) recommended that the first criterion in selecting cases should be to maximize what we can learn. This research selected cases by nomination of an expert knowledgeable about counties' Five Year School System Strategic Plan development. This individual is a West Virginia Department of Education administrator responsible for strategic plan policy development, plan format and content, professional development, and plan review. Nomination was used as the means of selecting sites in order to obtain the richest descriptions of the process resulting in portrayals that possess rigor, utility, and vitality.

Interviews. Interviewing as a method to obtain research data has a number of strengths (Marshall \& Rossman, 1995). “An interview is a useful way to get large amounts of data quickly ... Immediate follow-up and clarification is possible" (Marshall \& Rossman, 1995, p. 80-81). Interviews also assist the researcher in trying to understand the meaning interviewees attach to their activities. It is "useful for discovering complex interconnections in social relationships" (Marshall \& Rossman, 1995, p. 100). Of particular relevance to this study, interviewing has the ability to uncover the subjective side, or "native's perspective” (Marshall \& Rossman, 1995, p. 100), of organizational processes.

This research used semi-structured topical interviews. Glesne (2006) described topical interviews as a form "that focuses more on a program, issue, or process, than on people's lives" (p. 80). Glesne (2006) recommended a type of interviewing that is structured, open, and depth probing. It is structured in the sense that there are specific questions to be asked. It is open because new questions may need to be asked as unexpected leads arise. It is depth probing in order to further explore points of interest. Interviewing also allows for modification of the inquiry as saturation occurs. Saturation occurs when no additional data is found after repeated interviews (Flick, 2002). 
Documents. There are a number of advantages to including documents as a source of data in qualitative studies. Documents can be used to "furnish descriptive information, verify emerging hypothesis, advance new categories and hypothesis, offer historical understanding, and track change and development” (Merriam, 1988, p. 108). Documents are a particularly good source for data because they can ground an investigation in the context of the process being studied. Documents are also useful for comparative purposes. Another desirable quality of documents is their stability. "Unlike interviewing and observations, the presence of the investigator does not alter what is being studied. Documentary data are objective sources of data compared to other forms" (Merriam, 1998, p. 126).

Background of the researcher. It is necessary for a researcher conducting a qualitative study to disclose his background and experiences, especially those related to the topic being studied. This type of disclosure is important because the researcher's background and experiences may affect the investigation and results (Peshkin, 1988). I agree with Merriam's (1988) description of the role of an investigator's theoretical orientation.

The researcher has been socialized into a discipline that has its own vocabulary, concepts, and theories. One begins to think like a member of the discipline and to view the world through the discipline's lens. This perspective affects the nature of the questions raised, which in turn determines the research design, which in turn influences the conclusions drawn. (Merriam, 1988, p. 54)

As the researcher for this study, I am a doctoral level graduate student and veteran central office administrator with a total of 28 years of experience in public schools as a school psychologist and subsequently an administrator. I am new to the field of qualitative research. I have not conducted qualitative research interviews. However, I have served as an interviewer for 
hundreds of employment interviews and I have developed scores of employment interview questions.

Although I have not served as the primary author of a strategic plan, I have served on various committees that have developed these plans. I have also participated in the implementation of various plan components.

I selected this topic for study because the West Virginia Online Five Year Strategic Plan is intended to be an all encompassing process and document that provides "mechanisms to target resources strategically to the teaching and learning process to improve student, school, and school system performance" (WVDE, 2007, section 18.1). As a significant foundation and driving force it may be the key instrument and process that reflects a district's effectiveness in achieving school system improvement.

In my experience I have found the strategic planning process to be an effective vehicle to achieve group consensus on vision, mission, core beliefs, and goals. As an operational plan, it has been an effective means of communicating and implementing these components. Conversely, it is also a time consuming, cumbersome process. In my opinion, its effectiveness is hindered to a degree by its sheer volume and technical requirements. Also, the majority of practitioners in my county school system, at times, appear to be unaware of, or have forgotten, the plan's content and purpose.

This study focused on the development process. While the final written school system strategic plans may be reviewed and evaluated by local or state level actors, there is not a formal process in place to examine the development process. This process, the dynamics of the interactions, and decisions of its members shape the final document and may impact the integrity of its implementation. 
Research method. The following sections will describe and justify this research's methods and processes. This includes site selection and sampling procedures, data collection and management, and data analysis.

Site selection and sampling procedures. To investigate the district level strategic planning process, this study used a multi-site case study. This approach allows an investigation to obtain detailed, in-depth data collection involving multiple sources of information rich in context (Creswell, 1998). Patton (1990) believed that certain kinds of research questions are best answered through case study. The case study approach may also attempt to build theory from an inductive mode (Merriam, 1988).

The interviewees in this research study were key members of school district's Five Year School System Strategic Plan teams. Purposive sampling was used to identify critical (Patton, 1990) or conceptually important cases (Weiss, 1994). Stake (1995) referred to this approach as instrumental case study because the purpose is particularization not generalization. The most distinctive characteristic of this mode of inquiry is its emphasis on interpretation. The selection of critical or conceptually important cases added robustness to the research's descriptions of the strategic planning process.

There were two criteria for selection of sites for this research. The first criterion was nomination by an expert knowledgeable about counties' Five Year School System Strategic Plans. This individual was a West Virginia Department of Education administrator responsible for strategic plan policy development, plan format and content, professional development, and plan review. The second criterion was the nominated sites' willingness to participate in the study.

This selection process was chosen in order to understand and interpret strategic planning examples that were recognized as employing a comprehensive development process in contrast 
to single, isolated authorship. These cases may be important conceptually thereby leading to a greater likelihood of producing theory that may help explain the contexts, processes, and understandings that are necessary for successful strategic plan development.

The West Virginia Department of Education does not assign a score or ranking to county plans. It does not deliberately single out any particular county school systems as having the best or worst plans. It does provide a feedback rubric to assist in improving the document.

As a result, to select county school systems for this study it was necessary to solicit the opinion of a West Virginia Department of Education plan reviewer. During a telephone interview this individual was asked to identify counties that appeared to have a well developed process and plan. This individual, an administrator in West Virginia Department of Education's Office of Title II School and School System Improvement, nominated four county school systems.

The school and school district strategic plans are reviewed by one of four administrators in the West Virginia Department of Education's School Improvement office. Following their reviews the four reviewers discuss their findings and opinions. They also discuss which counties would be considered to be the best. According to the nominator, the four counties identified represented an amalgamation of the four reviewers' opinions.

Multiple sites, rather than a single site, were selected by nomination because of this study's purpose: to describe and develop understandings of the strategic plan development process. In comparison to single-case designs "The evidence from multiple cases is often considered more compelling, and the overall study is therefore regarded as being more robust" (Yin, 2003, p. 46). To determine the number of sites for this multi-case study it is more important to ask the question "Does the sampling strategy support the study's purpose?" (Patton, 2002, p. 245) than it is to judge it on the basis of probability sampling guidelines. Stake (1995) 
agreed: "Case study research is not sampling research. We do not study a case primarily to understand other cases. The first criterion should be to maximize what we can learn" (Patton, 2002, p. 4). Because this study was more interested in depth than breadth, a smaller number of sites were selected.

There are no rules for sample size in qualitative inquiry ... A researcher could study a specific set of experiences for a larger number of people (seeking breadth) or ... a smaller number of people (seeking depth). In-depth information from a small number of people can be very valuable, especially if the cases are information rich. (Patton, 2002, p. 244)

Each identified county office was contacted to solicit tentative study participation and to identify the strategic plan team members. The superintendent was then approached, provided with an explanation of the purpose and methods of the study, and asked to participate in the study. Three to five team members were interviewed in each of the four nominated districts. The selection of key team members to be interviewed was based on a conversation with the team leader and a review of the team membership and respective roles. Additional interviewees could have been identified by one of the closing questions. This question asked the current interviewee if there was a specific person they believe should be interviewed to further the understanding of the plan development process. This is a type of snowball sampling. Snowball sampling (Patton, 1990) “is an approach for locating information-rich key informants or critical cases" (p. 237).

Two county school systems, other than the four nominated, were selected for a pilot case study. The pilot case study process assisted in the development of the case study protocol including refinement of the interview questions. As Yin (1984) pointed out, the case study protocol "is essential if you are using a multiple case design" (p. 64). This informal protocol 
included an overview of the project, field procedures, case study questions, and a guide for the report. Embedded in this protocol were the interview questions as well as the analysis and interpretation processes.

Data collection and management: interviews. The first type of data collection was semistructured, topical interviews of key members of the four nominated districts' Five Year School System Strategic Plan teams. The key team members, such as the team leader and primary document author, were anticipated to be good informants. Flick (1998) described good informants as having "the necessary knowledge and experience of the issue or object at their disposal" (p. 70). These good informants should also have the ability to reflect and articulate, be willing to participate in the study, and have the time to be interviewed or observed.

These key team members may also be what Marshall and Rossman (1995) describe as elite individuals. The selection of elites for interviewing has several advantages. "Elites often contribute insight and meaning to the interview process because they are intelligent and quick thinking people, at home in the realm of ideas, policies, and generalizations" (p. 84).

The interviews for this research were conducted in the private offices of the various school district administrators. Participants were interviewed using primarily the questions on the interview protocol. The protocol can be found in Appendix A of this document.

In addition to the general questions probes were used to develop further understanding. The interviews were recorded and transcribed prior to their analysis. Immediately following each interview personal reflections and observations were recorded as field notes. These included comments on areas that might have required further investigation or additional information.

These interviews used a series of open-ended questions that sought to obtain the in-depth conversations and rich descriptions (Marshall \& Rossman, 1995) necessary to answer the 
research questions. Auerbach and Silverstein (2006) recommended asking approximately six general questions.

If you ask many more than six questions, the interview will exhaust people, and they will not be able to complete it. If you ask many fewer than six questions, people probably will not give you as much detail as you need in order to understand their subjective experiences. (p. 16)

Lichtman (2006) described five types of questions that are useful when conducting semistructured interviews: grand tour questions, specific example questions, comparison/contrast questions, new elements/topics questions, and closing questions. This study's interview began with a grand tour question about the development process. The next questions were designed to examine specific examples, or aspects, of the planning process. The interview then introduced a new element, opinion, before finishing with a closing style question.

A matrix, available in Appendix B, was developed to check for correspondence between the proposed interview questions and the study's guiding research questions. The matrix contains linkages between the interview questions, research questions, and the corresponding foundations from literature cited in chapter two. The matrix also includes cues that helped probe for more indepth information. This served as a check on the interview questions' ability to elicit responses that would answer the research questions. These tentative answers also served as cues to develop probes or request elaboration. Lichtman (2006) described probes and elaboration as "strategies for questioning" (p. 124). "Strategies for questioning refer to techniques you can use to get the respondent to talk and reveal what he or she thinks or believes about something" (Lichtman, 2006, p. 124). In this study probes and requests for elaboration were necessary to obtain additional information about unanticipated themes and to gain further understanding of a topic. 
The interview questions were varied through the course of the interviews as unanticipated themes arose and as saturation occurred. Theoretical saturation occurs when "no additional data are being found whereby the sociologist can develop properties of the category" (Glaser \& Strauss, 1967, p. 61). Theoretical saturation of a category is reached when:

(1) no new or relevant data seem to emerge regarding a category; (2) the category development is dense, insofar as all of the paradigm elements are accounted for, along with variation and process; (3) the relationships between categories are well established and validated. (Strauss, 1990, p. 188)

Data collection and management: document cache. The second source of data for this study was each site's Five Year School System Strategic Plan core document and available supporting materials such as agendas or meeting notes and minutes. Document review can be a valuable data source if it contains information or insights relevant to the research questions (Merriam, 1988). Merriam (1988) described documentary material as "good sources for qualitative case studies because they can ground an investigation in the context of the problem being investigated" (p. 109).

A document cache was developed and maintained for each site. "A cache is a collection of documents related by topic which contain primary data for analyses ... Documents in a cache can be analyzed to obtain salient information about an event, person, social scene, or issue" (Hazi, 1982, n.p.). This study's cache included five year core plans, agendas, presentation materials, and other documents that were identified during the interviews. Researcher field notes and an audit trail were maintained.

Data analysis. Patton (1990) described qualitative data analysis as: 
A painstaking process requiring long hours of careful work going over notes, organizing the data, looking for patterns, checking emergent patterns against the data, cross validating data sources and findings, and making linkages among the various parts of the data and the emergent dimensions of the analysis. (p. 379)

Although there are no absolute rules for qualitative data analysis and interpretation, Patton (1990) emphasized that each researcher is expected "to fairly represent the data and communicate what the data reveal given the purpose of the study" (p. 372). Instead of absolute rules there are strategies, guidelines, and ideas. Patton contrasted these with rules because they "are meant to be suggestive and facilitating rather than confining, comprehensive, or exhaustive" (p. 372).

This research's data analysis began during the data collection process. During the collection process preliminary findings were identified through the interviews, documents, and field notes. Merriam (1994) stated that "data collection and data analysis should be a simultaneous activity in qualitative research" (p. 186).

Miles and Huberman (1994) described a three step qualitative data analysis: data reduction, data display, and drawing and verifying conclusions. The first step in the process is the reduction of data. "Data reduction is the process of selecting, focusing, simplifying, abstracting, and transforming the data (p. 10)."

To assist in this data reduction process a case record was organized for each site. The case record included all the major information, transcripts and documents which were used during the individual and cross-case analyses. Coding procedures were used to categorize the data based on the conceptual nature of the research questions and according to the themes that 
emerged during analysis. These categories should be exhaustive, mutually exclusive, and as sensitive to the data as possible (Merriam, 1998).

Each of the fourteen interview transcripts were coded with categories based on the review of the literature and aligned with the research questions. A table (Appendix C) was created that included the three research questions and four major theoretical construct categories. The coding categories were also revised as new categories emerged during the analysis process. The categories, patterns, and themes used to understand and interpret the strategic planning process came, in part, from this inductive analysis. This analysis is considered inductive because they "emerge out of the data rather than being imposed prior to data collection and analysis" (Patton, 1990, p. 390). These categories, patterns, and themes were represented by both participants' indigenous labels and concepts as well as researcher constructed labels and concepts based on the review of the literature. The constant comparative method (Creswell, 1998) established these inductively emerging themes as salient in this data reduction process. The data reduction process was primarily a within-case analysis. A mental matrix began to form that would later be the basis for the cross case analysis and further data reduction.

The second step in the data analysis process was data display. Displaying data is the process of organizing and assembling information in order to identify findings. As recommended by Creswell (1998) the format used for this multi-site case study was to first consider each case and respective identified themes. This within-case analysis was followed by a thematic analysis across cases as well as interpretation of the meaning of the cases.

A constant comparative method (Creswell, 1998), taking information from data collection and comparing it to emerging categories, was used. Merriam (1998) described this as "the continuous comparison of incidents, respondent's remarks, and so on with each other. Units of 
data - bits of information - are literally sorted into groupings that have something in common" (p. 179). The constant comparative method was used to analyze and compare emerging categories and themes from the various interviewees. The emerging categories and themes identified during analysis of each site's document cache were also used in this comparison. The resultant findings were substantiated by triangulation with interviews, documents, and field notes. Triangulation, the combination of multiple methods to test for consistency and "to illuminate an inquiry question" (Patton, 2002, p. 248), is one of the reasons this study used the combined data collection methods of interviews and documents. The within-case, cross-case, constant comparative, and triangulation analysis methods were employed, in part, to ensure rigor.

The analysis process occurred jointly with my dissertation committee chairperson who served as a facilitator and audience. A series of face-to-face meetings were held. These meetings were initially verbal discussion about the data and preliminary findings in a narrative. As the analysis progressed visual displays were created to help conceptualize the research findings. During these meetings the analysis began to take a more cross-case focus as commonalities and patterns were identified as answers to the three research questions.

This cross-case analysis resulted in a view of the four districts as multiple exemplars. The answers to the research questions revealed continual commonalities between the four districts. Each of the districts exemplified a remarkably similar planning style and process and had multiple common facilitators and barriers. The data analysis became a process of deconstructing the phenomena, strategic planning, and then inspecting it carefully for essential elements and components. The elements were then rebuilt back into a whole to display the findings. At this stage the analysis became synthesis. 
The commonalities and patterns obtained during data analysis lead to a decision to present the findings as a cross-case report. Although speaking in more of a general sense, Miles and Huberman's (1994) description of their qualitative orientation provides the basis for a crosscase presentation of this research's findings:

We think that social phenomena exist not only in the mind but also in the objective world and that some lawful and reasonably stable relationships are to be found among them.

The lawfulness comes from the regularities and sequences that link together phenomena. From these patterns we can derive constructs that underlie individual and social life. (p.

4)

Data analysis continued during the writing and revising of drafts for the results and conclusions chapters. This was the third step of the data analysis process: drawing and verifying conclusions. Drawing conclusions is the process of determining what things mean. These conclusions were developed tentatively at first and then verified or dismissed as data analysis continued. Again my dissertation committee chairperson served as a peer reviewer and debriefer during the drafting and revising of the findings' and conclusions' narratives.

A member check was performed by providing four of the interviewees with a copy of the results and soliciting their feedback. Stake (1994) defined member checks as "presenting draft materials to actors for confirmation and further illumination" (p. 172).

Interpretation and presentation of findings. Yin (1984) described the written report that may result from a multi-site case study as a multiple case report. The report may consist of the cross-case analysis covering descriptive and explanatory topics. In this type of report each section may be devoted to a separate cross-case issue with the information from the individual cases dispersed throughout each section. 
The case study narrative begins with a description of the data followed by interpretive portrayals and commentary. The first role of the qualitative researcher in presenting the findings is description. This should be a thick description (Denzin \& Lincoln, 1998) of the data. This thick description allows the reader to understand the results and draw his or her own conclusions. Merriam (1994) recommended including both particular and general descriptions: "Particular description consists of quotes from people interviewed, quotes from field notes, and narrative vignettes of everyday life ... General description is needed to tell the reader whether the vignettes and quotes are typical of the data as a whole" (p. 200).

Portrayals were created to interpret and represent the themes that had been identified. A portrayal is the author's representation of the particularistic, descriptive, and heuristic results of the case study. Merriam (1994) defined a theme as "an overarching concept or theoretical formulation that has emerged from the data analysis" (p. 190). This can, for example, be done metaphorically to create a portrait or construal of the themes as they are represented by the data. In addition to narrative, data displays can communicate understandings and interpretations. Displays are designed to organize and assemble information in a comprehensible, compact form so that the audience "can see what is happening and either draw justified conclusions or move on to the next step of analysis the display suggests may be useful" (Merriam, 1994, p. 197) Several tentative displays were created during the analysis process. These were different styles of figures to consider which were most useful for illustrating the findings. Those that most meaningfully conveyed the findings were refined and included in the results and conclusions chapters. A return to the literature resulted in a conceptualization of the process that paralleled existing theory.

The narrative includes interpretive commentary to convey the lessons learned from this study of the strategic planning process. Interpretive commentary "points the reader to those 
details that are salient for the author, and to the meaning-interpretations of the author" (Merriam, 1994, p. 200).

Assurances of soundness. Garman and Piantanida (1999) emphasized that:

To a great extent, the credibility of a qualitative inquiry rests upon the researcher's ability to articulate a logic of justification in a clear and cogent manner. Of critical importance is the extent to which the procedures fit with the knowledge generating assumptions that underpin the inquiry. (p. 147)

This section presents criteria that may be used to judge the soundness of this proposed research. The following criteria are highlighted as they relate to the purpose and methods of this multi-site case study: integrity, verite', rigor, utility, vitality, and ethics. The descriptions of these criteria are taken primarily from Garman and Piantanida (1999).

The integrity of a study can be judged by its structural soundness. Are the research rationale and methods logical, appropriate, and consistent with the selected research tradition? This study's research questions, each examining the process of strategic plan development, were best answered by a qualitative approach. The research methods, interviews and the assembly of a cache of documents provided a view and allowed for analysis that was rich in description, depth, understanding, and interpretation. The within-case analyses of individual sites lead to a crosscase analysis that identified salient themes.

The second criterion for judging the soundness of this study is its verite'. Verite' relates to the intellectual honesty and authenticity of a study. "Does the work ring true?" (Garman \& Piantanida, 1999, p. 148). Has the researcher made the effort to obtain a "mindset conducive to an authentic inquiry" (Garman \& Piantanida, 1999, p. 147). Does the researcher account for his or her own actions and thoughts during the study? Is the core portrayal used to describe the topic 
and its context authentic? As the researcher, I have described my experience with strategic planning. The effects of this experience were recorded and examined with an audit trail that includes reflections, comments, and case notes. It was also this experience that gave me the desire to investigate the planning process. A vivid portrayal and in-depth interpretation of this process could advantage future researchers, policy makers, and practitioners.

In order for rigor to be demonstrated a study must show sufficient depth of intellect through sound portrayals (Garman \& Piantanida, 1999). This requires carefulness and accuracy throughout the study as well as a certain amount of elegance within the narrative so that it engages, enlightens, and challenges the reader. This study's literature review provided background and a conceptual framework for the study. The interviews of key informants and the cache of documents provided authentic descriptions. Saturation, coding, the constant comparative method of theme development, cross-case analysis, and triangulation each helped assure authenticity and intellectual rigor. The utility of a study is its significance and "the implications the researcher is able to draw from the portrayal of the phenomenon" (Garman \& Piantanida, 1999, p. 151). This research is relevant to West Virginia school districts because strategic planning is required, by policy, on a yearly basis. The literature review in chapter two showed that strategic planning is a common practice in school systems across the United States. This study contributes to current research literature because the development process is one of the least studied aspects of strategic planning.

The vitality of a study is determined by its vibrancy, intensity and excitement of discovery (Garman \& Piantanida, 1999). Does the portrayal possess verisimilitude? In order to obtain a degree of vitality this study used vivid quotations and descriptions, metaphors to assist in the expression of its portrayals, and displays to convey meaning. 
The final criterion of soundness that this section will discuss is ethics. Sites and interviewees remain anonymous in order to safeguard the interests of the participants. Because I know some of the interviewees, this privacy extends beyond the study's data collection, analysis, descriptions, portrayals, and displays.

Summary. This qualitative, multi-site case study described and developed understandings of the processes used to develop the West Virginia Five Year School System Strategic Plan. It was approached from an interpretive paradigm in order to investigate the complex issues and processes involved in the development of the West Virginia Five Year School System Strategic Plan. The study was guided by three research questions: How do county office personnel develop the West Virginia Five Year School System Strategic Plan? What styles of development do they use? and What are the facilitators and barriers to development? Four county school systems, as identified by nomination, that have a well developed process for developing the Five Year School System Strategic Plan were used in this multi-site case study. Two data collection methods were used. The first data collection method was semi-structured, topical interviews of key team members from the respective county school systems. Three to five team members were interviewed. The second data collection method was a cache of documents such as the respective district's plan. Within-case and cross-case analyses of the data lead to a presentation of the study's descriptions, portrayals, and interpretations. A meaningful portrayal and interpretation of the strategic planning process could advantage future researchers, policy makers, and practitioners. 


\section{Chapter Four}

\section{Cross-Case Report}

The purpose of this study was to describe and develop understandings about the West Virginia Five Year School System Strategic Plan development process. Its three research questions were: How do county office personnel develop the West Virginia Five-Year School System Strategic Plan? What styles of development do they use? and What are the facilitators and barriers to development? Four county school systems, nominated by a West Virginia Department of Education (WVDE) administrator responsible for strategic plan review, were used in this multi-site case study. A total of 14 district and school level administrators were interviewed for this research. These interviews, the first of two data collection methods, were conducted during the summer of 2009. Conducting interviews during the summer was problematic in terms of scheduling common time but provided access to superintendents and assistant superintendents who, admitted that, if it was during the school year, they might not have agreed to be participants. The second data collection method was a cache of relevant documents.

The findings are presented to address the research questions. Either an example or a quotation is given to illustrate each finding. Quotes from the interview transcripts and documents from the caches used in this chapter and the final chapter are identified by district and interviewee or document. Fictional names were given to each school system. For example, (A.1.1) represents Academy County Schools, interviewee number one, transcript page one. For documents, (A.D.1) represents Academy County Schools, document one. Documents included the core strategic plans, committee meeting PowerPoint handouts, other training handouts, and strategic plan summaries. Selected literature was used to define the concepts that were revealed though the data analysis. 
The findings obtained during the cross-case analysis revealed commonalities between the four districts' strategic plan development style and process. The identified facilitators and barriers to the process were also commonalities. Therefore, a cross-case report format was chosen to present this research's findings. I define a cross-case report as a report that combines the typical or essential characteristics of a multiple-case study.

Yin (2003) described four types of written products that could be generated from multiple-case studies. The last of these four is comparable to the cross-case report used to report my research results. In this style no separate chapters or sections are devoted to the individual cases.

The entire report may consist of the cross-case analysis, whether purely descriptive or also covering explanatory topics ... Each chapter or section would be devoted to a separate cross-case issue, and the information from the individual cases would be dispersed throughout each chapter or section. Summary information, if not ignored altogether, might be presented in abbreviated vignettes. (p. 149)

Abbreviated characterizations and descriptions of each of the four districts precede the cross-case report. The cross-case report begins with a description of the style and process these school districts used to develop the five-year strategic plan. Each component of the process is described in sequence. Facilitators to the plan development process are then described within two elements of the process: (a) teaming and (b) decision-making. These findings either facilitated teaming and decision-making or were results of these processes. Facilitators to teaming and decision-making are divided into two sets: those that occurred prior to planning, precursors, and those that occurred during the process. Facilitative precursors to the planning 
process are addressed primarily within a discussion of teaming. Facilitators present during the process are described within sections on teaming and decision-making.

Barriers to the process included document size, plan submission deadlines, technology, and plan format changes. Related findings are presented next. These findings are descriptions of the administrators' opinions of their planning process and strategic planning as an instrument for school system improvement.

District overviews. This section presents an abbreviated characterization and description of each of the four county school systems. These are presented, in part, to highlight the fact that, although these districts differed in some ways, a common strategic plan development process occurred. These overviews include selections of context, demographics, and outcomes. Metaphorical fictional names were given to each school system.

Academy County Schools. The administration and district office of Academy County Schools displayed a sense of precision, order, and purpose. The office staff was courteous and professional. The office complex and individual offices where the interviews were conducted were clean, neat, and appeared efficient. Their strategic plan document also reflected this order and clarity.

Academy School District has an enrollment of approximately 5,000 students who attend its 13 schools. Its population is $90 \%$ white and about half of the students come from low income homes. Academy's most recent statewide achievement test scores, spring 2009, were in the top ten of West Virginia's 55 districts for each of the four subject areas assessed: reading/language arts, mathematics, science, and social studies. All thirteen of Academy County's schools made Adequate Yearly Progress (AYP) for the 2008-2009 school year. The district did not make AYP 
because an insufficient percentage of students in two subgroups achieved scores in the proficient range: blacks and students with disabilities.

Fusion County Schools. About a decade ago Fusion County Schools consolidated its schools. This resulted in its current configuration of two elementary, one middle, and one high school. This consolidation occurred through a major planning effort that engaged its parents and communities. One of the results of its consolidation planning effort was a new high school, an impressive contemporary structure that also houses the district offices.

Fusion County, one of the smallest school systems in the state with 1,500 students, has a reputation for outstanding results. The county is a consistent leader in academic achievement and serves as a demonstration model for progressive initiatives of its own as well as state-wide efforts. Fusion County is predominantly white, the most rural of the four case study districts, and had the highest percentage, 54, of students coming from low income homes. Their summative achievement scores for the 2008-2009 school year ranked in the top ten in West Virginia. Their scores in mathematics were the second highest in the state. Despite their impressive achievement scores only three out of four schools achieved AYP. The students with disabilities subgroup was problematic for the individual school that did not make AYP and was also responsible for the district's failure to make AYP.

Gamble County Schools. Gamble County Schools appeared poised to take the risks necessary to move its school district forward. The posture and tone of these interviewees suggested uneasiness about the limited effectiveness of recent strategic planning and school improvement efforts. They described their attempts to be on the cutting edge of progressive school improvement. For example, during the interviews they proclaimed an emphasis on the three Rs: rigor, relevance, and relationships and, most recently, have promoted an organizational 
health initiative (G.2.6). Gamble's district administrators seemed willing to roll-the-dice. Not in the sense that they were just taking a chance, but, that they were willing to attempt aggressive, innovative approaches if that is what was required to move their system forward.

Gamble School District is one of West Virginia's largest school systems with 12,000 students. It has a mix of urban, one city of 60,000 residents, and rural environments. Approximately ten percent of their student body is minorities. Although generally above the state average, Gamble's achievement scores are not as high as the other three case study districts. Nineteen of Gamble's 26 schools made AYP for the 2008-2009 school year. The district did not make AYP because of three subgroups' scores: black, low SES, and students with disabilities.

Heritage County Schools. The final school district in this multi-site case study was Heritage. Its district offices are housed in a turn of the century, brick building. The main conference room and superintendent's office each have rich wood trim evident of the craftsmanship of a previous era. The mantels in both of these rooms supported simple and tasteful awards and recognitions.

Heritage County Schools' most recent achievement scores were some of the best in the state. The district was third in West Virginia for reading/language arts and fifth in both math and social studies. The county's 8,000 students attend Heritage's 19 schools. Eighteen of its 19 schools achieved AYP in 2008-2009. These top achievement scores were not sufficient for the district to make AYP because of the performance of the students with disabilities subgroup.

The strategic plan development process. The first finding presented is these school systems' use of a common overall development style and process. The similar strategic planning process that these school districts used was a result of both the phenomenon and context, the state's planning mandate. Though somewhat inseparable, it is important to consider each. Yin 
(2003) used these two components as the basis for his description of case study: "A case study is an empirical inquiry that investigates a contemporary phenomenon within its real-life context, especially when the boundaries between phenomenon and context are not clearly evident" ( $p$. $13)$.

The common plan development style and process occurred, in part, because the West Virginia Department of Education's strategic plan format is very prescriptive and these districts, by their own admission, were very compliant. Therefore, it is not unexpected to find common plan components and a typical process.

Background. West Virginia school districts and schools have been using the current fiveyear on-line strategic plan format since the 2005-2006 school year. The first year required the most significant effort from districts and schools because it was an entirely new plan. Subsequent years required review and revision but not necessarily an entire re-write.

Once the plan is developed, the finalized Five-Year School District Strategic Plan document is required to be submitted electronically to the West Virginia Department of Education, during September of each school year, for review. School level plans are due in October. During and following submission of the school district and school plans, action steps are implemented, outcomes are evaluated, adjustments are made as necessary, and, eventually, the entire cycle is repeated when school districts and schools revisit the strategic planning process in preparation for the next school year.

Workshops sponsored by the West Virginia State Department of Education have primarily focused on the format and content of the plan rather than the planning process (WVDE, 2009). Therefore, although the plan's format, and the state department of education's professional development, may account for some similarities, they do not account for all aspects 
of the common development process found in this study. The following are examples of why plan similarities resulted from the state department's format. When interviewees were asked this probe, "Did your committee include any components in the plan that were not part of the WVDE's original format?", these were the typical responses:

No, we followed the format. (A.3.3)

I don't think so. I'm sure we wouldn't. (F.4.2)

I don’t think so. It was fairly structured in terms of what you could do. (H.2.2)

A popular style of strategic planning in public schools is the Cambridge Model (Conley, 1992, Cook, 2001). The West Virginia Department of Education's strategic plan steps and sequence are very similar to the Cambridge Model (Cook, 2001). The differences between the two models were minor. For example, the Cambridge Model lists internal data analysis and external data analysis as separate steps while they are grouped together in the WVDE model. Another minor difference is the substitution of the term "committee" for "team" by the WVDE model. The following are the major sequenced components of the West Virginia Five-Year Strategic Plan:

1. Select planning committee members.

2. Establish core beliefs.

3. Prepare mission statement.

4. Conduct data analysis/Prioritize strategic issues.

5. Develop goals and objectives.

6. Develop action steps.

The following diagram (Figure 1) illustrates the planning steps identified by this research. The diagram was based primarily on a document within Gamble School District's cache (G.D.2). 
Figure 1. West Virginia School District Strategic Planning Steps

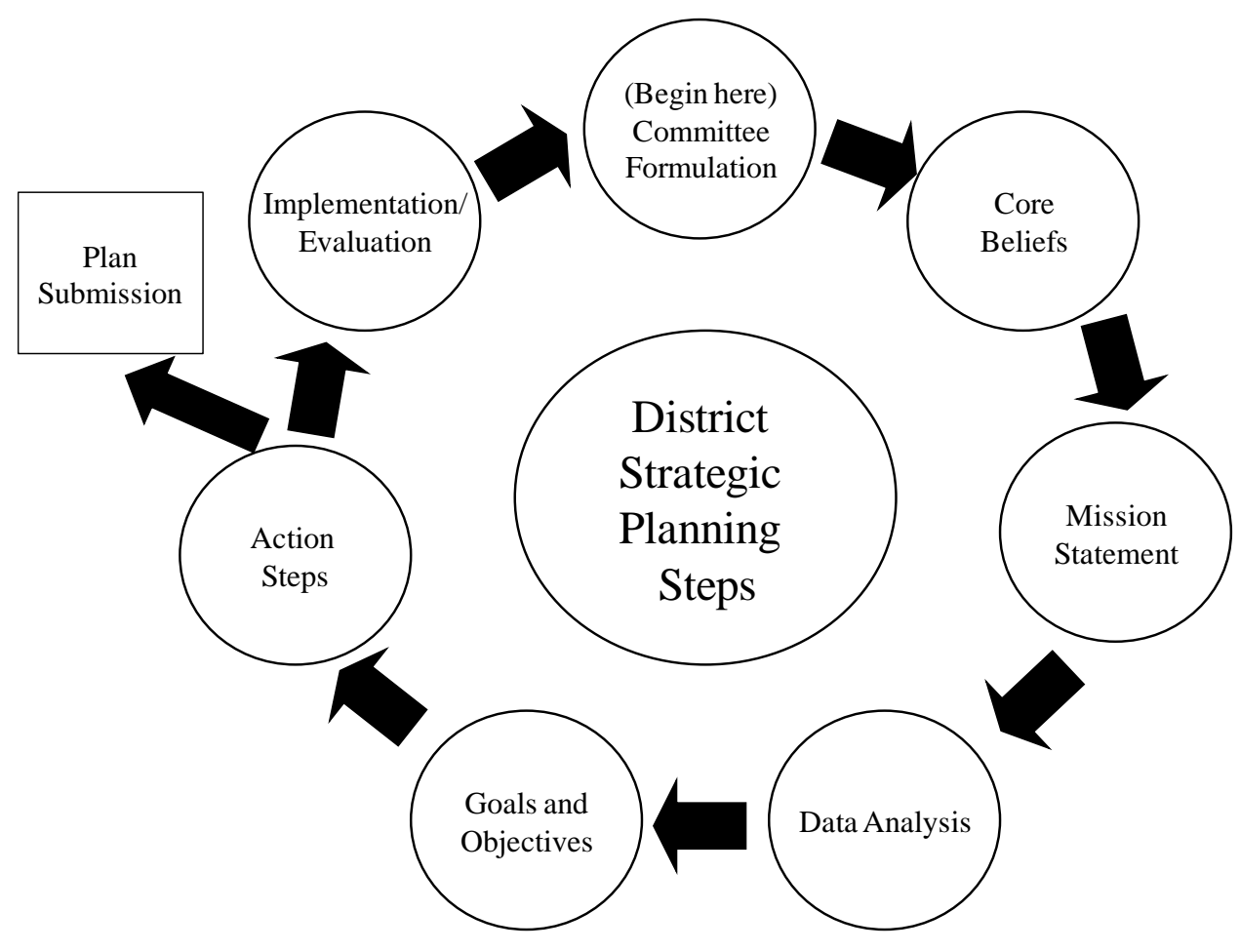

This figure illustrates the seven steps of strategic planning. These steps do not necessarily indicate distinct planning meetings. The steps are recursive rather than unidirectional. Discussion and decisions at one step may cause a return to prior steps.

Although the plan's components were mandated by the West Virginia Department of Education, district administrators had the discretion to create their own development process. Exercising this discretion, these four districts used a remarkably similar process. The next sections review each step and these districts' process.

Planning committee formulation. The process began with the assembly of a large planning committee, or team, composed of various stakeholders. Cook (2001) described the planning team as one of the most important factors in the process. This author also described 
team attributes: "The planning team must represent every component of the school community ... and the planning team must be manageable in size" (Cook, 2001, p. 85).

The West Virginia strategic planning format substituted the term "committee" for "team", therefore, this group is generally referred to as a committee throughout this document. This is an example of a minor terminology difference between Cook's Cambridge Model (2001) and the WVDE model.

The planning committee members were selected by a core group of central office administrators led by the superintendent or assistant superintendent. Each committee included representation from the central office administration, school principals, teachers, parents, and business and community leaders. The size of these committees varied from 30 to 70 members. The following quotation is typical of how the districts in this research assembled their committees:

Well, the first thing we do is try to pull a committee together and we try to balance that committee so that teachers from various levels within the system, elementary, middle, high school, are represented. Various types of teachers are represented, regular ed[ucation], special ed[ucation], Title I, also at the high school level, of course, the various disciplines. We like to have representation from the school administrative staff, as well, and then some central office people. Then we also invite parents and again we try to look at different walks of life from different areas of the county to make sure that we have a good representation. Parents of students with special needs, we like to make sure are on the committee. Also then community and business leaders we think are essential. So then we bring all those people together. (G.2.1) 
After selecting committee members, the core group of central office administrators determined the anticipated focus and purpose of the initial committee meetings, estimated the number of meetings necessary to develop the strategic plan, and set tentative meeting dates.

The strategic plan development process initially was lead by a facilitator. The facilitator organized the meeting and structured the meeting agenda. The facilitator for the first large committee meeting was the superintendent or assistant superintendent.

During the initial committee meeting the facilitator began the process with a strategic planning overview, established the tone for the meetings, and conveyed the committee's expectations and responsibilities. A federal programs director described how her district attempted to set the tone:

One of the main things that we used to do was to set the tone for the meetings. You bring people in and you tell them your expectations as a group. One of those is that everybody that you called together is a person of goodwill. You're not here to represent your hidden agenda. But that everybody who's brought together in this group is a person of goodwill who is looking for the ultimate good to come out of the system. That's the sort of thing, I think, that sets the tone for everything we did. We'd never have a session that we didn't start with that. (G.1.2)

The planning committee also addressed specific topics that were considered important to the development process. For example, one district used a PowerPoint presentation during an initial meeting to train the committee in consensual decision-making (G.1.2).

In order to develop the strategic plan document, the committee had the responsibility to identify core beliefs, formulate a mission statement, perform data analysis and prioritize issues, 
and develop broad goals, specific objectives, and detailed action steps. These components are described in the next sections.

Core beliefs and mission statement. Two of the initial committee duties were the identification of core beliefs and the development of a mission statement. If core beliefs and a mission statement existed they were reviewed and revised. A superintendent described this process of review and revision:

What I would do was give them the old one [mission statement] and I would give them one or two that I believed might be better, got their input on it, and ended up writing one that was completely different, but it had parts from each one. Then I had them rank order our beliefs. As a matter of fact I went to training with Larry Lezotte and he really made me aware of the importance of the flow, core beliefs flowing from the mission statement. (H.2.2)

A considerable amount of time was spent by the committee writing a mission statement and identifying core beliefs. The result for one district was a very direct mission statement: “Academy County Schools will provide educational opportunities that ensure each student a foundation for success" (A.D.1). In another district the mission statement was first an unwieldy compilation of verbiage that they later revised.

We used to say Gamble County Schools will produce men and women who passionately embrace the unlimited power of education by fully developing the unique gifts, talents, and potential of the individual students assuring that each will adapt, excel, and continuously lead as a citizen of the world. Now that's a beautiful statement and I can remember vividly the many hours, the many, many, many hours, it took to get to that. But 
I can't find one person in Gamble County who could ever repeat it. You couldn't do it.

There's too much in it. Instead, we want[ed] something memorable. (G.1.2)

Data analysis. The next step was data analysis. The data analysis performed by the committee was extensive. This analysis took the committee one or more meetings to complete. For example, the data analysis section of one final core plan was 12 pages long and included both narrative and tables (A.D.1). The content of this data analysis was identified by headings within the WVDE strategic plan document (A.D.1). The data analysis activity included a review of external trend data such as census statistics on population trends, high school/college completion rates, median household income, and unemployment rates. Student achievement data used in the analysis included such examples as the West Virginia Educational Standards Test, Adequate Yearly Progress (AYP) results, ACT Plan and Explore, ACT and SAT, and advance placement testing scores. The data analysis typically included a review of other district statistics such as graduation rates, attendance rates, and discipline totals. An analysis of culture, conditions, and practices was performed based on survey results as well as anecdotal evidence.

Strategic issues were then identified and prioritized. These were based on the data analysis results and an evaluation of the effectiveness of the prior year plan's action steps. The evaluation considered monitoring reports such as those from West Virginia's Office of Educational Performance Audits. The strategic issues were also identified through federal programs' self-assessments, state on-site monitorings, or policy requirements, such as those for Title I and special education programs. For example, a prioritized strategic issue for one school district was to organize a team of teachers to research effective middle/high school Response to Intervention (RtI) programs and to develop and plan for implementation of this process during the 2010-2011 school year (F.D.1). 
Goals and objectives. Once the core beliefs, mission statement, data analysis/ prioritization of strategic issues planning steps occurred, it was time to develop broad goals and objectives. It was the intent of the WVDE that these goals and objectives "targeted resources strategically to the teaching and learning process to improve student, school, and school system performance" (WVDE, 2007, section 18.1).

Each of the four districts' goals and objectives were impacted by federal policy, such as NCLB and its accountability requirements, and state policy. These districts complied with policy as represented within the strategic plan. For example, because NCLB bases accountability primarily on literacy and numeracy achievement scores, each of these districts included a goal or objective related to reading/language arts and mathematics (A.D.1; F.D.1; G.D.1; H.D.1).

Potential goals and objectives, and to some extent action steps, were typically created during brainstorming sessions (F.2.2; H.1.1; H.3.1). An open discussion followed the brainstorming sessions. The resultant goals and objectives were decided upon through consensus (A.1.1; F.2.1; F.3.3; H.2.2; H.3.2; G.1.4; G.2.2; G.3.1). The goals tended to be limited in number, three to eight, and focused on academic achievement. A superintendent described how his committee developed its broad goals:

Those were really initially done with the board at that initial meeting. The [committee] worked collaboratively to develop those. It wasn't just a single individual sitting down and developing those. It started from those four core beliefs about teaching and children. The five goals were an outcome of that day. We've since added a sixth goal that was required for the technology plan. Then we added another goal that was required for Title I and another goal which is specific to special ed. So we had those five goals that we 
started with and we've had to add three for specific requirements that have come down to us from the state. But it was overall input for those five. (H.2.2)

Although goals were developed and decided upon by the committee, the West Virginia Department of Education also influenced the strategic plan. One superintendent explicitly acknowledged the influence of the state on the committee's goal development process. This superintendent related that he likes to see where the state is going with its initiatives and then try to translate it into a county level initiative: "Anything we see coming down the pike we try to look at how we can put that into a goal in the five year plan" (F.3.2). A school principal from the same district suggested an even stronger influence by the state when asked how her committee arrived at broader goals and objectives:

Most of those are really just direction from the state and what they wanted to see in a plan. It also was looking at our needs, a needs assessment, and the direction the board wanted us to go. We try to make sure that those goals and our belief statements are things we can work on, things that we truly believe in and use daily. (F.4.2)

This principal was referring, in part, to the literacy and mathematics goals encouraged as a result of the No Child Left Behind (NCLB) legislation's focus on these subject areas for its AYP determinations.

The committee's broad goals consistently focused on instruction and academic achievement. For example, one district's first goal was to provide all students with a studentcentered learning environment focused on progressive instruction and assessment practices. Another district's first two goals focused on academic achievement (A.D.1). Its plan stated that all students would be proficient at grade level in mathematics and that all students would be proficient at grade level in reading/language arts. 
Subsequently, a few measureable objectives were developed for each goal. For the preceding mathematics goal there were three objectives:

1. There will be an annual increase in the percentage of students in the economically disadvantaged subgroup scoring at or above mastery in mathematics.

2. There will be an annual increase in the percentage of students in the disabilities subgroup scoring at or above mastery in mathematics.

3. There will be an annual increase in the percentage of all students scoring at or above mastery in mathematics. (A.D.1)

Action steps. Cook (2001) defined action steps as "a detailed description of the specific actions required to achieve specific results necessary for the implementation of the plan" (p. 73). The committee's action steps described specific activities to be performed to accomplish their goals and objectives. The following are examples from Academy School District of action steps intended to help achieve the goal of all students being proficient at grade level in reading/language arts:

1. Form a K-12 literacy model team. The team members will be the elementary reading interventionist, the middle school reading interventionist, and the high school reading interventionist.

2. The K-12 literacy model leadership team will assess and plan literacy professional development focus.

3. The K-12 literacy model leadership team will serve as models and mentors to all reading/language arts teachers.

4. Data-driven decision-making will guide literacy improvement planning. (A.D.1) 
Smaller groups were typically used to develop some specific objectives and the action steps. For example, action steps were developed by small committees, by departments, and at times, by individuals (A.1.1; F.2.2; F.4.1; H.1.1; G.2.2; G.2.2). A division of the full committee into subcommittees also occurred occasionally at the data analysis level (G.1.1).

To develop more specific objectives and the actions steps, leadership and responsibility were distributed among committee members. For example, leaders may be assigned to each of the smaller groups or subcommittees and given the responsibility of developing subject specific objectives and action steps. After these smaller groups, departments, or individuals developed the tentative objectives and action steps, they were brought back to the full committee for review and selection.

The strategic plan's final priorities, goals, objectives, and actions steps were decided upon through consensus. The exception to this was highly specialized areas such as Title I and special education. In these instances the full planning committee tended to accept a departmental recommendation, particularly when it came to compliance matters. The finalized plan was then: (a) submitted, in September of each school year, to the West Virginia Department of Education for review, (b) communicated to various stakeholders at the beginning of each school year, and (c) implemented according to its actions steps throughout each school year.

Implementation and evaluation. The final steps in strategic planning are implementation and evaluation. Although this research's focus was on the plan development process rather than implementation and evaluation, their importance to the effectiveness of strategic planning is noteworthy. Pressman and Wildavsky (1984) define implementation as the ability to "forge links in the chain of causation between initial conditions and future consequences ... so as to obtain the desired results" (p. 13). 
A principal described how implementation was monitored and celebrated:

[Implementation's] become a big deal ... One of the things [the superintendent] does in meetings is share where each building is in their strategic plan ... It's funny because when we have faculty senate and the president reports out that [the elementary] school is at $76 \%$ completion of their action steps, it's a big deal. They cheer, they clap, and they're excited. Let's get to $92 \%$ next month. (F.4.7)

Evaluation is important because, "by observing the difference between intended and actual consequences" (Pressman \& Wildavsky, 1984, p. 15) it can be determined whether the implemented action steps effectively met the plan's stated goals and objectives. An assistant superintendent described her recognition of this importance:

The whole intention from my point of view of the planning process is to make sure that the district moves forward and the district moves toward reaching its goals. How do we assess that? We look at the data to determine the targets that we set. Did we reach them? Did we at least make progress toward them? That's how we assess the effectiveness of the plan. (G.2.6)

Implementation and evaluation also contribute to the recursive nature of the strategic planning process. As a result of the effectiveness or ineffectiveness of the implementation of the various action steps, it may be necessary to revisit the plan and planning process. Adjustments were made to the plan based on the outcomes of the actions steps and changing environmental factors such as new policy mandates. A special education director described this recursiveness: "The plan is always changing. You always have to go in and do a little updating. You can't just write the plan and let it sit. It has to have updates and changes to it all the time" (F.1.4). Another 
administrator reiterated the fluidity of the plan: "We constantly look at our plan and work with our plan. It is a live document kind of thing" (H.1.3).

The data obtained to evaluate the effectiveness of each planning year's action steps become part of the subsequent school year's strategic planning process. This completes the cycle. A superintendent described this succession:

I think you always have to review the work that you did in the previous year to see what action steps were actually completed and which ones seem to be ongoing ... So we do that each year. We sit down, look at what we've done, and what we see as the focus for the coming year, and we develop our plan accordingly. (H.2.2)

Facilitators to strategic planning. This section introduces facilitators of the strategic plan development process. Two primary elements of these districts' process facilitated plan development: teaming and decision-making. There were also several secondary facilitators to the planning process and, in particular, to the teaming and decision-making that occurred. These facilitators are categorized into three types: precursors, within process facilitators, and process results facilitators.

Four precursors supported the teaming process. These were the components of the plan, professional development, team members' prior planning experience, and team members' experience as public educators or administrators. The precursors are listed in no particular order of importance because their relevance varied between districts.

The teaming and decision-making that occurred during the four districts' approach to the strategic planning process produced several research findings related to facilitation. These findings are: 
1. Facilitator role.

2. Distributed leadership.

3. Collaborative group processes.

4. A decision-making sequence.

5. Consensual decision-making.

6. Promotion of a common purpose.

7. Positive attitudes.

The first five on this list facilitated the districts' teaming and decision-making. The remaining two findings, common purpose and positive attitudes, were results of the process.

The teaming precursors that facilitated the planning process are presented first in the following sections. Teaming research findings are then discussed followed by decision-making. Process result findings are reviewed prior to the introduction of a diagram depicting the facilitation of strategic planning and its teaming and decision-making.

Teaming and its precursors. A key finding from this research was that, given the discretion to create their own development process, these districts described similar teams and teaming practices. Bryson (1995) described a team as:

The basic vehicle for furthering strategic planning ... There are two reasons why teams are so important. The first is that no one person can have all the relevant quantitative and qualitative information, so forming a team is one way to increase the information available for strategic planning. The second reason is political. To be viable, strategic planning and strategies need support at many points throughout the organization and from external stakeholders. A strategic plan and intended strategies need the support of a critical coalition when they are adopted and during implementation. (p. 219) 
This research found four precursors that facilitated the teaming process: (a) the components of the plan, (b) professional development, (c) team members' prior planning experience, and (d) team members' experience as public educators or administrators. Each of these four precursors will be described in the following sections.

Components of the plan. Two points are noteworthy regarding the components of the plan: (a) The components were considered to be facilitators of the process and (b) the West Virginia Department of Education's strategic plan components are very similar to the popular Cambridge Model (Cook, 2001). One administrator was specifically supportive of and equated her district's model with the Cambridge Model: "We implement the Cambridge Model. It's really the most adaptable to education from all I've looked at. I've got others back here, but, that's the one I found most adaptable to education" (G.1.4).

The district administrators interviewed for this research were supportive and complimentary of the current plan's components and sequence: "It was structured fairly well in terms of what you should do" (H.2.5) and "I don't think we would do anything outside of the format, that's enough in itself' (F.1.3). The assistant superintendent in one district noted that her district was one of the four or five county school systems the state used to pilot the new plan. As a result of this involvement, they had the opportunity to help revise it and were supportive of the plan (G.2.2).

Professional development. A commonly cited facilitator was professional development (A.1.1; A.2.2; A.2.3; F.1.1; F.2.2; F.4.4; F.5.3). Each of the four districts sent teams to the West Virginia Department of Education's strategic plan development training. This training typically consisted of an overview of the purpose of strategic planning and the required components. During the training, examples of core beliefs, mission statements, goals, objectives and action 
steps were provided. Because the plan required online submission, a significant portion of the training was devoted to the technical aspects of this process. This training emphasized technology more than the development process (WVDE, 2009).

Two of the case-study districts also brought in state department of education or regional education service agency representatives for additional plan training. A third district had a team member, a federal programs director, with more formal strategic plan professional development on the Cambridge Model. Her training occurred over three separate sessions through attendance at presentations by Dr. William Cook's organization. In addition to training on strategic planning's steps and sequence, the federal programs director credited her professional development with emphasizing the importance of setting a proper tone and using consensual decision-making.

Prior planning experience. Prior experience with strategic planning, or planning in general, was described as a facilitator (A.3.3). Although many of the interviewees had only a few years experience in their current positions, most were experienced administrators and, at some point in their careers, had participated in some type of organizational planning (F.2.2). This facilitated the process because these individuals were supportive of planning in general and their familiarity was used to the team's advantage by distributing leadership. Experienced planners could, for example, be relied upon to facilitate topical components of team meetings, such as how to achieve consensus (G.1.1). They could also be used to lead subcommittees. For example, the district's testing coordinator may lead the data analysis (G.1.2).

Public educator/administrator experience. Eleven of the 14 interviewees had over 25 years of experience in public schools. This experience translated into knowledge of federal, state and local policy requirements including strategic planning (F.5.1). These individuals were also 
very familiar with their local school boards, school systems, staffs, and communities (H.2.1). This knowledge assisted the teams, for example, in their determination of, and prioritization of, goals and objectives (F.5.1). Prior interpersonal relationships with staffs, parents, and community members also facilitated teaming by enhancing collegiality and collaboration (A.3.5).

Facilitators of teaming. The teaming that occurred during the four districts' strategic planning processes produced additional research findings. Three findings, discussed in the next sections, were: (a) the facilitator role (b) distributed leadership, and (c) collaboration.

The facilitator role. The superintendent or assistant superintendent served as the facilitator to organize and assist the strategic planning process (A.3.1; F.3.1; G.2.1; H.2.1). Describing the importance of this facilitator role Bryson (1995) stated:

Facilitators are often helpful in moving a strategic planning process along because of their group-process skills and the attention they can give to structuring and managing group interactions ... A skilled facilitator can also help build up the level of trust in a group (p. 217).

An assistant superintendent described how she facilitated the teaming process:

My viewpoint is to spearhead the strategic planning committee ... I think very shared leadership is how I would describe it. [There was] a lot of facilitating going on with leading that group ... You can't come in and be directive because people will feel as if they were pushed through a process that really didn't matter . . . I look at my role in these types of things as a facilitator to bring out the opinions of people and to facilitate their thinking process so that they can come up with conclusions. (G.2.2)

This facilitation also came, at times, from other administrators: 
We had a main facilitator during the meetings, who happened to be [the federal programs director], through a lot of it. She led the process and the committee through the steps that we needed to go through to get to the finish line. (G.2.2)

The facilitator's involvement was greatest at the beginning of the planning process. In addition to this initial organization and coordination, the facilitator was responsible for maintaining the team's progress and ensuring that the team accomplished its duties. A curriculum director described the role her assistant superintendent took:

The past four years it has been [the assistant superintendent]. He's the one who pulls us together. He's the one who leads us. Last year or the year before we wanted to make sure everything [was] up-to-date with the $21^{\text {st }}$ century . . He's the one who kind of funnels that in. (H.3.1)

Distributed leadership. Although the initial team meetings demonstrated a more topdown, facilitator role from the superintendent or assistant superintendent, leadership during the process quickly became more distributed. Distributed leadership means shared leadership, participatory leadership and democratic leadership (Spillane, 2004). The term is appropriate for this research because distributed leadership attempts to describe the interactions of people rather than the actions of leaders. "A distributed perspective on leadership argues that school leadership practice is distributed in the interactions of school leaders, followers, and their situation" (Spillane, 2004, p. 2).

Although the administrators interviewed during this research did not use the term distributed leadership, they described its practice (A.1.2; F.1.1; G.2.1). For example, although the superintendent or assistant superintendent was the initial leader and facilitator, leadership was subsequently distributed to many others (F.1.1; G.1.3; G.2.1). This distribution of leadership 
took the form of: (a) topical leaders for the large group, (b) sub-committee leadership, and (c) departmental leadership. The following excerpt describes an example of topical leadership: Let's say it was a meeting that was going to focus on data. At that point, [the assessment coordinator] might come in and take leadership for that period of time with the group, sharing the data and giving some information. If it was a process piece, like teaching consensus, I was probably brought up at that point to demonstrate how we do what we're going to do. We're now going to try to reach consensus on the beliefs, and then I would lead that piece. We shared pieces of the leadership, but [the assistant superintendent] was in charge to see that it all got done. (G.1.3)

Team leadership occurred as the teams developed action steps in subject areas, programmatic levels, or specific topics such as technology. For example, in one instance a district's testing coordinator was assigned to a team responsible for developing action steps for universal screening and benchmark testing (G.1.2). Departmental leadership typically occurred for federally funded areas, such as Title I and special education (H.1.3), or for technology.

The way these teams distributed leadership was advantageous to the process and facilitated positive results. Gleaned from the responses (F.1.1; G.1.3; G.2.1) and demeanor of the administrators, it was advantageous to the process because it:

1. Capitalized on the expertise, experience, and strengths of various team members (G.1.3) and

2. Facilitated communication during and after the development process (H.1.3). The way these teams distributed leadership was credited with positive results because it:

1. Elevated feelings of satisfaction, pride, and purpose (F.1.1).

2. Resulted in a more engaging, interactive, and cohesive development process (F.5.4). 
3. Enhanced ownership that supported and sustained implementation and evaluation (H.1.3).

As mentioned previously, these teams included experienced public educators and administrators. Distributing leadership to these individuals facilitated the accomplishment of team and departmental duties (H.1.1). The following example illustrates the team's interaction and cooperation:

The individual department heads were given a lot of input. We were able to voice our opinions. We are all respected and our opinions [were] not just dismissed. We worked well together and we respected each other's opinions (A.1.2)

The facilitation that occurred as a result of the distribution of leadership also carried over from the plan development process to implementation and evaluation (A.3.2). Distributed leadership was credited with contributing to positive outcomes at these stages (A.3.2).

An administrator in another district described how her superintendent honored their distribution of leadership and consensual decisions:

[The superintendent] doesn't go in and mess with anybody's information unless that's something we've talked about. To be honest I don't think I have ever gone in and seen where he had changed anything ... I don't ever feel like he makes decisions and just tells us what to do. (F.1.2)

Collaboration. The districts described a collaborative teaming process that was based on context and the maturity of the strategic plan development process (H.1.1). Miller and Buttram (1991) described collaboration as "a system of values where there is a belief in participation, cooperation, and interdependence" (p.281). Collaboration recognizes individual interests and 
needs and requires trust and a willingness to share authority. Research shows that a team's ability to collaborate is increasingly important for practitioners (Brizee, 2008).

Collaboration was evident in these districts and existed for differing lengths of time. Similarities between these districts' were quickly evident when entering their administrative offices. Observation of staffs before, between, and after interviews revealed a sense of collegiality, comfort, and mutual professional respect. This sense of collegiality and mutual respect was also evident during the interviews.

For two of the districts, collaboration was described to have existed within their organization for years. Collaboration was considered to be a natural part of the way these districts did things. A special education director described this phenomenon:

The teams worked together, not just during the five year strategic plan. I mean there was a collaborative relationship prior to just the plan so that was helpful and that has gotten stronger over the last four years. It wasn't because of the plan. It was because of what it was. (H.1.1)

Collaborative skills also developed as members worked together on teams that preceded and followed the strategic planning requirement. For example, these administrators described a significant overlap in team membership between the district's leadership team and the strategic planning team (H.1.2; H.3.3).

A team's ability to collaborate also appeared to influence its comfort level with the process. For example, as a district matured in this process they were more likely to develop objectives and action steps departmentally or individually prior to presentation to the team (H.1.1; H.3.2; G.2.2). This was done because prior collaborative relationships had established a level of trust and respect among team members. 
Decision-making findings. There were two findings in this research relevant to the decision-making that occurred during these districts' strategic planning process. First, there was a five step decision-making sequence which included: (a) brainstorming, (b) discussion, (c) selection, (d) verification of alignment, and (e) prioritization. Second, the districts each practiced consensual decision-making during several steps in the process. Figure 2 is a diagram representing the five steps that occurred during the decision-making process.

Figure 2. The Five Step, Consensual Decision-Making Sequence within Strategic Planning.

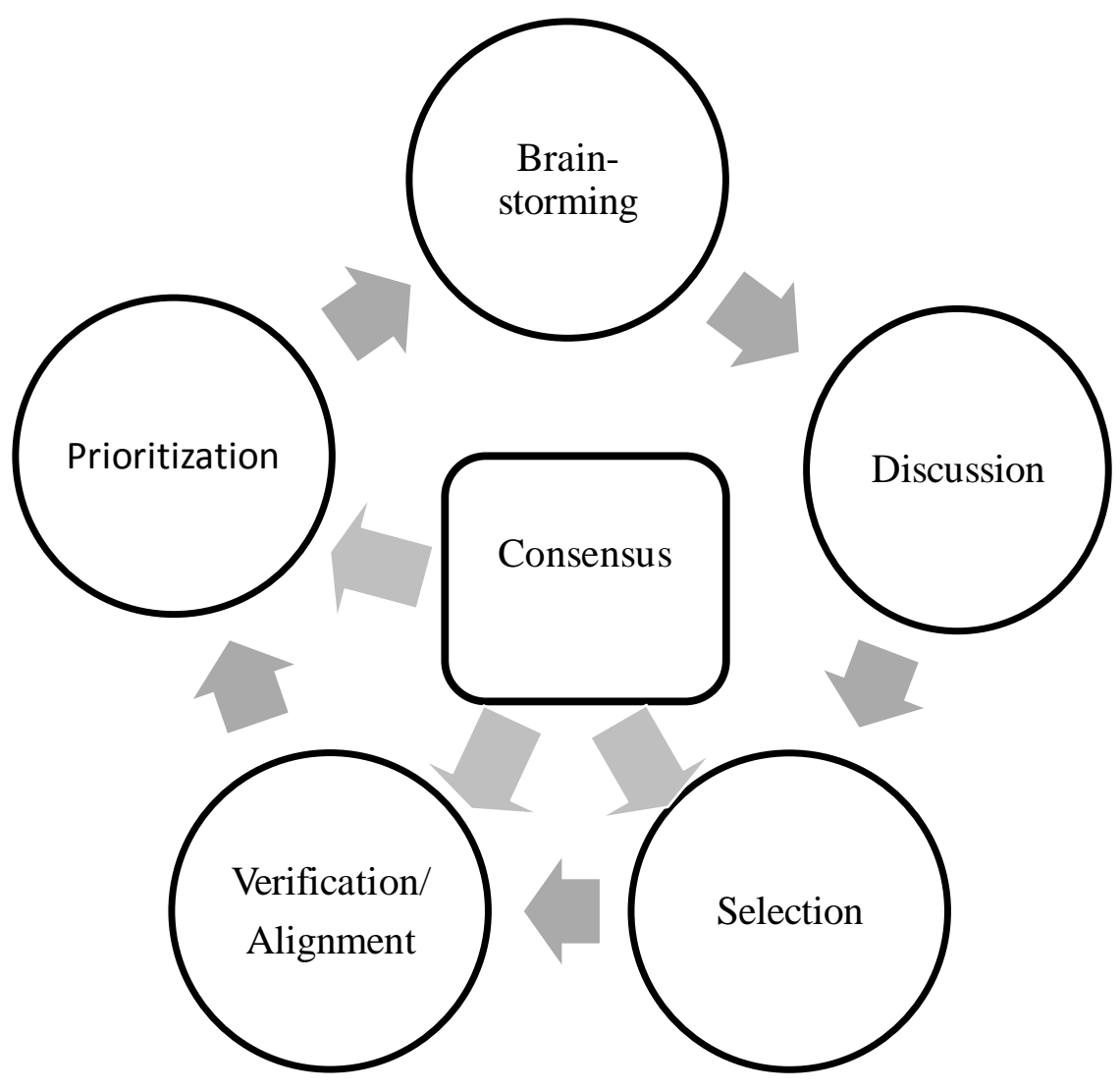

Decision-making sequence. The first step in this sequence is brainstorming. Following a determination of the district's core beliefs and mission, and during or following the data analysis process, a common approach to identifying goals, objectives, and action steps was brainstorming. 
A curriculum coordinator said: "We brainstorm as a group. Everybody has input. So the first couple of times we meet, it's great brainstorming as a group" (H.3.1).

Once potential goals and objectives are identified, it becomes necessary for the team to select which ones would be part of the plan. The second step in the decision-making sequence is discussion. In this instance, the potential goals and objectives are discussed prior to the third step, selection by consensus. The brainstorming process is then repeated by the full planning committee or subcommittees to identify action steps. The final action steps are discussed by the full committee and again selected by consensus. An assistant superintendent explained this process:

What we are typically able to do with a huge group is we get our beliefs down, get our mission down, and get our broad goals down. Then I send those back to basically an internal team to look at the proposed action steps. When we get those proposed action steps we come back to the large committee with a proposal ... So we kind of put it out there for consensus. (G.2.2)

During the fourth step of the process the selected goals, objectives, and action steps are reviewed to verify: (a) the goals' alignment with the core beliefs, mission, and prioritized strategic issues, (b) the objectives' alignment with, and delineation of, goals, and (c) the anticipated ability of the action steps to accomplish the goals and objectives. As a final step the action steps are prioritized based on the consideration and allocation of available resources, particularly funding.

Consensual decision-making. Interviewees repeatedly proclaimed that their decisions were arrived at by consensus (A.1.1; F.2.1; F.3.3; H.2.2; H.3.2; G.1.4; G.2.2; G.3.1). Interviewees from three of the four districts specifically mentioned the word "consensus" when 
they described their decision-making process. An assistant superintendent explained her team's reliance on consensus:

The ultimate thing was there was no voting involved. It was always consensus. There was no, well, we'll let the superintendent decide because we can't figure it out. No, we had to battle it out until we figured it out. (G.2.3)

Calderman (1999) suggested that an operational definition for consensual decisionmaking was "that every person has an opportunity to have a voice in the process and that there is agreement that decisions are reached by and supported by all” (p. 398). Consensual decisionmaking may have been used by these teams because, as Huff and Reger (1987) found, groups using a consensus approach were more satisfied than groups using other approaches.

Gamble School District took a very deliberate approach to make consensual decisionmaking part of its planning process:

We trained people in consensus and in working as a team before we did anything. I really think that's the most effective part of the process. From the beginning we had some people that, with any large group, you're going to look at them and you're going to think there's somebody that could be difficult. You don't want to just bring 'yes' people to a group like this. We had some really outspoken personalities representing a lot of things that could have easily become hidden agendas. It could have been very obvious who some of these people were representing or what idea. But when you lay it on the table in the very beginning, people respect that amazingly and, in no time at all, we had them understanding. I wouldn't have believed this if I hadn't seen it, how consensus works. (G.1.2) 
Process results. Of the seven findings that emerged inductively from the analysis of teaming and decision-making, two were associated with results: (a) common purpose and (b) positive attitudes.

Common purpose. Teaming and consensual decision-making resulted in the development of common purposes for these districts. Kaufman and Herman (1991) described why this is important:

Common visions, purposes, and missions will provide a common set of results - a 'North Star' - toward which all educational stakeholders may steer. When there are shared purposes and payoffs, a common good is created leading to a win-win situation and a cooperative environment. (p. 10)

A common purpose was achieved when everybody on the committee was given the opportunity for input. A superintendent expressed committee members' need for input:

People need to feel like they have had some input into [the plan]. During the construction of the plan itself, I believe you need as many constituents as you can get: community members, teachers, service personnel, and administrators. All of that gives people a feeling that input was taken from all the different areas. (F.3.4)

This opportunity for input also enhanced the effectiveness of the strategic plan. A veteran curriculum director linked input to effective change efforts: "The only way I think you can really make true change is to listen to everyone that can give information to you and make suggestions. Then take those [suggestions] and do the best you can with them" (F.5.2).

A second characteristic of teaming that helped achieve a common purpose was collaboration. An assistant superintendent related how collaborative teaming lead toward a common purpose and helped them focus: 
I think at the school level in working collaboratively with them they've realized that as a school system that we're all working towards the same goal. It's not that one school has one set of goals and another school has another set of goals. We're all focused and going in the same direction and we help each other. (A.3.6)

Another assistant superintendent spoke about how collaboration and input promoted a sense of common purpose:

I think another good thing about planning collaboratively as a group is, it allows the opportunity for educators at all grade levels, all different schools, to come together so that no one is truly working in isolation. And as our stakeholders, whether it's a school or someone out from the community, they're able to speak to the fact that, yes, I had some input on the five year plan, this is what we're doing, and it makes it more like we are doing this and we are not being told to do this. (A.2.6)

This common purpose may be reflected in the district as a whole or within specific organizational activities, such as professional development. A director of Title services shared how strategic planning helped to focus professional development (G.1.2). Previously the district had a habit of trying to do every good thing that came along. The strategic planning process was credited with giving the district's professional development more focus. This district now only selects professional development that supports its goals. As a result of the strategic planning process the district strategically determined goals that were measurable and based on data. After the goals were established the committee looked for research about instructional practices that might help the district achieve its goals. When practices were identified, the appropriate type and amount of professional development was selected. 
For one district the end result of its planning process was an increased ability to work together toward a common goal. A principal described the effect of her committee's planning process on her district:

I tell our superintendent all the time those of us who have been here for years and years and years, it is the first that we all feel like we're working together for a common goal. Nobody's worried about their own little domain anymore. It's what can we all do to make our whole school system, as a whole, the best it can be, not just worrying that your school be the best it can be. (F.4.6)

The curriculum director in this district agreed: "For the first time in a long time we have a whole administrative team that is on the same page as far as where we're headed and what our mission is down the road" (F.5.1).

A sustained common purpose can have long term benefits such as embedding new practices into the organization. For example, a superintendent described how his district had incorporated $21^{\text {st }}$ century learning into its practices (H.1.1). The following is his description of this phenomenon:

One of the things we did last year was to look at the items in the strategic plan to determine which ones are embedded in the culture at this point and really don't need to be identified in the strategic plan. They're just part of what we do every day as opposed to those that really need to have a focus to make sure that they're being properly implemented. So we do that each year. We sit down, look at what we've done, and what we see as the focus for the coming year, and develop our plan accordingly. (H.2.2) Positive attitude. Both context and the planning process can influence the positive sentiment of committee members. The majority of the administrators interviewed appeared to 
savor the opportunity to describe their process, recount the steps they took, and proclaim the outcomes of their planning efforts. An assistant superintendent expressed her respect of, and appreciation for, her committee members and reflected the commitment of district educators when asked about her opinion of the process and its impact:

It's outstanding. I think that everything is aligned in our county and we're very fortunate to have great teachers and great administrators who have the ability to really focus on student achievement and take the attitude, whatever it takes to make our students successful. (A.2.5)

The context that these districts were operating within may also be responsible for the positive attitudes of the individuals involved in strategic planning. Each district had been involved in planning processes prior to the state department of education's requirement for a five-year strategic plan. A treasurer reported that his district had always been goal-oriented and involved in planning (F.2.2):

Before the five-year plan it was the unified school improvement plan. Most of the administrators in the system have had 20 some years of experience in school administration so they went through that unified school improvement plan, served on teams that went to other counties to audit the unified plans. I know myself I went to a county to audit the unified plan probably 10 years ago. (F.2.2)

The most veteran of all the four districts' administrators, a director of curriculum and instruction with 29 years in her current position and 41 years of experience in public education, related her district's current process to one the district initiated 19 years ago:

When we built our new high school we did a major strategic plan in trying to develop and get an idea from the community because it was consolidating two areas together, to say, 
what do you want the diploma from this school to look like, what is it going to represent, what are the kids going to be able to do ... That plan affects everything we have done since then, since 1990. (F.6.1)

The superintendent from one district assured that his district would have a strategic planning process even if it wasn't a state department of education requirement:

I think we would, even if we didn't have this compliance document, would have some sort of strategic planning document, probably with not all of the hoops you have to jump through with this particular one in terms of the little check boxes ... We would have had some sort of planning and a document regardless of whether or not we had to have the strategic plan as it is now. (H.2.4)

The positive attitude resulting from these districts' current and previous planning efforts appeared to increase their commitment to the process. Carlson and Awkerman (1991) emphasized the importance of commitment to effective planning:

In organizations where successful planning occurs, there is a commitment to the planning process. It is essential that people in key positions understand and be committed to the planning process. That commitment must be communicated to and understood by every member of the organization. (p. 274)

Commitment to the development process and the plan is also important because it may translate into commitment to implementation and evaluation. Commitment is necessary to sustain effective school improvement efforts. School improvement in conservative institutions like public schools requires a significant level of commitment (Schein, 2004). The effectiveness of school improvement, through changing leadership, politics, and environments, may be dependent upon it. 
The previous sections described facilitators to the planning process. Two broad facilitators of the process were teaming and decision-making. This research also identified facilitators that existed or occurred before the process, facilitators that occurred during the process, and results of the process that facilitated these districts' efforts. Figure 3 depicts the combination of teaming and decision-making that occurred during the planning process and highlights the facilitators that preceded, occurred during, and were a result of the process.

Figure 3. Facilitators of the Strategic Plan Development Process.

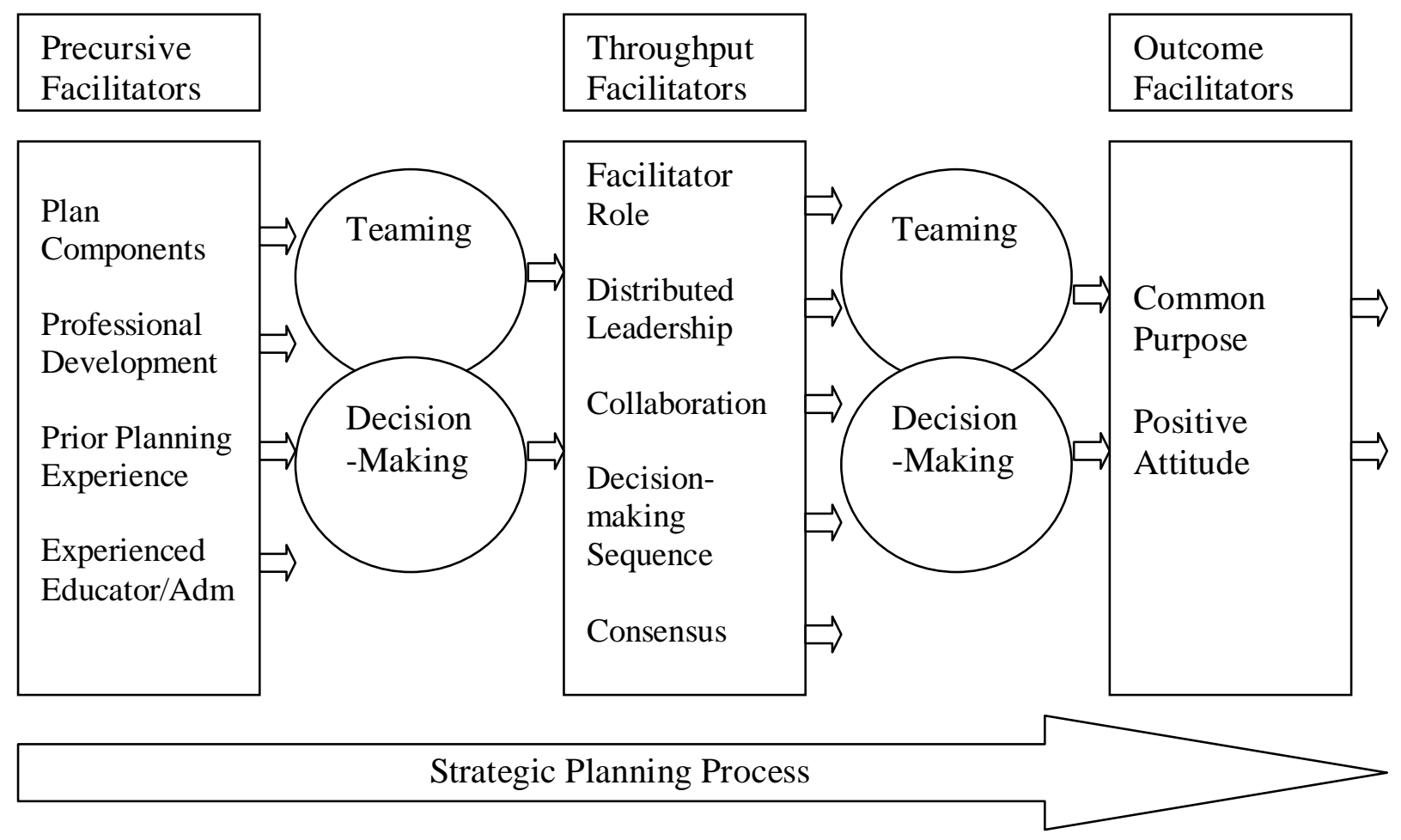

This figure illustrates the flow of the planning process moving from left to right. The four precursors that facilitated teaming and decision-making are introduced first in the left side column. Teaming and decision-making are overlapped to illustrate the integration of these elements. The middle column in the figure represents the facilitators that occurred during the planning process. The top three in this column, the facilitator role, distributed leadership and 
collaboration, are primarily associated with teaming. The bottom two facilitators, the decisionmaking sequence and consensus, correspond to the decision-making process. Two findings were identified that were a result of the planning process: common purpose and positive attitudes. Each of these may facilitate: (a) implementation of the plan's goals, objectives, and action steps and (b) evaluation of the plan's effectiveness in achieving school system improvement.

Barriers. This research identified four barriers to the strategic plan development process: (a) the size of the completed document, (b) the plan's submission deadlines, (c) the technology and software requirements of the plan, and (d) the plan's formatting and content changes and updates. Although the last two of these were described by the administrators as barriers, neither the software requirements nor the plan changes and updates appeared to impact the process or the plan.

Document size. The size of the completed document was described by administrators as a barrier (F.3.4) (H.2.3). Document size inhibited strategic planning in three ways: (a) communication to audiences, (b) coordination between departments, and (c) the time required to complete the document.

The size of the completed document has been an issue since the beginning of the WVDE strategic plan requirement (F.3.4; H.2.3). The original on-line WVDE strategic plan that school districts used during the 2005-2006 school year resulted in lengthy documents. One superintendent noted that the completed plan for their small county used to be over 140 pages (F.3.5). In addition to the content, the length of the document was a result of an inefficient, runon printing format. The newest version of the strategic plan has a more efficient print format that has reduced the size of the final document. Administrators acknowledged that these types of improvements had occurred (F.3.4). 
Although reduced in size by the new format, the plans remained one the largest documents that the school districts handled. Plans still easily exceeded 100 pages. Contributing to this size, is the use of the document as a compliance instrument for departments such as Title I, special education, and technology. For example, the printed plans for special education and Title I in one district each exceeded 30 pages (G.D.2).

The plan serves as a compliance document in several ways. First, strategic planning is required by West Virginia state law (18-2E-5, 2007) and West Virginia State Board of Education policy (Policy 2320, 2007). As mentioned previously, it also serves as a compliance document for specific departments such as special education and Title I. Each of these federal programs requires the annual submission of a Local Education Agency (LEA) Application in order to receive their budget allocations for each school year.

The compliance sections of the plan, other large portions such as the action steps, which sometimes numbered in the hundreds (G.1.4), and the extensive data analysis (A.3.3) each contributed to the length of the documents. Previous research has questioned the utility of such lengthy planning documents. According to Davies and Ellison (1998): "The thicker the plan the less it affects classroom practice" (p. 2). Taken to the extreme, Reeves (2007-2008) suggested that "there is evidence that schools are well served by one-page plans that are clearly focused and simple enough that every participant in the process understands his or her role in executing the plan" (p. 87).

The next sections discuss the three ways document size and compliance features inhibited the strategic planning process: communication, coordination, and time required.

Communication. As a compliance document, the strategic plan's audience is the West Virginia Department of Education. However, to be an effective instrument for school 
improvement, the plan must be communicated to, and understood by, audiences other than the state department of education. These audiences include the strategic planning committee, district office staffs, school staffs, parents, and the community. Bryson (1995) emphasized the importance of investing in communication:

People must be given an opportunity to develop shared meanings and appreciations that will further the implementation of change goals. People must hear about the proposed changes, preferably many times and across multiple channels, so that the messages will sink in. Further, people must be able to talk about the changes in order to understand them, fit them into their own interpretive schemes, adapt them to their own circumstances, and explore the implications. (p.181)

An assistant superintendent acknowledged the importance of communicating her plan's purpose to the district's constituents. "We need to realize that we're not done until the district has internalized those goals and objectives that we have set (G.3.6).” Although this district's goals were limited in number, the amount of objectives and action steps the district developed prohibited their issuance through any concise format. She observed that this created a stumbling block when the district's committee was "getting out the word about [the plan]" (G.3.5).

In order for the strategic plan to achieve utility as a communication instrument the committees had to alter the document's format and reduce its size. Sometimes this was done by creating a new document (G.D.2). In other instances the committees used features built into the plan's software (G.D.1). For example, the WVDE strategic plan software has a feature that creates a core plan. The core plan includes a list of committee members, the mission statement, core beliefs, goals and objectives, data analysis, and many of the action steps. It omits parts of departmental compliance components such as those specific to Title I, special education, and 
technology. An example core plan is included in Appendix E. Despite the reduction in size, none of the administrators reported using the core plan as the primary means to communicate the purpose of their strategic plan. Instead, they created new documents that summarized the plan. For example, one district created a one page handout that included the mission statement, core beliefs, goals, and objectives (G.D.2).

Coordination. Document size and the compliance features of the plan impacted coordination in two ways: (a) they changed the committee's structure and (b) they inhibited interdepartmental interactions.

Document size impacted coordination of the teaming process by changing the committee's structure. Planning requirements, such as the extensive data analysis and development of numerous action steps, are difficult tasks to accomplish with large committees. Therefore, districts found it necessary to break down their full committees to manage the volume of action steps. An assistant superintendent described this reduction of the full committee into subcommittees:

Getting down to the action steps with a large group is very difficult. So, what we typically are able to do with a huge group is: We get our beliefs down, get our mission down, and get our broad goals down. Then I send those back to internal teams to look at proposed action steps and objectives. Then we come back to the large committee with a proposal and make any changes to them. (G.2.2)

The isolation created by the compliance features of the plan inhibited coordination between departments. For example, both Title I and special education use the strategic plan document to fulfill these department's requirement of an annual application and budget. Significant portions of these compliance sections are completed by departmental administrators 
outside of the strategic plan committee process. This isolation inhibited, but did not prevent, the committee's ability to coordinate its planning activities and to practice the type of collaboration necessary for a unified district-wide strategic effort. A special education director described this isolation:

Until this year, quite frankly, my plan was just my department . . . I am embarrassed to say that, as a special education director, I wasn't included the first year. When I talk to my colleagues I know they feel they have a limited role in some counties . . . You kind of get self-centered about your own stuff ... I was very surprised at how many folks on the plan [team] admitted that they didn't know very much about the federal compliance areas. (H.1.2)

The four school districts in this research overcame the isolation, and, in the end, produced a plan that achieved a common purpose. They completed the compliance requirements and recognized that they needed to reduce the interference that came with this compliance in order to stay true to the intent of their planning efforts (H.2.5).

Time required. Completing the extensive content and compliance components within the document required considerable schedule coordination, meeting time, and writing time (A.1.2; A.3.5; F.1.4). Monthly committee meetings, held over a span of approximately six months, were typical for these districts (A.1.2).

Holding multiple meetings required coordination of many schedules. This coordination of schedules was a frequent challenge due to the variety of duties and responsibility assigned to these administrators (A.2.4). This could result in delays to the projected planning committee meetings or committee members' cancellation or postponement of other duties. Committees adjusted to this by beginning their process months before the plan due dates (A.1.2). 
Although most interviewees felt that they had sufficient time to meet and develop their document, they quickly added that there is never enough time (A.2.4; A.3.4; G.1.5). In part, this is because administrators typically spend the majority of their time on operational issues. If administrators spend too much of their time in planning meetings it may be at the expense of the day-to-day demands of various operational issues. These committees balanced their day-to-day duties with the committee meeting schedules and allocated sufficient time to write and edit the various sections of the plan (A.2.4; G.1.5).

Deadlines. The second barrier to the plan development process was the deadlines associated with the document (H.2.5). In particular, the districts were concerned with the timing of the various deadlines associated with the plan. The district plan must be submitted to the WVDE in September of each school year and individual school plans are due in October. Different compliance sections, such as special education and Title I, have deadlines that precede both of these deadlines. For example, the special education section is due July first.

These varying deadlines were described as inhibiting coordination and cohesiveness (G.1.5; G.2.4). For example, action steps had to be developed for the Title I and special education compliance sections before the planning committee had reached that step in their process (H.1.2).

The timing of these deadlines was also a barrier, in part, because it confused districts. For example, were district's to imply that the order of the deadlines was intentional? The differing due dates for the district and school plans, in particular, were questioned. The sequence of due dates, district plan preceding school plans, was controversial (G.3.5). This controversy occurred because the districts interpreted this sequence to mean that: District goals and objectives should provide direction for the schools (F.3.3). 
One superintendent favored this sequence. In this administrator's opinion the district plan should precede school plans because his expectation was that the school plans should reflect and adopt the district's broad goals (F.3.3). In another district this sequence was questioned for its apparent promotion of a district plan that is too top-down directive (G.3.5). This district's administrators wrestled with the potential advantage of allowing school plans to be the driving force behind the district plan. The district's assistant superintendent described her dilemma:

We've been disappointed as a county that we haven't made more progress. The conclusion that we've come to is that we're too directive from the top and that the schools don't have ownership of their own goals and objectives ... We really should let [the schools] do all of this before we do the district plan, because, rather than letting the county plan drive the schools, should the county be looking at the schools' plans first? So we're thinking that [the order of the due dates] should almost be reversed.

Technology. The final two barriers, technology and the plan updates, were relatively minor and trivial. Although minor or trivial, the technological aspects of the plan were commonly described as a barrier by these administrators (F.3.7; H.2.5; F.2.5). The WVDE designed plan was developed and made available to districts and schools as an on-line document. It must be completed and submitted to the WVDE in its on-line format. The plan is located within the WVDE's website. District personnel sign-on to the site with a username and password. Various personnel may work on the plan simultaneously. For example, a Title I director may complete that portion of the plan while a special education director is working on other compliance sections. Submission of the compliance sections and the final plan is done by various departmental administrators according to respective deadlines. 
The on-line plan is navigated through a typical, expandable menu located on the left side of the screen. Many aspects of the software are consistent with common word processing applications. These include bolding, underlining, italicizing and font style, size, and format. Some typical editing features are missing such as spell-check and a thesaurus.

Other aspects of the software are more unusual. For example, narrative and data for most sections of the plan must be entered within a text box (Appendix F) and then made part of the plan by clicking on a radio/option button to "update". Although tables and graphs can be imported to the text box, they frequently lose their formatting. By "updating" and exiting the text box the entered text and graphics become part of the plan and available for viewing. These types of technical requirements and limitations, as well as occasional glitches, were described as both a distraction and frustration (A.2.3).

In the early years of the strategic planning requirement the novel, technical nature of the plan consumed the resources and attention of committees. Although the electronic document was described as being continually improved technically, there remained concerns about the on-line features, or lack thereof, of the software (F.3.7). The earliest versions of the plans also printed out in an inefficient and distracting run-on format. A superintendent, speaking of a particular state department of education administrator's efforts in this regard, stated:

He took that software, which was very cumbersome in the first five years, really redid it, and it's much, much better now. It took our plan, which was ridiculous, it was like 140 pages long for a small county, and reduced it by over half, again, because of the software. (F.3.5)

Despite the improvements, concerns remained about the size of, and technical requirements for, the plan. A district administrator made this comment: "The thing that just 
seems so cumbersome to me is the online portion of the plan. I mean, it is a humongous document, and, the online plan, it's a little more cumbersome than you would expect" (F.1.2). Although the committees moved past these technical distractions at the district level, they remained a distraction to planning at the school level according to one assistant superintendent. Describing the effectiveness of the process to date at the school level this administrator stated: I think it's been minimal so far, and I think it's because we've concentrated on the mechanics of getting the plan done. How you go to the computer and turn it on and get it to come up and how you put in the data and so forth rather than actually sitting with school teams and getting down and dirty about the data, taking a hard look in the mirror, and determining what it is your school needs to do to improve and then setting targets and monitoring improvement along the way. (G.3.7)

Plan updates. The on-line formatting of the plan received a significant update from the West Virginia Department of Education prior to the 2008/2009 school year. Changes also occurred yearly to the original formatting and content of the plan. Changes continue within different sections of the current software. For example, text boxes now include additional tool bar features. Additional plan content has also been required. Most recently, summer 2009, new sections were added to allow federal programs to be compliant with the American Recovery and Reinvestment Act's reporting requirements.

The constant changes to both the software and the plan's content were described as confusing and frustrating. A superintendent expressed his frustration with this changing electronic format: "I think the major challenge we've had is the change in formatting of the plan that's occurred seemingly every year"' (H.2.4). 
These planning committees moved past the inconveniences caused by the software requirements, limitations, and changes. These barriers' impact on the overall planning process may be overcome, but, in the short term, they do consume the time of committees and create some level of frustration (F.2.2).

While technology and plan updates were more minor or trivial barriers, document size, the compliance sections, and plan deadlines have the potential of being more impactful barriers. These four districts' committees limited their impact by emphasizing the true intent of the strategic planning process: school system improvement. These committees stayed true to the spirit of the process, something that may not occur in all school districts and may not be possible to mandate.

Related findings: perceptions of the process. This set of related findings focuses on the district administrators' perceptions of strategic planning. The first group of questions used during this study's interviews targeted the strategic plan development process. The second group of interview questions was designed to obtain interviewee's perception of strategic planning. These questions solicited each administrator's opinion of their district's process, strategic planning as a state department of education requirement, and their judgment of its effectiveness.

The interviewees in these four districts overwhelmingly supported the strategic plan development process as an improvement method at the district level (A.2.4; A.3.5; F.3.7; H.1.5; H.3.3; G.1.7; G.2.7). Their opinions are mixed regarding its effectiveness and impact at the individual school and classroom levels. This concern will be discussed following some examples highlighting their opinions about the five-year on-line strategic plan requirement, the process, and its effectiveness at the district level. 
The assistant superintendent of Academy County Schools endorsed strategic planning and stated she is in favor of writing a five-year strategic plan for several reasons:

It gives you direction as a county. You establish your goals based on your vision and mission. The development process gives people an opportunity for input about what is going to happen in the county school system. It also provides a format for you to report to your schools, the community, and the state department of education. (A.3.5)

The superintendent of Fusion County Schools was also a vocal advocate for the strategic plan requirement:

I really think it's important. And, again, it's the old adage of what gets monitored gets done. I like the fact that the state department's telling Fusion County schools you've got to write this thing. I get sick and tired of hearing stories of some counties down in the southern part of the state that are still so far out of whack in the way they do things that it's frustrating as a professional, and if the state's got to say you're going to do this in order to make sure it gets done, I'm OK with that. I like to be able to show off what we do, to be perfectly frank. I like having interviews like this. I like to be able to stand up in a superintendents' meeting and say this is what we're doing. (F.3.7)

This same superintendent also believed it could be a very effective method of school and school system improvement. Describing its potential for effectiveness, as well as his directive, top-down style, he related:

I believe it depends upon if the superintendent focuses value upon it. I remember when I first started doing school improvement plans when I was a principal. I did them because I had to do them. I never paid attention to them. And then the older and smarter I got, I really came to the conclusion that I could run a better school if I put more effort into that 
plan and followed it closer. For instance, make it a permanent agenda item on LSIC meetings. Make it a permanent agenda item on curriculum team meetings so it's constantly being focused upon. Then as I became a central office administrator and a superintendent I brought that with me and I honestly believe that it drives everything we do. It makes my central office people ... I put their feet to the fire once a month to say where are you with this one. Our meetings sometimes last a while, especially at the beginning of the year because we're going down through lots of action steps. Then as you get towards the end of the year they get much, much quicker because you've already accomplished the majority of them. So to me it's very important to success. (F.3.7) There was near unanimous support among interviewees for their district's process, the state department of education's planning requirement, and its effectiveness, at least at the district level. Interviewees' opinions about its impact at the school and classroom levels were mixed. The special education director in Fusion School District has seen an impact at the classroom level:

I know that it has rattled the cages of a lot of teachers. I think we have a phenomenal group of educators in our school system, but, there are some teachers who are very set in their ways. This is how they want to do things and they believe that's the best way to educate kids. I truly believe [the superintendent has] taken them outside of their comfort zone and a lot of them are finding that maybe there is more to be offered. What they do is great and we don't want to take that away from them, but, there also may be some other ways to think about things. And I think that's all [the superintendent is] asking of them - is to continue what you're doing because it's obviously good but let's also look at 
some other things. So I think it has benefited teaching in the sense that it's forced the hands of teachers a little bit to look outside of what they already do. (F.2.6)

Concerns about its effectiveness at the school and classroom levels were uncovered with probes to the question about effectiveness. For example, the curriculum director in Heritage School District worried about whether the plan is being properly communicated to their teachers: I'll be real honest with you. First of all, I worry how many teachers really see it. That's a biggie. So if the teacher doesn't see it, how do they know how things are going ... My concern is ... I'm not worrying about the schools following it, but, do all the teachers see that? They know we have these goals and this is where we're going and this is why we're using it but to actually sit down ... We don't know. Overall though, I think [Heritage] County teachers are aware and they know it's a guide. (H.3.5)

The director of title programs for Gamble County Schools suggested that there is an impact that may not have been directly or immediately attributed to the planning process. She relayed that many people never made the association with what happened in the end and the planning process that got them there. "There's a whole lot of impact out there, whether people knew it or not in another thing" (G.1.8). She also acknowledged that the process needed to be better developed at the school level. Their district's next efforts will be directed more at the school level. They are going to try to create more autonomy at the school level. If they can successfully promote the process at the school level and get them to make more decisions, they believe the plans will be a more effective instrument of improvement by impacting teaching and learning. 
The assistant superintendent in this same school district expressed her desire for more impact and effectiveness at the school level. In response to the probe about the school level she offered this concern about its impact:

I think it's been minimal so far. I think it's because we've concentrated on the mechanics of getting the plan done rather than actually sitting with school teams and getting down and dirty about data, taking a hard look in the mirror, determining what it is your school needs to do to improve, and then setting targets and monitoring that improvement along the way. To be honest, to this date I do not feel it's been effective at the school level simply because, to them, it's just another thing that has to be done. They don't see the value of it. They're too wrapped up in their day-to-day stuff to understand that the strategic plan can be something proactive that drives their staff and that it would be better to be in that mode than to be reactive and having to back up. But I think we're getting there! (G.3.7)

To summarize this section, these districts valued the strategic planning process and requirement at both the district and school levels. These districts related that their mastery at the district level encouraged and identified the need to replicate and support these planning efforts at the school level in order to maximize the plan's potential impact on teaching and learning. Concerns remained about fidelity and effectiveness at the school level. Its impact on teaching and learning received mixed reviews.

Summary. The purpose of this study was to describe and develop understandings about the West Virginia Five Year School System Strategic Plan development process. Its three research questions were: How do county office personnel develop the West Virginia Five Year School System Strategic Plan? What styles of development do they use? and What are the 
facilitators and barriers to development? Four county school systems, nominated by a West Virginia Department of Education administrator responsible for strategic plan review, were used in this multi-site case study.

The findings obtained during the cross-case analysis revealed commonalities between the four districts' strategic plan development style and process. The identified facilitators and barriers to the process were also commonalities.

This chapter, a cross-case report, began with a description of the style and process these school districts used to develop the five-year strategic plan. Each plan development step was described in sequence. The following were the major sequenced steps of the West Virginia Five Year Strategic Plan:

1. Select planning committee members.

2. Establish core beliefs.

3. Prepare mission statement.

4. Conduct data analysis/Prioritize strategic issues.

5. Develop goals and objectives.

6. Develop action steps.

Facilitators to the plan development process were then described within two elements of the process: teaming and decision-making. Facilitative precursors to the planning process were addressed. The four precursors were: the components of the plan, professional development, team members' prior planning experience, and team members experience as public educators or administrators. 
Additional facilitators were identified within the contexts of teaming and decisionmaking. These findings either facilitated teaming and decision-making or were results of these processes. These findings were:

1. Facilitator role.

2. Distributed leadership.

3. Collaborative group processes.

4. A decision-making sequence.

5. Consensual decision-making.

6. Promotion of a common purpose.

7. Positive affect.

Barriers to the process included document size, plan submission deadlines, technology, and plan format changes. These four district teams limited the barriers' impact by emphasizing the true intent of the strategic planning process: school system improvement.

Related findings were then presented. These included the administrators' opinions of their planning process and strategic planning as an instrument for school system improvement. This narrative conveyed these administrators' favorable opinions of both their planning process and the state department of education's requirement that every district and school annually complete a strategic plan. The plan's impact and effectiveness at the district level was described as exceeding its effect at the school and classroom levels. 


\section{Chapter Five}

\section{Conclusions, Discussion, and Recommendations}

The purpose of this research was to describe and develop understandings of the West Virginia Five Year School System Strategic Plan development process in selected county school districts. Its research questions were: How do county office personnel develop the West Virginia Five Year School System Strategic Plan? What styles of development do they use? and What are the facilitators and barriers to development?

This research was intended to be both explanatory and exploratory. It was explanatory in its descriptions and interpretations. This research was exploratory because, rather than testing hypotheses based on an existing theory or model, it provided a description of the strategic plan process used by these nominated districts.

These descriptions and interpretations were offered to advance an understanding of the strategic plan development process. The understandings derived from these explanations are neither static nor normative. The planning process used by these districts has evolved and will continue to evolve. Therefore, the process used in subsequent years may differ somewhat from the results of this research. For example, one administrator suggested that her district's emphasis may shift to school level planning in the near future (F.3.5).

These understandings are also not meant to be normative. The districts used in this research were nominated. They are not representative of the typical West Virginia school district. These four school systems operate in contexts that probably differ from other school districts. For example, they expressed the will and apparently possessed the capacity to plan. This will and capacity may have preceded current planning mandates and could continue to exist in the absence of state or federal planning mandates. 
Several conclusions have been developed that are based on these districts' processes. These conclusions are presented first in this chapter. A discussion about strategic planning follows these conclusions. The chapter then concludes with recommendations for theory, policy, practice, and future research.

Conclusions. The following conclusions are based on the research findings presented in chapter four. These conclusions are categorized into four general areas: the planning process, development style, facilitators and barriers, and the intent of strategic planning.

1. The strategic planning model dictated the sequence of steps the four districts followed during their development process. Underlying this model, each district used a common social discourse and knowledge building process during their team meetings. This included the sharing of knowledge, such as data analysis, the creation of potential goals and objectives through brainstorming, prioritization and selection of these goals and objectives through consensual decision-making, and the development and selection of more specific action steps.

2. The four districts in this research complied with and followed the strategic plan style offered by the West Virginia Department of Education (WVDE, 2007). This style was similar to the Cambridge model (Cook, 2001) and included the following seven components: (a) a committee of stakeholders, (b) core beliefs, (c) a mission statement, (d) data analysis, (e) goals and objectives, (f) action steps, and (g) implementation and evaluation. This style also captures the decisions that had to be made by these teams.

3. The facilitators to planning overcame the effect of the barriers resulting in team members viewing the strategic planning process as useful. Teaming and decision-making were the two primary elements of the process that served as facilitators to these districts' planning efforts. There were also several secondary facilitators, such as precursors, that supported the planning 
process and, in particular, the teaming and decision-making that occurred. Facilitators occurred during the planning process and there were also facilitators that were a result of the process. This research also identified barriers to the strategic plan development process. While some were more minor or trivial, others such as document size, the compliance sections, and plan deadlines had the potential of being more impactful barriers.

4. The administrators from these four districts supported strategic planning and attempted to use it as a method and instrument to achieve school system improvement. While the districts' immediate goal was compliance with the state and individual programmatic mandates, they tried to use strategic planning to their best advantage. To achieve their goals districts balanced barriers, such as the compliance features and unwieldy size and format of the document, with the positive attributes and intent of the process. In doing so they avoided an air of compliance and, instead, set a tone that was constructive. This resulted in a plan aimed at school system improvement and gave their teams common purpose and positive attitudes.

Discussion. This section begins with general considerations about the strategic planning process and a brief review of some limitations. The discussion then focuses on the process identified by this research and offers a more critical view of public school systems' strategic planning. This discussion section concludes with two specific aspects of the process: leadership and decision-making.

If it is true that "the process of planning is more valuable than the plan itself" (Huff \& Reger, 1987, p. 226) then why has the planning process in public education proved to be such an elusive and seldom researched topic? Although much has been written about strategic planning in schools (Hambright \& Diamentes, 2004), the majority of this has been how-to books and opinion pieces and has been mostly prescriptive rather than explanatory. Huff and Reger (1987) 
observed this decades ago: "Of interest is the field's continuing practice of prescribing before describing, of giving normative advice before empirical evidence supports it” (p. 227).

Part of the reason the field has developed this way may be that process itself is a difficult concept to define, describe and capture within theory. For example, the formulation of strategy may occur through relatively unstructured, iterative, social, creative, and political processes. Frederickson (1983) in his article on strategic process research pointed out that "no theory of social behavior can simultaneously be generalizable, accurate, and simple” (p. 572).

Because of the complexity of organizational planning, it may take a combination of theories from several fields to adequately conceptualize it. Huff and Reger (1987) describing strategic planning research in a variety of organizational settings stated that:

It is both interesting and puzzling that strategic management and organizational theory researchers study the same phenomenon but work independently of each other. Rarely does either group reference the other's work, nor have they employed the same variables or tested each other's theories. (p. 221)

Over two decades later it may still be hard to dispute their claim.

Another aspect of the planning process that makes it difficult to research is an inability to define its boundaries. "Planning is a highly complex managerial function that must be tailored to the specific circumstances of each school and must be properly integrated with the other managerial functions" (Beach \& Lindahl, 2007, p.20). Because of this complexity and integration with other functions, in order to understand planning we must understand organizations. Johnson (1990) noted this complexity with a call for "explanatory models which integrate organizational, cognitive and cultural dimensions" (p. 183). 
Systems theory may be the overarching model that could be used to represent organizational planning. However, systems theory alone does not describe or account for specifics such as the social process, leadership, and decision-making that occurs during planning.

This complexity creates difficulties for researchers because strategic planning may "simultaneously exhibit the characteristics of several models" (Frederickson, 1983, p. 570). Frederickson was speaking primarily of strategic planning as it occurred in businesses. However, it is unlikely that in organizations such as school systems one theory or model could describe all aspects of planning. Because of this complexity, Frederickson recommended that instead of attempting to test entire models, "investigators focus their efforts on individual process characteristics and questions" (p. 570).

The results, presented in chapter four as answers to this study's research questions, attempted to maintain this focus. Rather than build a comprehensive strategic planning model based on any one theory, it described relevant aspects such as the style, process, and facilitators and barriers. Because of the dynamic complexity present in the strategic planning process, I agree with Frederickson's (1983) statement that: “The value of strategic process research will be realized only when it provides an understanding of important phenomena and helps improve organizational performance" (p. 573).

This discussion section will next take a broader and more theoretical view of strategic planning than the results presented in chapter four. A brief consideration of strategic planning's strengths and limitations precedes a conceptual model of the planning process based on stasis theory. Following these sections is a critical discussion about strategic planning and, in particular, decision-making. 
Strategic planning. This research's participants' endorsement of strategic planning and adherence to state policy may be understood, in part, through their particular contexts. The context that these districts operated in included an existing planning foundation. These districts had already adopted, and made part of their practice, planning as a method of school system improvement. The similarities between the policy requirements and their existing planning knowledge and experience may have allowed these districts to more easily employ a process that conformed to the state department of education requirement. Their planning practices may have already been very similar to the state's policy mandates. Therefore, they may have more readily accommodated a strategic planning requirement into their current practices than districts that were not employing district-wide planning.

The ability to interpret and make sense of the strategic planning mandate may have helped these districts overcome barriers that appeared during the planning process. Their prior planning experience and desire to achieve school system improvement could have provided them with the vision necessary to see past barriers such as the compliance features of the plan. Districts lacking previous planning experience and the desire for school system improvement may have been more easily distracted, delayed, and frustrated by the barriers.

In order for districts to remain true to the intent of the planning process they may need to achieve this type of awareness. Without it, state policy mandates, such as strategic planning, could have the unintended opposite effect. Spillane (1999) found that the way state policy plays out at the local level can "actually undermine the development of local policy makers' understanding of the more substantive content and pedagogical ideas: It distracts local policy makers' attention from the more substantive reform ideas" (p. 565). If school districts focus on the strategic plan as a compliance document, they may just "go through the motions" of the 
planning process. The result may be satisfactory in a compliance sense yet superficial. This type of planning and plan may lack the innovative and sincere strategic intent necessary for school improvement. Previous research (Spillane, 1999) found that "compliance mechanisms were much more successful in drawing local policy makers' attention to topic coverage than to more substantive changes" (p. 565).

Strategic planning limitations. The five-year strategic planning process and format created limitations and raised questions about these school districts' planning practices. First, the cumbersome, technical nature of the product consumed a considerable portion of these teams' available resources, including time and attention. High performing districts could make better use of their time and personnel to advance school improvement efforts. A second concern is that as a compliance document the plan appeared to limit the team's focus to those issues and topics identified within the plan's existing format. Awareness of this limitation and its effect on the strategic intent, or lack thereof, varied among interviewed team members. Although some creative and progressive initiatives were attributed to the planning process, these could not be described as radical, aggressive, or outside-of-the-box methods of school reform. Finally, the case study districts emphasized their belief in team planning practices. This planning may have occurred with or without the current state department of education requirement. It cannot be asserted the extent to which, overall, the current required strategic plan enhanced or inhibited school improvement efforts in these particular, non-typical, districts.

This leads to a caution: Simple replication of these districts' planning process, as supported by the identified facilitators, is probably an insufficient model and means to achieve strategic planning that results in school improvement. Context is important because capacity building may need to occur at many levels for strategic planning to be effective as a method of, 
and instrument for, school system improvement. Noting this qualification, there may be heuristic value in a theoretical model of the planning process.

A process model. In order to help conceptualize these districts' plan development process, a model is offered. Kaplan (1964) stated that the term model can be used loosely to refer to any scientific theory represented in a symbolic style. Rowan, Correnti, Miller, and Camburn (2009) noted that: "Much has been learned in succeeding decades about how to study designbased programs. The general idea has been to build a logic model that describes the theory in action" (p. 23).

This model is presented to advance an understanding of the complex social process and discourse that occurred during these districts' planning. It combines the findings of this research, such as teaming, brainstorming, and consensual decision-making, with a theory, stasis, that describes a social inquiry and knowledge building process. It identifies the hierarchical steps, the complexity of issues, and the recursive, cyclical nature of the process.

The advantage to a theoretical model, in comparison to a model based on a particular strategic planning style, is that is advances an understanding of the underlying processes used during planning. The names of strategic planning steps may change according to styles, such as the Cambridge Model, or policy, such as the WVDE's. The core process, however, may be essentially the same. I suggest that it is more important for planning teams to understand these essentials than it is for them to strictly adhere to the steps and format as mandated by policy or proffered by business and educational planning models.

The model presented in Figure 5 is based on this research's findings. The model parallels the findings of this research with an ancient theory, stasis. The research findings and this theory 
are combined within the model to develop an understanding of the planning process used by these school districts.

Stasis theory is used as a generative heuristic to enhance this model's ability to convey an understanding of the planning process. The model portrays the teaming and decision-making hierarchy underlying the strategic plan development process that occurred in these districts. Stasis theory is chosen because its description of the inquiry process parallels the findings of this research. Brizee (2008) recommended stasis theory as a theoretical model for teaming and decision-making because of its ability to foster critical thinking and assist teams in making better decisions. This author described it as a "rigorous yet flexible analytic process" (p. 383). Stasis theory is a four step social knowledge building process developed in ancient Greece and refined by Roman rhetoricians (Brizee, 2008). The model presented in Figure 5 is built more on the Greek's use of stasis as a system for inquiry and philosophy than it is on the Roman's use as a technique for argument. This viewpoint uses stasis "to build bridges rather than dig trenches" (p. 375). The stases should "act like a puzzle where the parties involved in discussion work together to build facts, agree on definition and quality, so they can develop policies that emerge as multi-sided, shared processes" (p. 376).

Figure 4 represents a model based on the theoretical constructs of stasis and this research's findings. The model demonstrates an integration of the teaming and decision-making steps that occurred during the case study districts' strategic plan development process. 
Figure 4. Stasis Theory as a Model of the Strategic Planning Process.

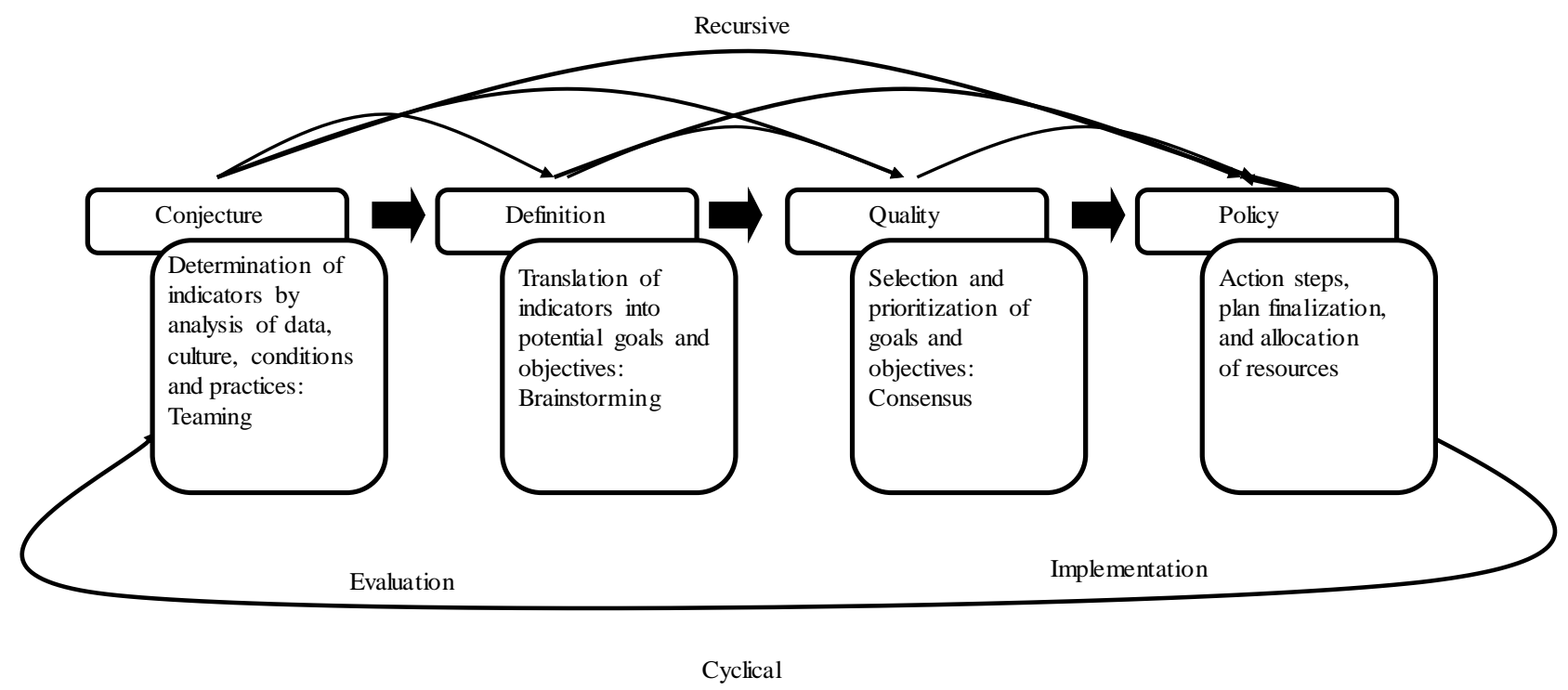

As represented in Figure 4 the four stases are: (a) conjecture, (b) definition, (c) quality, and (d) policy. Below each stasis box is a box containing a description of actions that occur at each of the four steps or stases. The actions are described in terms relevant to strategic planning and may include examples from this research.

Stasis theory, in the present application, asks teams to agree on: (a) facts as derived from data (conjecture), (b) the meaning of the issue in terms of goals or objectives (definition), (c) the prioritization or seriousness of the issues (quality), and (d) a determination of what should be done (policy). The first stasis, conjecture, is similar to the data analysis that occurred during these districts' planning process. The "facts" are primarily the results of the data analysis. Facts 
may also be a district's mission and core beliefs. The second stasis is definition. During this stage the facts are translated into potential goals and objectives. These were developed through the brainstorming that occurred during these districts' planning. The third stasis is quality. At this stage the team must determine the seriousness of the issues and prioritize their goals and objectives. The four districts in this study made these decisions through consensus. The final stasis is the development of policy: What should be done? During this stage the teams determined what action steps would accomplish their goals and objectives, allocated resources and finalized their plans.

In addition to the four steps, or stases, this model furthers an understanding of these districts' planning process in several other ways:

1. Logical hierarchy: The steps are hierarchical. Facts need to be determined prior to an identification of issues. The seriousness of the issues must be determined and weighed before determining what course of action will ensue.

2. Complexity of reason: The steps represent the complexity of issues involved in the planning and decision-making processes. Each element of stasis evokes more refined questions and discussion. This rhetoric leads "to an enriched invention strategy" (Fahnestock \& Secor, 1998, p. 218).

3. Recursiveness: The four stases are recursive. A question arising at any level can interrupt the process and necessitate another round of fact findings, issue identification, prioritization, and policy (goals, objectives, and action steps) establishment.

4. Cyclical: Following implementation and evaluation the cycle repeats itself. Implementation and evaluation may also result in a recursive return to any one of the four stases. 
A critical view of strategic planning. This section begins by contrasting strategic planning with other types of planning such as comprehensive or operational. Next is a consideration of fallacies attributed to strategic planning. This section concludes by considering the positive and negative attributes of strategic planning and, in particular, the leadership, teaming, and decision-making that occurred during the process used by the four districts in this research.

The utility of strategic planning has been debated in the literature since at least 1989 (Hamel \& Pralahad) and more recently regarding its use in public education (Cook, 2004; Schmoker, 2004). Part of this debate has centered on whether this type of planning is actually strategic. In contrast, what is presented as strategic planning may be more accurately described as comprehensive or operational planning.

A certain amount of this argument may be applied to the plans developed by the four districts in this research. Although this research did not focus on content, a review of the districts' core plans indicated that the terms operational and comprehensive could be used to describe their documents (A.D.1; H.D.1). It is unlikely, however, that this distinction in terms, strategic versus operational or comprehensive, had an impact on these teams' intent or process. They were able to compartmentalize the comprehensive compliance requirements. By doing so they recognized and reduced this type of barrier. This does not mean that these districts did not criticize this aspect of the planning requirement. The operational and comprehensive nature of the WVDE Five-Year Strategic Plan was recognized as a compliance matter and viewed as an unnecessary use of their time (H.2.4).

The preceding discussion considered that planning titled strategic may actually be another type of planning. If it could be assumed that the WVDE Five-Year Strategic Plan was 
truly a type of strategic planning, is this the most appropriate type of planning for public schools?

Strategic planning has been criticized in the literature for some of its fundamentals (Mintzberg, 1994; Bell, 2004). Strategic planning, as described by these authors, is based on three fallacies. First it is based on a predictable future. The planning process used by the districts in this research did not appear to formalize a prediction of the future beyond current or anticipated policy mandates, for example, Response to Intervention (A.D.1). Therefore, this fallacy may not be applicable to these districts' process.

The second fallacy described by Mintzberg and Bell was detachment of leadership. These researchers may have been discussing a business model when they stated that strategic planning tended to be carried out by management rather than the workers. Again, this fallacy does not appear to be pertinent to the districts in this research. Their teams included broad representation of a variety of constituent groups (G.D.1).

The third fallacy was formalization and effectiveness. If strategic plans are rigidly adhered to in a turbulent environment they may be, at least, unresponsive and, at worst, misguided. The districts in this research described their plans as living documents (H.1.2). This suggested that these teams revisited the planning process and document in response to changes in their environments and the effectiveness of implementation. Therefore, this fallacy may not be true of strategic planning as practiced by these districts. However, research examining implementation would be necessary to validate this hypothesis.

If these fallacies are not true of strategic planning as practiced by the districts in this study, can we conclude that strategic planning is appropriate and the most appropriate form of planning for public school systems? First, because this research is qualitative, it is descriptive 
more so than normative. Noting that caution, there are both positive and negative attributes of strategic planning as practiced by these districts. The next sections will discuss these qualities.

Strategic planning pros and cons: leadership and decision-making. This research identified several facilitators to the planning process. Two of these are discussed in the following sections: leadership and decision-making. One leadership issue that arose inductively from these case studies was distributed leadership. Distributed leadership was described by respondents as occurring throughout their teaming process and appeared to be a positive attribute of the strategic planning practiced by these four districts.

Each of the four districts attributed the initial and primary leadership that occurred during the strategic plan development process to their assistant superintendent or superintendent. At first glance this would appear to exemplify a traditional bureaucracy with its structure and authority. This structure and authority was used to organize, coordinate, and develop the initial strategic planning process. Once this was achieved, however, the teams quickly adopted a distributed leadership style that continued as the dominant model throughout the development process.

Using distributed leadership to describe these school systems beyond the strategic plan development process might, at first, be considered a rather exaggerated view. Groups and teams may share leadership during meetings without distributing this leadership across the organization. However, the interviewees from these districts described a sharing of leadership that extended beyond the planning process, permeating the organization, especially the professional staff (F.5.3). This perceived practice appeared to precede strategic planning and exert an influence beyond the process fostering collaboration, promoting common purpose, and facilitating implementation. Spillane (2004) described this distributed leadership as situational 
because as tasks are carried out, leadership practices emerge through the collaboration and interactions of individuals.

At the district level distributed leadership may be effectual as a leadership model because it enhances: (a) human relations by elevating feelings of satisfaction, pride, and purpose, (b) politics by increasing ownership and engagement, and (c) communication by creating a process that is more interactive, collaborative, and cohesive. Distributed leadership was described as advantageous for these districts and may also be effective for individual schools where a limited administrative structure could be enhanced by multiple sources of leadership developed across the school setting.

The second aspect of strategic planning included in this discussion of the positive and negative qualities of strategic planning focuses on decision-making. Many of the interviewees proudly and even emphatically stated that their decision-making processes occurred through consensus and only through consensus (A.1.1; F.2.1; F.3.3; H.2.2; H.3.2; G.1.4; G.2.2; G.3.1). This appeared to create positive attitudes among the interviewees. Huff and Reger (1987) in their review of strategic process research found that groups using a consensus approach were more satisfied than groups using either dialectical inquiry or a devil's advocate approach to decisionmaking. In this sense consensual decision-making may have been a motivating social factor that facilitated the group process. Other positive attributes of consensual decision-making may be its inclusiveness and its ability to encourage participation and cooperation. A consensual, participative decision-making process may create what Ouchi (1981) described as the ideal organizational culture resulting in egalitarianism. "Egalitarianism implies that each person can apply discretion and can work autonomously without close supervision, because they are to be trusted" (Ouchi, 1981, p. 429). 
Despite the positive attributes of consensual decision-making, these type of questions need to be raised: Does consensual decision-making optimize a school district's improvement efforts? and What happens to those initiatives that may be in the best interest of an organization but fail to achieve consensus because of political or social issues?

Early researchers such as Cyert and March (1963), and Selznick (1948), suggested that organizational behavior is less than optimal. Cyert and March identified one limiting characteristic of organizations as satisficing. Satisficing is described as the tendency of individuals and groups to settle on a satisfactory solution rather than the best solution. For example, an administrator in Gamble County described how her team would not include anything in their plan that was not derived consensually. "Bottom line is something doesn't go in the plan if there's someone who adamantly says I can't support that, there's no way" (G.1.3).

Selznick (1948) described another limiting organizational behavior as cooptation: "the process of absorbing new elements into the leadership or policy determining structure of an organization as a means of averting threats to its stability or existence" (p. 132). These districts' created teams that deliberately included a wide range of stakeholders. Broad representation may have advantages during brainstorming and implementation. However, the tradeoff may be increased complexity and tension during the decision-making process resulting in political rather than optimal choices. It is possible that these districts' strategic planning teams engaged in both satisficing and cooptation in order to decrease disruption and achieve consensus.

The preceding two theories of organizational behavior may be applied to decisionmaking in general. There may also be differences between types of decision-making. Potential limitations to consensual decision-making, in comparison to other more traditional authority models may include: (a) a tendency to preserve the status-quo or inside the box thinking, (b) 
susceptibility to disruption, (c) susceptibility to groupthink, and (d) its time consuming nature. Groupthink occurs when teams develop rationalizations about their organizations that result in an illusion of invulnerability (Hoy \& Miskel, 2005). The consequences of groupthink are "overestimation, closed mindedness, and pressure for unanimity" (p. 332). Consensus may also be unduly time consuming. An administrator in Gamble School District described her team's mission statement development:

I can remember vividly the many hours, the many, many, many, hours it took to get to [the mission statement]. But I can't find one person in [Gamble] County who could ever repeat it. You couldn't do it. There's too much in it (G.1.1).

The strategic planning, as practiced by these school systems, may also be intentionally or unintentionally incremental. An incremental approach may be advantageous if it is deliberate. It could also be restrictive or overly conservative if it is accidental. Braybrooke and Lindblom (1963) introduced the incremental strategy of decision-making as a realistic approach for organizations in complex situations where the outcomes are uncertain and informational resources have limitations. Measured decisions are reviewed and adjusted in response to their effectiveness within a changing environment.

Davies and Ellison (1998) later used the term incrementalism to describe a negative characteristic of strategic planning. Rather than being an intentional decision-making process of successive limited comparisons of goals and actions, incrementalism, as described by these authors, occurs when each subsequent plan becomes a minor revision of its predecessor. This type of decision-making may prevent teams and organizations from taking the fresh, outside the box view necessary to be creative and effective. Each plan becomes a revision of a previous plan 
continuing the same practices with minor adjustment. This type of incrementalism may be an unintended characteristic resulting from the WVDE's strategic planning design.

The WVDE strategic planning process is designed so that the initial five-year plan only has to be updated and revised during subsequent years. Although it would take a longitudinal evaluation of the content of these plans to confirm this, it could be predicted that goals remain the same or similar over the years with objectives and action steps being the only changes. This may occur for two reasons. First, the WVDE may inadvertently allow teams to reduce their effort by limiting strategic planning to updating and revising. The second reason may be a result of NCLB and AYP. AYP's accountability requirements may create a disproportionate focus on summative achievement scores in limited subject areas. This may result in narrow, incremental changes to specific curricular and instructional approaches.

This discussion reviewed some of the issues involved in the complex organizational process of strategic planning. This research's results and the issues identified within this discussion are the basis for the recommendations for theory, policy, practitioners, and future research presented in the next sections.

Recommendations for theory in use. This section first offers recommendations for the use of theory related to strategic planning. It concludes with recommendations for the use of theory relevant to a more specific component of the planning process: decision-making.

Planning and the formulation of strategy may occur through relatively unstructured, iterative, social, creative and political processes. Because of the complexity of the process, it may take a combination of theories from several fields to adequately conceptualize the process. Theory, from these various fields, needs to be translated into practice so that public school 
system planning teams can increase their understanding of the process and subsequently maximize their school improvement efforts.

Theory is useful to the extent that it is able to help us understand phenomena, in this case the dynamics of the organizational planning process. Kaplan (1964) defined theory as "the device for interpreting, criticizing, and unifying established laws, modifying them to fit data unanticipated in their formulation, and guiding the enterprise of discovering new and more powerful generalizations" (p. 295).

This research was designed to be descriptive and exploratory as it answered specific research questions. Because this research used qualitative methods it did not attempt to test any particular theory related to planning. Even if it were designed to be empirical, it is possible that no one theory could completely or adequately describe such a complex process as organizational planning.

Four theories may help understand the strategic planning process revealed through this research: systems, distributed leadership, stasis, and social decision scheme. The next sections will briefly describe these theories in relation to this research and provide recommendations for their consideration and use by practitioners.

Systems theory may be the overarching model that could be used to represent organizational planning. For example, systems theory was the basis for Figure 3, Facilitators of the Strategic Planning Development Process, presented in Chapter 4. However, in order to more accurately describe specific process characteristics additional theories are needed. These include theories from the fields of leadership, social processes, and decision-making.

The leadership that occurred during these districts' planning resembled the distributed type of leadership described by Spillane (2004). The administrators interviewed during this 
research frequently described its practice. This distribution of leadership took the form of topical leaders for the large group, sub-committee leadership, and departmental leadership. The way these teams distributed leadership appears to have been advantageous to the process and to positive results. The facilitation that occurred as a result of the distribution of leadership also carried over from the development process to implementation and evaluation. Some credited the sharing of leadership with contributing to positive outcomes at these stages. It is recommended that practitioners consider distributed leadership in their strategic planning.

The social processes that occurred during planning was conceptualized by the ancient theory of stasis. This theory was used to describe the discourse, inquiry, and knowledge building that occurred during these districts' planning process as represented in Figure 4, Stasis Theory as a Model of the Strategic Planning Process, in this chapter. Practitioners may be familiar with a strategic planning model such as the Cambridge Model. However, they may be less familiar with the underlying processes. Stasis theory suggests there are four common, underlying stases: (a) facts as derived from data (conjecture), (b) the meaning of the issue in terms of goals or objectives (definition), (c) the prioritization or seriousness of the issues (quality), and (d) a determination of what should be done (policy). A model based on stasis theory could enhance practitioners' understanding of the planning process.

Because of the importance of planning teams' decisions the next section will focus on decision-making and, in particular, the consensual decision-making process used by the four districts in this research. A theoretical view of how these districts made decisions, what these decisions were, and their effectiveness could provide a greater understanding of the dynamics involved when organizations such as public schools undertake improvement efforts. 
Much of decision-making research has focused on the individual dividing the field into approaches such as behaviorist and cognitive (Schneider \& Shanteau, 2003). While these approaches also have some utility in explaining group processes, they typically do not consider the social, political, and cultural aspects of organizational teams' decision-making. "Although almost everyone recognizes that decision-making takes place in a social and cultural context, relatively few researchers until now have managed to incorporate such factors" (Schneider \& Shanteau, 2003, p.7).

One theory that has been developed to describe the consensual decision-making phenomenon is social decision scheme theory. This theory views group interaction as "a combinational process wherein preferences for decision alternatives across group members must be combined in such a way as to allow the group to reach consensus on a single group choice" (Kameda, Tindale, \& Davis, 2003, p. 460). Social decision scheme theory examines the likelihood of a group favoring a particular decision alternative. Going strictly by proportionality would suggest that the probability that a group will choose a particular alternative is the proportion of members favoring that alternative. For example, if two out of six members prefer an alternative it has a 33 percent chance of being selected. Conversely, majority probability, as described by social decision scheme theory, predicts that whenever a majority of group members favor a particular decision alternative that alternative will be chosen by the group. Therefore, if two out of six members prefer an alternative it has a zero percent chance of being selected.

Social decision scheme theory and related research may be instructive to teams relying on consensual decision-making. Research has shown that these groups tend to adopt the majority's preference at the expense of members whose views are discrepant. "Majorities may contain only one more member than a competing minority, yet they define the group consensus nearly $100 \%$ 
of the time. This is particularly true when no demonstrable correct alternative exists" (p. 464). In these instances, which I suggest are similar to the strategic planning teams' decisions-making, the quality of a group decision depends more on what kinds of preferences are shared at the outset in a group, than it does on any data or alternatives presented during the decision-making process. This is a caution for high performing districts and could have serious ramifications for the strategic planning of dysfunctional and low-performing districts.

The strategic planning mandated by the WVDE required a team approach. This requirement may be based on the perception that groups bring a greater breadth and depth of knowledge with them and therefore make better decisions. If this perception is not accurate it could challenge the wisdom of allowing groups to make decisions through consensus.

One of the main reasons groups are often perceived to be superior to individuals in terms of decision quality or accuracy is that groups bring more cognitive resources to the particular decision task. However, recent research specifically looking at information processing in groups has shown that groups do not necessarily harness these cognitive resources in an optimal way. (Kameda, Tindale, \& Davis, 2003, p. 471)

Social decision scheme theory may improve our understanding of why this occurs. Theory may also be useful, for example, in understanding the positive and negatives consequences of consensual decision-making. Groups using consensus to make decisions during strategic planning need to be aware of this decision-making method's tendencies.

Social decision scheme is an example of one type of theory that could be translated into practice. Informing public school system planning teams of this theory may increase their awareness of the advantages and limitations of consensual decision-making and guide them to making improved choices. 
Recommendations for policy. Policy initiatives aimed at school improvement need to be considered at four levels of influence in public schooling: federal, state, district, and school. The next sections discuss policy at the federal and state levels and its influence on school districts and schools.

Federal. To date, federal policy has been silent on a strategic planning approach to school improvement. Instead, federal policy, such as NCLB, has a series of consequences for not achieving required accountability levels such as AYP.

The Alliance for Excellent Education has recently released a series of policy briefs imploring federal policy makers to consider the results of the Comprehensive School Reform Program (CSR) research when it reauthorizes the No Child Left Behind Act of 2001. In one of these briefs Pinkus (2009) proposed that:

There is an emerging consensus that the school improvement process should be systemic, led by states and districts, based on detailed information about student and school performance, and tailored to meet the individual needs of students and schools. (p. 1)

The point is: Federal and state policy must account for varying levels of school performance and contexts. Rowan, Correnti, Miller, and Camburn (2009) in their research on Comprehensive School Reform programs, focused on three determinants of program success: the nature of the problem, the nature of the program, and the social context. These determinants are relevant to policy making decisions focusing on school improvement: Not all low performing schools have the same contextual challenges. Rowan, et al. (2009) gave examples of differing social contexts that included:

The degree of conflict present over policy or goals, the coherence of the policy environment in which the change is attempted, the motivation and skill of the personnel 
implementing the program of intervention, and the organizational culture, climate, and authority structure under which implementing personnel work. (p. 20)

Therefore, the improvement process required by policy may be more effective by allowing for appropriate methods that are respectful of, and responsive to, these differing contexts. For example, high performing districts may be given more latitude and be permitted to submit abbreviated federal compliance documents such as those currently incorporated into the West Virginia Five Year Strategic Plan. This would allow these districts to focus more of their resources on progressive, experimental practices. Conversely, low performing districts may be required to adhere to a much more stringent process.

The process the four districts in this research used to develop their strategic plans may be instructive to federal policy makers as they develop accountability requirements, sanctions, and incentives. Current sanctions such as school choice and supplemental services may do little in terms of school improvement. They rely on indirectly pressuring schools to initiate improvement efforts. Restructuring, absent a defined and supportive proactive process, may also be ineffective. Without capacity building aimed at processes such as strategic planning, restructured school systems may just continue the "same old, same old" in a new skin. Tucci (2009), in another Alliance for Excellent Education policy brief, reiterated this by suggesting that transformation can only occur when a new vision for a school "is adopted and school leaders take ownership of a strategic improvement plan that is based on research and student data and implement that plan within a sufficient network of support and funding” (p. 2).

Pinkus (2009) observed that by 2008 most states had developed some type of comprehensive framework for school improvement. Similar to West Virginia's current format, these frameworks included tools such as templates, rubrics, and online protocols that walked 
schools and districts through the process of planning and implementation. Pinkus also concluded that "Comprehensive School Reform research and experience indicate that the process of choosing a restructuring strategy rivals the strategy itself in importance for successful change" (p. 2). This suggests that the teaming and decision-making processes themselves are as important to the success of implementation as the quality of the improvement model. In order for federal policy to support and require actions that result in effective school improvement, it may need to consider these types of frameworks and processes.

There are indications that federal policy may be moving in this direction. In 2008, the U.S. Department of Education initiated a pilot program that allowed eligible states to develop a "differentiated accountability system that would create a more nuanced system of distinguishing between schools in need of dramatic intervention, and those that are closer to meeting goals" (Pinkus, 2009, p. 5). A review of the proposals of the nine selected states showed that in describing strategies to be used with the lowest-performing schools, most states emphasized rigorous planning and decision-making processes. This included data analysis, needs assessments, diagnostic evaluations, and the involvement of teams of individuals.

Even more recent federal policy asks states to develop specific processes for low performing school. The Race to the Top Fund grant (2010), part of the American Recovery and Reinvestment Act, requires, as one of its broad goals, states to articulate a process for "turning around our lowest-achieving schools" (U. S. Department of Education, 2010, Program Description section). To be eligible for this funding states must develop a plan that “comprehensively and coherently addresses all of the four education reform areas . . in order to demonstrate that the state and its participating LEAs are taking a systemic approach to school reform” (U. S. Department of Education, 2009, p. 4). 
The process used to develop the WV five-year strategic plan, with appropriate changes to format and content, shows promise as a mechanism to improve schools identified as lowperforming. Adjusting the strategic planning process to district's varying contexts and pairing it with more aggressive approaches, such as restructuring, may be an improvement to NCLB's current methods.

State. State policy needs to create a process and document that is appropriate for high and low performing districts, in particular, as well as to take into consideration the variety of other demographic differences that exist among districts. Currently, in West Virginia public schools, the five-year on-line strategic plan is the most comprehensive process and document that is intended to "provide mechanisms to target resources strategically to the teaching and learning process to improve student, school and school system performance" (WVDE, 2007, section 18.1). State policy requires each public school and district to develop a five-year strategic plan. The requirement is the same for all districts regardless of performance status. The results of this research provide considerations for state policy makers about the planning process and the impact of context.

The four districts in this research, in general, had a positive view of this policy requirement, their development process, and its impact on their school districts. For example, it was described as generating a common purpose and promoting positive attitudes (A.3.6; F.4.6). The development process, which interviewees stated existed in their district prior to the current strategic planning requirement and would probably continue in its absence, was also highly regarded. Creating this level of acceptance in all school districts may be a challenge for state policy makers. Spillane's (1999) research showed that "in the LEAs that had developed rich understandings of substantive reform ideals, state policy was neither the source of this learning 
nor the primary impetus for change" (p. 564). This suggests that other circumstances, as in the case of the four districts in this research a predisposition to planning and school improvement, may be responsible for districts' performance.

Despite these districts' generally positive opinions, there were reservations about the WVDE strategic planning requirement. The interviewees in these districts voiced consistent criticism of the cumbersome nature of the document and the distraction and frustration created by the technical nature of the online format (F.3.7; H.2.5; F.2.5). Although these districts credited the WVDE with making significant technical improvements to the original electronic process and format, it was still the focus of the majority of the criticism. The sheer size of the document was also a concern (F.3.5). When districts spend too much of their available resources on paperwork to ensure that they meet state policy requirements they may never consider substantive school improvement ideas (Spillane, 1999).

The four districts in this research overcame these types of barriers. Other districts may not. By their nomination these districts were atypical. They had, by their own report, been involved in planning prior to the current policy requirement (F.3.2). They valued the process outside of the compliance mandate (H.2.6). Therefore, they may retain their existing or previous development process regardless of the state's format and content. An administrator in Gamble School District reflected this attitude: “I don't know that the five year plan has changed anything that we're doing in [Gamble] County because I believe we did a good job before the five year plan ever came into existence" (G.1.6).

Therefore, one recommendation based on this research addresses document size. The four districts in this research imply that a much briefer document would suffice (F.1.2). A balance needs to be achieved regarding the content and resultant size of the document. Too brief of a 
planning process and document may be problematic. School districts that lack the will and capacity may bastardize the process if the planning process and subsequent document are too brief. The next section discusses the will and capacity of districts.

"Rousing the will or motivation of local educators to reform is difficult" (Spillane, 1999, p. 558). Traditionally state policy makers have enforced compliance through a series of incentives and sanctions. A cognitive or constructivist perspective complicates the notion of cooperation with policy suggesting that it is not solely a matter of whether districts are rewarded or punished. Raising and sustaining the will of districts and schools may require more than an outside-in approach. To make a requirement, such as strategic planning, become a sustainable component of districts' and schools' practices may require a more pedagogical approach to state policy communication. A cognitive perspective would suggest professional development designed to build capacity that employs the fundamentals of constructivism, particularly, recognition of "where they are" as part of an effort to move them forward.

Currently the plan's content, format, and sequence appear to be used indirectly to encourage the plan development process. The steps and sequence of the plan most closely resemble the Cambridge Model for strategic planning. A specific planning process or model is not referenced however. WVDE training during the years that the five-year on-line strategic plan has been in place has focused primarily on the technical nature of the document, as well as its content. If the strategic plan document were to be significantly abbreviated, training could switch from an emphasis on compliance and technology to the development process.

Capacity building, support, technical assistance, and monitoring may need to occur to ensure that the development process and plan are developed with integrity, especially for low performing districts. This could challenge the capacity of a state department of education 
because the resources necessary to build capacity and support an effective planning process may exceed those necessary to ensure compliance with the completion of a document. However, a switch to an emphasis on process could have direct and indirect advantages.

One indirect advantage of a sustainable and generalizable process could be its broader impact, or spillover effect, on school improvement practices at both the district and school levels. Through organizational learning the process could improve the performance of a variety of school teams, such as leadership teams, literacy teams, and the ten-year comprehensive facilities plan committee. Organizational learning may be a more important consequence of the strategic planning process than the seemingly rigid and prescriptive objectives and actions steps these plans are more commonly known for.

Recommendations for practitioners. This section provides recommendations for practitioners, particularly those at the district level. The district level was selected for the focus of this research. Many state and federal education policies had focused on the individual school, instead of the district, as the most important setting for school improvement (Marsh, 2000). Recent research (McLaughlin \& Talbert, 2003) supported a focus on the school district as the unit of change.

Two recommendations for practitioners are offered based on the results of this research. First, districts need to recognize their own need for capacity building and organizational learning on several levels. Secondly, a greater recognition and understanding of the planning process may allow districts to remain focused on intent. A brief discussion of planning precedes these two points.

This research's purpose was to describe and develop understandings of the West Virginia Five-Year School System Strategic Plan development process. Planning, and more recently 
strategic planning, has been required in West Virginia public school systems for almost three decades now. Planning is also a requirement in many other states, yet its utility continues to be questioned (Conley, 1992). "Planning is an essential managerial function in schools, yet it is held in low regard. Why is this?" (Beach \& Lindahl, 2007, p. 20). Beach and Lindahl traced public school planning back to the 1960s and 1970s and found barriers similar to the findings in this research. These authors described planning as a formal, exhaustive process that: Typically produced voluminous plans, most of which were never implemented and did little more than collect dust on the school's, district's, and state department of education's collective shelves. In the subsequent two decades, one specific model of planning, strategic planning, dominated schools' planning agendas and practices, in many cases it was mandated by the state or by the school's accrediting agency. It too was highly demanding of time and resources, often without identifiable results. Consequently, it is not surprising that the word planning has taken on negative connotations in many school settings. (p. $19-20)$

The four districts in this research did not convey negative connotations about planning as a requirement, however, they did identify barriers similar to those described by Beach and Lindahl (2007). This raises a couple of questions: (a) What allowed these districts to remain true to the intent of the process and (b) How does this translate into recommendations for practitioners? The next sections will answer these questions.

First, districts may have to recognize their own need to build capacity and promote organizational learning on several levels. A simple example is the need to provide their teams with professional development on strategic planning. For this type of professional development, in addition to the content present in recent WVDE training, I recommend it includes an overview 
of planning styles and approaches emphasizing process in addition to content. This could be built into existing organizational learning practices or developed as an entirely new set of practices. An understanding of process could build capacity specifically for the strategic planning requirement and, as discussed in the preceding policy section, spill over into other teaming practices such as a district's leadership team, literacy teams, ten-year comprehensive facilities plan committee, and others.

A greater recognition and understanding of the planning process may also allow districts to remain focused on their intent and not be distracted by the barriers that arise, such as those identified in this research. By intent I mean a much broader scope than the core beliefs, goals and objectives enumerated in any specific plan. Intent, as used here, means school improvement on a systemic level.

Intent, in this more abstract sense, includes such things as the advantages identified by McLaughlin and Talbert (2003). These researchers identified four advantages to systemic planning. First, an ongoing planning process allows districts to be proactive instead of reactive to state and federal accountability pressures. Second, clear and consensual goals allow districts to grant significant authority to their teams, whether they are district level teams or school level teams. I add a caution here that administrators should be aware of both the strengths and limitations of consensual decision-making. In this sense, administrators and other team members need to be able to remove themselves from the process and take an objective and critical view of their teams' recommendations. Third, a well functioning process and team allows school improvement efforts to be sustainable through changes in leadership. Finally, the social and political advantages of the teaming process need to be recognized. These include, for example, the ability to achieve consensus and the resultant common purpose and positive attitudes 
identified in this research. These organizational attributes are important because the most innovative goals and objectives may not impact teaching and learning without the support of constituents at all levels.

Recommendations for future research. These case studies suggest several important topics for future research. Three potential areas for future research are strategic planning, leadership, and decision-making.

Additional qualititative research on strategic planning could occur at the school level. The present research findings resulted in mixed opinions about the strategic planning process and its effectiveness at the school level. A view of process at this level is important because school level planning efforts may have a greater opportunity to directly impact teaching and learning.

Because school improvement is the goal of strategic planning, additional studies investigating the long term effectiveness of strategic planning are needed. Longitudinal studies could focus on strategic plan content analysis, implementation, and evaluation. This research could use quantitative or qualitative methodology to evaluate the impact of implementation through measures such as student variables; achievement scores, grades, graduation rate, and attitudes, and staff variables; instructional practices and climate. Without demonstrating verifiable outcomes, the process and plan cannot be claimed to be more effective than any number of other resource consuming bureaucratic exercises.

Research investigating the interplay and integration of school and district level plans and planning processes is also recommended. For example, this research found two school districts with opposing views about whether a top-down, district lead process is the superior approach or whether school based planning should precede and drive district planning. Potential research questions would be: (a) What is the effect of school level strategic planning preceding and 
becoming the basis for district level planning? versus (b) What is the effect of district level planning preceding and establishing the overarching framework for school level planning?

A research topic in the area of leadership could be distributed leadership. A qualitative approach could contrast the leadership practices of high performing districts that are recognized for employing a quality strategic planning process with those of low performing districts with low rated planning practices to determine if distributed leadership contributes to their success.

The third potential area for future research is decision-making. Each of the districts in this research used a consensual approach. Consensus as an approach to decision-making may have both positive and negative consequences in relation to school improvement efforts. Additional qualitative research using direct observation may further our understanding of consensus as a social and political phenomenon occurring in the dynamic school environment. The decisions resulting from this process could be evaluated, for example, to judge their creativity, ingenuity, and outside-the-box thinking. Although an optimizing, rational approach to decision-making is desirable, future research's ability to describe a realistic approach to decision-making that considers leadership, social, political, and contextual factors may be more useful to both policy makers and practitioners. 


\section{References}

Adams, C.F. \& Mecca, T.V. (1990). Strategic planning as a basis for restructuring schools. Paper presented at the University Council for Educational Administration annual conference, Pittsburgh, PA. (ERIC Document Reproduction Service No. ED325925).

Adams, D. (1991). Planning models and paradigms. In R.V. Carlson \& G. Awkerman (Eds.), Educational planning: Concepts, strategies, and practices (pp. 5-20). New York: Longman.

Anderson, S.L. (1991). Planning in the District of Columbia public schools. In R.V. Carlson \& G. Awkerman (Eds.), Educational planning: Concepts, strategies, and practices (pp. 341-362). New York: Longman.

Auerbach, C. F. \& Silverstein, L. B. (2006). Qualitative data: An introduction to coding and analysis. New York: New York University Press.

Bell, W. (2004). Strategic planning in primary schools: A tale of no significance? Management Information Exchange, 18(4), 33-36.

Beach, R. H. \& Lindahl, R. A. (2007) The role of planning in the school improvement process. Educational Planning, 16(2), 19-43.

Bingham, W. D. (1996). Strategic planning: A process for restructuring the public schools and improving community support. Dissertations Abstracts International, 57, 04A.

Bracker, J. (1980). The historical development of the strategic management concept. Academy of Management Review. 5(2), 219-224.

Braybrook, D. \& Lindblom, C. E. (1963). The strategy of decision. New York: Free Press.

Brizee, H. A. (2008). Stasis theory as a strategy for workplace teaming and decision making. Journal of Technical Writing and Communication, 38(4), 363-385. 
Bryson, J. M. (1995). Strategic planning for public and nonprofit organizations: A guide to strengthening and sustaining organizational achievement. San Francisco, CA: JosseyBass.

Busler, B. S. (1992). The role of strategic planning and its effect on decision-making in Wisconsin public schools. Dissertations Abstracts International, 53, 07A.

Calderman, P. E. (1999, December) The decision dance: Staff decision making in a restructuring urban middle school. Urban Review, 31(4), 385-417.

Commission on Educational Quality and Equity. (1998, January). Providing a thorough and efficient system of schools: Quality and equity. Charleston, WV.

Conley, D.T. (1992). Strategic planning in America's schools: An exploratory study. Paper presented at the annual meeting of the American Educational Research Association, San Francisco, CA. (ERIC Document Reproduction Service No. ED345359).

Cook, W.J. (2001). Strategic planning for America's schools. Montgomery, AL: The Cambridge Group.

Cook, W.J. (2004, September). When the smoke clears. Phi Delta Kappan, 86(1), 73-75, 83.

Creswell, J. (1998). Qualitative inquiry and research design: Choosing among five traditions. London: Sage.

Cyert, R. M. \& March, J. G. (1963). A behavioral theory of the firm. Englewood Cliffs, NJ: Prentice-Hall.

Cyert, R. M. \& March, J. G. (1959). Modern organization theory. New York: Wiley

Davies, B. \& Ellison, L. (1998, November). Strategic planning in schools: An oxymoron [Electronic Version] School Leadership \& Management 18(4), 461-473. 
Distelzweig, H. \& Clark, C. (2006). Strategy formulation. Retrieved January 25, 2008 from http://www.referenceforbusiness.com/management/Sc-Str/Strategy-Levels.html

Dooris, M.J. (2002-2003). Two decades of strategic planning. Planning for Higher Education. $31(2), 26-32$.

Fahnestock, J. \& Secor, M. (1998). The stases in scientific and literary argument. Written Communication 5(9), 427-443.

Feek, K. P. (1999). Responding to change: Environmental scanning in strategic planning in Washington State schools. Dissertations Abstract International, 61, 02A.

Flick, U. (1998). An introduction to qualitative research. London: Sage.

Flick, U. (2002). An introduction to qualitative research ( $2^{\text {nd }}$ ed.). London: Sage.

Frederickson, J. W. (1983). Strategic process research: Questions and recommendations. Academy of Management Review, 8(4), 565-575.

Friedman, J. \& Hudson, B. (1974). Knowledge and action: A guide to planning theory. Journal of the American Planning Association, 40(1), 8-42.

Fullan, M. (2008, April 9). School leadership's unfinished agenda. Education Week, (28), 36, 28.

Garman, N. B. (1994). Qualitative inquiry: Meaning and menace for educational researchers. Keynote speech presented at the Mini-conference on Qualitative Research, Flinders Institute for the Study of Teaching, Adelaide, Australia.

Garman, N. B. \& Piantanida, M. (1999). The qualitative dissertation: A guide for students and faculty. Thousand Oaks, California: Corwin Press.

Glaser, B. G. \& Strauss, A. L. (1967). The discovery of grounded theory: Strategies for qualitative research. New York: Aldine Publishing Company.

Glesne, C. (2003). Becoming qualitative researchers: An introduction. Boston: Pearson. 
Goertz, M.E., Floden, R.E., \& O’Day, J. (1995, July). Studies of education reform: Systemic reform. Retrieved April 11, 2008 from http://www.ed.gov/pubs/SER/SysReform/index.html

Hambright, G. \& Diamantes, T. (2004, Fall). An analysis of prevailing K-12 educational strategic planning models. Education, 125(1), 97-103.

Hamel, G. \& Prahalad, C.K. (1989, May/June). Strategic intent. Harvard Business Review, 83(7), $148-161$.

Hazi, H. M. (1982, September). A grounded theory study using a cache of documents to explicate legal control of supervisory practice in Pennsylvania. The Researcher, 1(1), n.p.

Hayden, J.G. (1993). Strategic planning: It's essential for rural schools. If you fail to plan, you plan to fail. Paper presented at the annual conference of the National Rural Education Association, Burlington, VT. (ERIC Document Reproduction Service No. ED 364393).

Hoff, D. J. (2007, October 24). Bush says he would veto NCLB reauthorization bill that lacked key elements. Education Week, 27(9), 12.

Honig, M. I. (2007). Policy implementation and learning: How organizational and sociocultural learning theories elaborate district central office roles in complex educational improvement efforts. Seattle, WA: University of Washington, Center for the Study of Teaching and Policy.

Hoy, W. K. \& Miskel, C. G. (2005). Educational administration: Theory, research, and practice ( $7^{\text {th }}$ ed.). New York: McGraw-Hill.

Huff, A. S. \& Reger, R. K. (1987). A review of strategic process research. Journal of Management, 13(2), 211-236. 
Jackson, C., Blamick, W.E., \& Morrison, J.L. (1989). Planning for the future of the Orange County public schools. Paper presented to the sixth general assembly of the World Future Society, Washington, DC. (ERIC Document Reproduction Service No. ED309566).

Jackson, D. R. (2006). Negotiating strategic change in a small suburban school district: The concept of a systems leader. Dissertation Abstracts International, 67, 05A.

Jobs through Education Act, WV Stat. Ann. § 18-1-4, 6; § 18-2E-4, 5, 7, 8; § 18B-1-1e (LexisNexis, 1997).

Johnson, G. (1990). Managing strategic change: The role of symbolic action. British Journal of Management, 1, 183-200.

Johnson, J. A. (2004). Strategic planning in the Millard Public Schools 1989 - 2003. Dissertations Abstract International, 65, 09A. (UMI No. 3147144).

Kalan, N.T. \& Kinzer, S.M. (1991). Planning in the Broward County (Florida) public schools. In R.V. Carlson \& G. Awkerman (Eds.), Educational planning: Concepts, strategies, and practices (pp. 341-362). New York: Longman.

Kameda, T., Tindale, R. S., \& Davis, J. H. (2003). Cognitions, preferences, and social sharedness: Past, present, and future directions in group decision making. In Schneider, S. L. \& Shanteau, J. (Eds.) Emerging perspectives on judgment and decision making. Cambridge, MA: Cambridge University Press.

Kaplan, A. (1964). The conduct of inquiry: Methodology for behavioral science. San Francisco: Chandler Publishing Co.

Kaufman, R. \& Herman. J. (1991). Planning in education: Rethinking, restructuring, revitalizing. Lancaster, PA: Technomic. 
Katz, D. \& Kahn, R. L. (1966). The social psychology of organizations. New York: John Wiley \& Sons.

Kennedy, M. (2005). Inside teaching: How classroom life undermines reform. Cambridge, MA: Harvard University Press.

Knight, J. (1997). Strategic planning for school managers. London: Kogan Page.

Krathwohl, D. R. (1998). Methods of educational and social science research ( $2^{\text {nd }}$ ed.). Long Grove, Illinois: Waveland Press.

Kondracke, M. (2008, April 8). A nation still at risk. The Exponent Telegram, p. A4.

March, J. G. (1966). Varieties in political theory. Englewood Cliffs, NJ: Prentice-Hall.

Marsh, J. A. (2000, September). Connecting districts to the policy dialogue: A review of literature on the relationship of districts with states, schools, and communities. Seattle, WA: University of Washington, Center for the Study of Teaching and Policy.

Marshall, C. \& Rossman, G.B. (1995). Designing qualitative research ( $2^{\text {nd }}$ ed.). Thousand Oaks, CA: Sage.

Mayo, D.T. (2006). Strategic planning tools. Retrieved January 25, 2008 from http://www.referenceforbusiness.com/management/Sc-Str/Strategy-Levels.html

McLaughlin, M. \& Talbert, J. (2003, September). Reforming districts: How districts support school reform. Seattle, WA: University of Washington, Center for the Study of Teaching and Policy.

Mendenhall, M.E. (2006). Strategic planning failure. Retrieved January 25, 2008 from http://www.referenceforbusiness.com/management/Sc-Str/Strategy-Levels.html Merriam, S. B. (1988). Case study research in education: A qualitative approach. San Francisco: Jossey-Bass. 
Merriam, S. B. (1998). Qualitative research and case study applications in education. San Francisco: Jossey-Bass.

Miles, M. B. \& Huberman, A. M. (1994). Qualitative data analysis: An expanded sourcebook ( $2^{\text {nd }}$ ed.). Thousand Oaks, CA: Sage.

Miller, R. \& Buttram, J. L. (1991). Collaborative planning: Changing the game rules. In R. V. Carlson \& G. Awkerman (Eds.) Educational planning: Concepts, strategies, and practices (pp. 279-294). New York: Longman.

Mintzberg, H. (1994). The rise and fall of strategic planning. New York: The Free Press.

Mintzberg, H. (1983). Power in and around organizations. Englewood Cliffs, NJ: Prentice-Hall. Moldof, E.P. (1993). Schools and strategic planning: Using a traditional business tool. School Business Affairs, 59(2), 21-24.

Monzo, K. K. (2007, December 5). America idles on international reading test. Education Week, 27(14), 11.

New Jersey Board of Education. (2003). Strategic plan for improvement in public education in the state of New Jersey [Electronic Version]. Trenton, NJ.

Oram, C. D. (1997). The central office and school restructuring. Dissertations Abstract International, 58, 10A.

Ouchi, W. G. (1981). Theory z: How American business can meet the Japanese challenge. Reading, MA: Addison-Wesley.

Patton, M. Q. (1990). Qualitative evaluation and research methods (2 ${ }^{\text {nd }}$ ed.). Newbury Park, CA: Sage.

Patton, M. Q. (2002). Qualitative evaluation and research methods (3 ${ }^{\text {rd }}$ ed.). Newbury Park, CA: Sage. 
Pauley v. Bailey, 174 W. Va. 167; 324 S. E.2d 128 (1984)

Peshkin, A. (1988). In search of subjectivity--One's own. Educational Researcher, October, 1721.

Peters, T. J. \& Waterman, R. H., Jr. (1982). In search of excellence: Lessons from America's best-run companies. New York: Harper \& Row.

Pinkus, L. M. (2009, April). Action required: Addressing the nation's lowest-performing high schools. Alliance for Excellent Education (Policy Brief). Washington, DC.

Pressman, J. L. \& Wildavsky, A. (1984). Implementation (3rd ed.). Berkeley, CA: University of California Press.

Reeves, D. B. (2007/2008, December/January). Making strategic planning work. Educational Leadership, 65(4), 86-87.

Resnick, L. B. \& Hall, M. W. (1998, Fall). Learning organizations for sustainable education reform. Daedalus, 127(4), 89-119.

Riley, R. W. \& Peterson, T. K. (2008, September 24). Before the 'either-or' era. Education Week, 28(5), 1.

Rowan, B., Correnti, R., Miller, R. J., \& Camburn, E. M. (2009, August). School improvement by design: Lesson from a study of comprehensive school reform progress. Philadelphia, PA: Consortium for Policy Research in Education.

Schein, E. H. (2004). Organizational culture and leadership (3rd ed.). San Francisco, CA: Jossey-Bass.

Schmoker, M. (2004, September). Learning communities at the crossroads: Toward the best schools we've ever had. Phi Delta Kappan, 86(1), 84-88. 
Schneider, S. L. \& Shanteau, J. (2003). Introduction: Where to decision making. In Schneider, S. L. \& Shanteau, J. (Eds.) Emerging perspectives on judgment and decision making . Cambridge, MA: Cambridge University Press.

Senge, P. M. (1990). The fifth discipline: The art and practice of the learning organization. New York: Doubleday.

Selznick, P. (1948). Foundation of the theory of organization. American sociological review, $1948,13,25-35$.

Shafritz, J. M., Ott, J. S., \& Jang, Y. S. (Eds.) (2005). Classics of organizational theory (6 ${ }^{\text {th }}$ ed.). Belmont, CA: Wadsworth.

Sloane, R. L. (2003). Perceptions of organizational learning resulting from strategic planning in a private educational institution. Dissertations Abstract International, 64, 07A.

Soltis, J. (1984). On the nature of educational research. Educational Researcher, 13(10), 5-10.

Spillane, J. (1999). A cognitive perspective on the role of the local educational agency in implementing instructional policy: Accounting for local variability. Educational Administrative Quarterly, 34(1), 31-57.

Spillane, J. (1999). State and local government relations in the era of standards-based reform: Standards, state policy instruments, and local instructional policy making. Educational Policy, 13(4), 546-572.

Spillane, J. Reiser, B. J., \& Reimer, T. (2002). Policy implementation and cognition: Reframing and refocusing implementation research. Review of Educational Research, 72(3), 387431.

Spillane, J. (2004) Distributed leadership: What's all the hoopla? Retrieved September 13, 2009 from www.northwestern.edu/ipr/publications/.../Spillane_DistribLead.pdf. 
Stake, R.E. (1995). The art of case study research. Thousand Oaks, CA: Sage.

Strauss, A. L. (1990). Basics of qualitative research: Grounded theory procedures and techniques. Newbury Park, CA: Sage.

Supovitz, J. A. (2006). The case for district based reform: Leading, building, and sustaining school improvement. Cambridge, MA: Harvard Education Press.

Supovitz, J. A. (2007, November 28). Why we need district-based reform: Supporting systemwide instructional improvement. Education Week, (27), 27-28.

Tucci, T. N. (2009, July). Whole-school reform: Transforming the nation's low-performing high schools. Alliance for Excellent Education (Policy Brief). Washington, DC.

Tyack, D. \& Cuban, L. (1995). Tinkering toward utopia: A century of public school reform. Cambridge, MA: Harvard University Press.

United States Department of Education. (2009). Race to the top program executive summary. Retrieved January 18, 2010, from http://www.ed.gov/programs/racetothetop/resources United States Department of Education. (2010). Race to the top fund. Retrieved January 18, 2010, from http://www.ed.gov/programs/racetothetop/resources

Vincent, T. J. (1992). School district improvement through strategic planning: A case study. Dissertations Abstract International, 53, 11A. (UMI No. 9234859).

Weick, K. E. (1976, March). Educational organizations as loosely coupled systems. Administrative Science Quarterly, 21, 1-19.

Weiss, R.S. (1994). Learning from strangers: The art and method of qualitative interview studies. New York: Free Press

West Virginia Board of Education. (1981). Standards for educational quality (2320). Charleston, WV. 
West Virginia Board of Education. (1983). A master plan for public education. Charleston, WV.

West Virginia Board of Education. (1992). Performance based accreditation system: High quality standards, annual performance measures, annual improvement plan, on-site review (2320). Charleston, WV.

West Virginia Board of Education. (2007). A process for improving education: Performance based accreditation system (2320). Charleston, WV.

West Virginia Board of Education. (2007). Assuring the quality of education: Regulations for education programs (2510). Charleston, WV.

West Virginia Department of Education. (1990). Training manual and handbook for on-site reviews. Charleston, WV.

West Virginia Department of Education. (1997). Guidelines for development of the unified county improvement plan. Charleston, WV.

West Virginia Department of Education. (2009). WVDE online strategic planning professional development. Retrieved October 31, 2009, from West Virginia Department of Education Web site: https://sites.google.com/a/wvde.k12.wv.us/wvde-online-strategic-planningprofessional-development-2-0.

W. Va. Code, § 18-2E-5, A Performance Based Accreditation System, 1988.

West Virginia School Laws Annotated. § 18-2E-5 (Lexis/Nexis, 2007).

Western Institute for Research and Evaluation (WIRE). (1993, August). A statewide study of strategic planning in Utah's public schools: Current status and recommendations for the future. Logan, UT.

Woods, K. L. \& Woods, S. H. (1981). Are corporate strategic planning techniques useful in public higher education? Cullowhee, NC: Western Carolina University, Office of 
Institutional Studies and Planning. (ERIC Document Reproduction Service No. ED212215).

Yanchar, S. C. \& Williams, D. D. (2006, December). Reconsidering the compatibility thesis and eclecticism: Five guidelines for method use. Educational Researcher, 39(9), 3-12.

Yin, R. K. (1984). Case study research: Design and methods (Applied social research methods series, Vol. 5). Beverly Hills, CA: Sage.

Yin, R. K. (2003). Case study research: Design and methods (Applied social research methods series, Vol. 5) ( $3^{\text {rd }}$ ed.). Beverly Hills, CA: Sage. 
Appendix A

Interview Protocol and Questions 


\section{Interview Protocol}

\section{Script:}

Hello, my name is Vic Fisher. I am a doctoral student in West Virginia University's educational leadership program. The primary investigator for this research is my committee chairperson, Dr. Helen Hazi, a professor in educational leadership. West Virginia University's acknowledgement for this research is on file. Participants in this study must be 18 years of age and older.

Thank you for agreeing to participate in this research of the five year school system strategic plan. Interviewing individuals, such as you, who participated in the five year school system strategic planning process will help me investigate how school districts develop these plans. The information gathered in my research will be used in my doctoral dissertation.

Your participation is entirely voluntary. You may refuse to participate, quit at any time, or skip any question with no negative affect to your employment status. You have my assurance that confidentiality will be maintained throughout the data collection and reporting processes.

The purpose of this research is to describe the styles and methods your county used during this process. I am interested in learning about the process your county used to develop its plan. The first set of questions will focus primarily on the development of the plan. The second set of questions will ask your opinion of the strategic planning process. In conclusion, I will ask if you have anything you want to add that we have not talked about. I may also contact you at a later date if questions arise about this interview. Please feel free to contact me if you have any questions or additional thoughts.

Do I have your permission to record this interview and take notes to ensure the accuracy of your responses? yes no Do you have any questions before we begin?

County school system:

Name of subject:

Location, date and time of interview: 1

Job title:

Number of years in this position:

Number of years in this county school system:

Number of years in PreK-12 education:

Number of years a member of the five year plan committee:

Certifications held:

Degrees held:

Gender: 


\section{Interview Questions}

\section{- Probes}

\section{Plan Development}

1. Describe the development process your county used to create its Five Year School System Strategic Plan.

- What were your responsibilities in this process?

- Tell me about the leadership that occurred during your team's meetings.

- How did your team arrive at its broader goals and objectives?

- Were your plan's components developed primarily by individuals, departments, or by the team?

- Do you feel that individual team member's opinions and ideas were given due consideration?

- (If so) Please describe an example.

- If there were any conflicts, differences of opinion, and subsequent decisions to be made how did your team address these?

$\circ$ (If so) Please describe an example.

- What steps do you perceive as necessary in the plan development process?

$\circ$ Did your team include any components in the plan that were not part of the WVDE's original format?

- Was there anything different about your county's development process than you expected?

- Were there any particularly creative, surprising, or novel goals or initiatives that came out of this process?

2. a. What background and experiences were helpful for the individuals in this process?

b. What facilitated the team's planning process?

- Can you give me some specific examples?

- Did your team members have prior planning experience?

- What type of strategic planning professional development did your team receive?

- Did you have sufficient meeting time?

- Were team members' schedules flexible enough to arrange team meeting times?

- Did your team appear to value this process and its purpose?

3. What barriers or challenges did you face during this process?

- Can you give me some specific examples?

- What bearing does time have on the team planning process?

- Were your team members sufficiently trained and prepared for the planning process?

- Were there any naysayers about the strategic plan requirement or the process?

\section{Perception of the Process}

1. What were the intended outcomes of the planning process and how are they assessed?

2. What is your opinion of the process your county used to develop the plan? 
- Since you've been in strategic planning as a group, have you had the opportunity to discuss it and improvements to the process?

- What types of changes, if any, would you recommend?

- What do you think the ideal strategic plan development process should look like?

3. What is your opinion of the requirement that each county school system develop a five year school system strategic plan?

4. How effective do you feel the five year school system strategic plan is as a process and instrument to achieve school system improvement?

- What do you think have been the benefits to the improvement process at the school level?

- What do you think the impact has been on teaching and learning?

\section{Closing}

1. Is there a specific person in your county that you suggest I interview to help further my understanding of your county's plan development process?

2. Do you have anything you want to add that we have not talked about? 
Appendix B

Interview Question Matrix 
Interview Question Matrix

\begin{tabular}{|c|c|c|c|}
\hline \multicolumn{4}{|l|}{ Plan Development } \\
\hline Interview Question & Research Question & Literature Cite & Anticipated Responses \\
\hline $\begin{array}{l}\text { 1. Describe the } \\
\text { development process your } \\
\text { county used to create its } \\
\text { Five Year School System } \\
\text { Strategic Plan. }\end{array}$ & 1,2 & $\begin{array}{l}\text { Conley (1992); Cook (2001); } \\
\text { WIRE (1993) }\end{array}$ & $\begin{array}{l}\text { A team of professionals meets } \\
\text { several times. Vision, mission, } \\
\text { goals, action steps are developed. } \\
\text { Draft is prepared and reviewed. The } \\
\text { contrast between sites may be a top- } \\
\text { down vs. bottom-up development } \\
\text { process. }\end{array}$ \\
\hline $\begin{array}{l}\text { 2. a. What background and } \\
\text { experiences were helpful } \\
\text { for the individuals in this } \\
\text { process? } \\
\text { b. What types of resources } \\
\text { were helpful in this } \\
\text { process? }\end{array}$ & 3 & $\begin{array}{l}\text { Adams \& Mecca (1990); Cook } \\
(2001)\end{array}$ & $\begin{array}{l}\text { Individuals - prior experience and } \\
\text { knowledge, access to data, } \\
\text { technological prowess, training } \\
\text { session attendance, leadership skill, } \\
\text { consensus building/decision } \\
\text { making, commitment and interest. } \\
\text { Resources - team planning sessions, } \\
\text { time allotments or schedules, } \\
\text { technology. }\end{array}$ \\
\hline $\begin{array}{l}\text { 3. What barriers or } \\
\text { challenges did you face } \\
\text { during this process? }\end{array}$ & 3 & $\begin{array}{l}\text { Adams \& Mecca (1990); Cook } \\
\text { (2001); WIRE (1993) }\end{array}$ & $\begin{array}{l}\text { Concrete items - plan format, } \\
\text { technology, time restrictions, or } \\
\text { competing duties. } \\
\text { Interpersonal/Political -group } \\
\text { dynamics, political agendas, lack } \\
\text { of leadership, planning process may } \\
\text { be viewed as a compliance exercise. }\end{array}$ \\
\hline
\end{tabular}




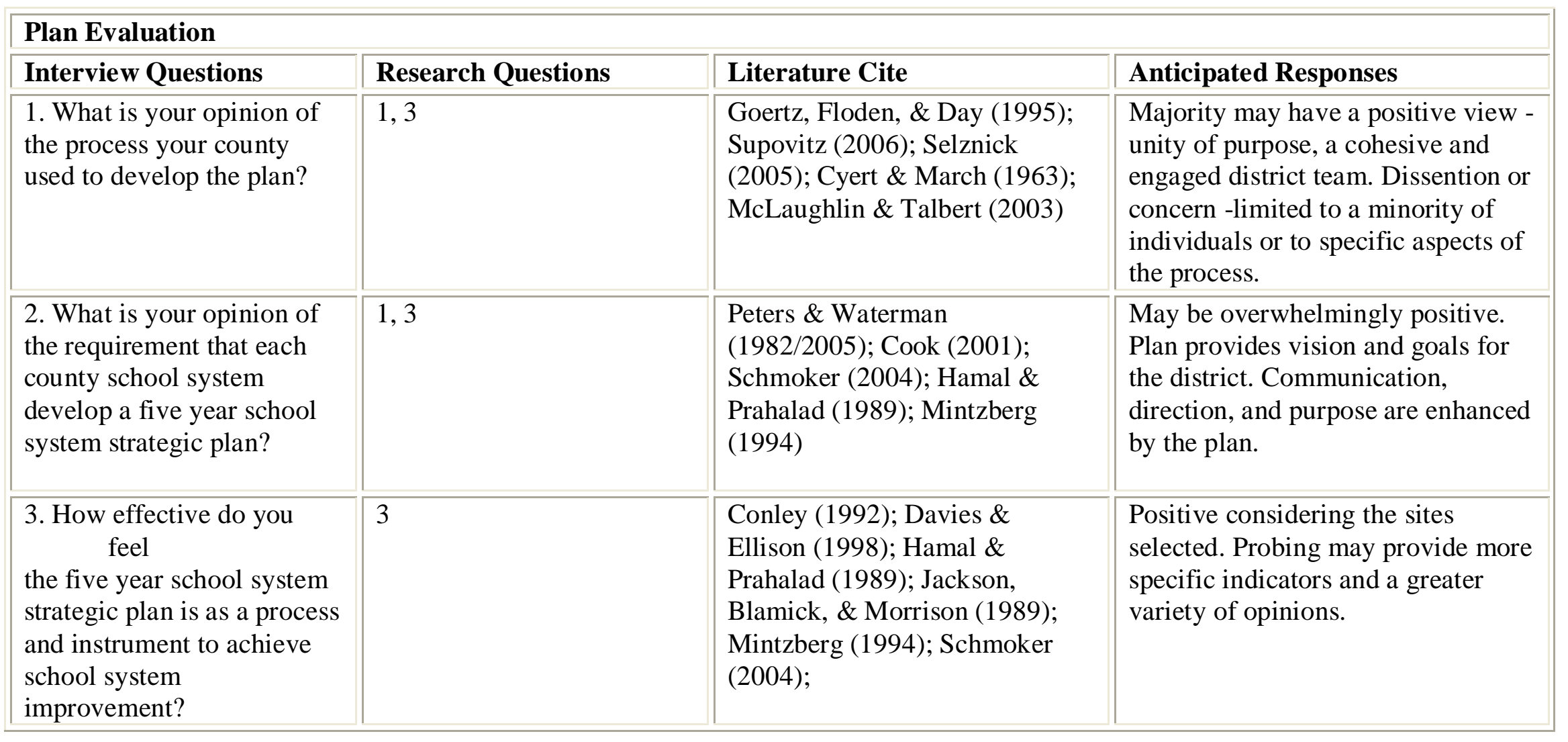


Appendix C

Investigative, Coding, and Analytic Approaches to Research Questions and Prominent Theoretical Concepts 


\section{Investigative, Coding, and Analytic Approaches to Research Questions and Prominent Theoretical Concepts}

\begin{tabular}{|c|c|c|c|c|c|c|c|}
\hline $\begin{array}{l}\text { Research } \\
\text { Question(RC)/Theoretical } \\
\text { Concept(TC) }\end{array}$ & $\mathbf{R C}$ & TC & $\begin{array}{l}\text { Source: } \\
\text { Interview(I)/Document(D) }\end{array}$ & $\mathbf{I}$ & D & $\begin{array}{l}\text { Coding Examples } \\
\text { (Tentative) }\end{array}$ & Analysis/Interpretation \\
\hline \multicolumn{8}{|l|}{ Research Questions } \\
\hline $\begin{array}{l}\text { How do county office } \\
\text { personnel develop the WV } \\
5 \text { yr. school system } \\
\text { strategic plan? } \\
\text { Dynamic complexity }\end{array}$ & $X$ & $\mathrm{X}$ & & $\begin{array}{l}X \\
X\end{array}$ & & & $\begin{array}{l}\text { Multiple-case report } \\
\text { describing, portraying, and } \\
\text { summarizing within-case } \\
\text { and cross-case analyses }\end{array}$ \\
\hline $\begin{array}{l}\text { What styles of } \\
\text { development do they use? }\end{array}$ & $X$ & & $\begin{array}{l}\text { Describe the development } \\
\text { process... } \\
\text { What steps do you } \\
\text { perceive...? } \\
\text { What components are } \\
\text { contained in the plan? }\end{array}$ & $\begin{array}{l}X \\
X\end{array}$ & $\mathrm{X}$ & MC = Cambridge Model & $\begin{array}{l}\text { Existing model or novel } \\
\text { process? }\end{array}$ \\
\hline $\begin{array}{l}\text { What are the facilitators } \\
\text { and barriers to } \\
\text { development? }\end{array}$ & $\mathrm{X}$ & & $\begin{array}{l}\text { What background and } \\
\text { experiences were } \\
\text { helpful...? } \\
\text { What types of resources } \\
\text { were helpful...? } \\
\text { What barriers or challenges } \\
\text { did you face...? }\end{array}$ & $\begin{array}{l}X \\
X \\
X\end{array}$ & & $\begin{array}{l}\text { If a Facilitator }= \\
\text { Code }+(\mathrm{F}) \\
\text { If a Barrier }=\text { Code }+(\mathrm{B}) \\
\text { Pr = Prior Strategic } \\
\text { Planning } \\
\text { PD = Professional Dev. } \\
\text { Tm= Time } \\
\mathrm{R}= \\
\text { Resources/Material/Data } \\
\text { E = } \\
\text { Emphasis/Leadership } \\
\text { Ex = Experience }\end{array}$ & $\begin{array}{l}\text { Descriptions, portrayals, } \\
\text { and commentary on effect. }\end{array}$ \\
\hline
\end{tabular}




\begin{tabular}{|c|c|c|c|c|c|c|}
\hline \multicolumn{7}{|c|}{ Theoretical Concepts/Categories } \\
\hline Bottom-up vs. Top-down & $\mathrm{X}$ & $\begin{array}{l}\text { Describe the development } \\
\text { process... } \\
\text { Describe the leadership that } \\
\text { occurred... } \\
\text { What were your } \\
\text { responsibilities...? } \\
\text { What is your opinion of the } \\
\text { process...? } \\
\text { What types of changes...? } \\
\text { What do you think ideal } \\
\text { plan...? }\end{array}$ & $\begin{array}{l}X \\
X \\
X \\
X \\
X \\
X\end{array}$ & & $\begin{array}{l}\mathrm{BU}=\text { Bottom-up } \\
\mathrm{TD}=\text { Top-down }\end{array}$ & $\begin{array}{l}\text { Portrayal/characterization } \\
\text { of leadership style. }\end{array}$ \\
\hline Loose-Tight Properties & $\mathrm{X}$ & $\begin{array}{l}\text { Describe the development } \\
\text { process... } \\
\text { Describe the leadership that } \\
\text { occurred... } \\
\text { What were your } \\
\text { responsibilities...? } \\
\text { What is your opinion of the } \\
\text { process...? } \\
\text { What types of changes...? } \\
\text { What do you think ideal } \\
\text { plan...? }\end{array}$ & $\begin{array}{l}X \\
X \\
X \\
X \\
X \\
X\end{array}$ & & $\begin{array}{l}\mathrm{L}=\text { Loose } \\
\mathrm{Tg}=\text { Tight }\end{array}$ & $\begin{array}{l}\text { Portrayal/characterization } \\
\text { of leadership style. }\end{array}$ \\
\hline $\begin{array}{l}\text { Coherence vs. } \\
\text { Fragmentation }\end{array}$ & $\mathrm{X}$ & $\begin{array}{l}\text { (Prior concept's questions } \\
\text { plus) } \\
\text { Are the goals and } \\
\text { objectives in the plan } \\
\text { shared or departmental? }\end{array}$ & $\mathrm{X}$ & X & $\begin{array}{l}\mathrm{S}=\text { Shared (Coherence) } \\
\mathrm{D}=\text { Departmental } \\
\text { (Fragmented) }\end{array}$ & $\begin{array}{l}\text { Portrayal/characterization } \\
\text { of process and document's } \\
\text { integration or lack thereof. }\end{array}$ \\
\hline Distributed & $\mathrm{X}$ & $\begin{array}{l}\text { Tell me about the } \\
\text { leadership...? } \\
\text { Were your plan's } \\
\text { components developed...? }\end{array}$ & $\begin{array}{l}X \\
X\end{array}$ & & Ds $=$ Distributed & Portrayals/examples \\
\hline
\end{tabular}




\begin{tabular}{|c|c|c|c|c|c|c|}
\hline \multicolumn{7}{|l|}{ Motivation } \\
\hline Egalitarianism & $\mathrm{X}$ & $\begin{array}{l}\text { What were your } \\
\text { responsibilities...? } \\
\text { What was different...than } \\
\text { you expected? } \\
\text { What is your opinion of the } \\
\text { process...? } \\
\text { What do you think ideal } \\
\text { plan process...? }\end{array}$ & $\begin{array}{l}X \\
X \\
X \\
X\end{array}$ & & $\begin{array}{l}\mathrm{V}=\text { Contributions } \\
\text { valued (egalitarianism) } \\
\text { Ig = Contributions } \\
\text { ignored/not solicited }\end{array}$ & Portrayals, commentary \\
\hline Equifinality & $\mathrm{X}$ & $\begin{array}{l}\text { How do site styles } \\
\text { compare/contrast? } \\
\text { How do document goals } \\
\text { compare/contrast? }\end{array}$ & $\mathrm{X}$ & $X$ & & $\begin{array}{l}\text { Cross-case analysis, } \\
\text { description, commentary }\end{array}$ \\
\hline \multicolumn{7}{|c|}{ Decision Making } \\
\hline Consensual & $\mathrm{X}$ & $\begin{array}{l}\text { How did your team arrive } \\
\text { at its broader goals...? } \\
\text { If there were any conflicts, } \\
\text { differences of opinion...? }\end{array}$ & $\begin{array}{l}X \\
X\end{array}$ & & $\mathrm{C}=$ Consensual & Description, portrayals \\
\hline Co-optation & $\mathrm{X}$ & $\begin{array}{l}\text { Describe the development } \\
\text { process... } \\
\text { What is your opinion of the } \\
\text { process...? } \\
\text { What types of changes...? } \\
\text { What do you think the ideal } \\
\text { plan process...? }\end{array}$ & $\begin{array}{l}X \\
X \\
X \\
X\end{array}$ & & $\begin{array}{l}\text { Lk = Lacks } \\
\text { impact/business as usual } \\
\text { Im = Impacted org. } \\
\text { Co = Co-opting }\end{array}$ & Description, portrayals \\
\hline Satisficing & $\mathrm{X}$ & $\begin{array}{l}\text { How effective do you feel } \\
\text { the plan is...? } \\
\text { Are goals typical/within } \\
\text { tradition or do they } \\
\text { maximize? }\end{array}$ & $X$ & $\mathbf{X}$ & $\begin{array}{l}\mathrm{Tr}=\text { Typical/traditional } \\
\mathrm{Ag}= \\
\text { Aggressive/innovative } \\
\text { St = Satisficing }\end{array}$ & $\begin{array}{l}\text { Portrayals/examples, } \\
\text { commentary }\end{array}$ \\
\hline
\end{tabular}




\begin{tabular}{|c|c|c|c|c|c|c|}
\hline Incrementalism & $\mathrm{X}$ & $\begin{array}{l}\text { Do the plan } \\
\text { goals/objectives, based on a } \\
\text { year to year comparison, } \\
\text { reflect gradual increases } \\
\text { and revisions or are there } \\
\text { leaps in standards and/or } \\
\text { initiatives? }\end{array}$ & & $\mathbf{X}$ & $\begin{array}{l}\text { In = Incremental } \\
\text { Nv = Novel, creative, } \\
\text { without a pattern }\end{array}$ & $\begin{array}{l}\text { Portrayals, interpretive } \\
\text { commentary }\end{array}$ \\
\hline \multicolumn{7}{|l|}{ Communication } \\
\hline $\begin{array}{l}\text { Constructivist/Cognitive } \\
\text { Vs. } \\
\text { Behavioral }\end{array}$ & & $\begin{array}{l}\text { What were the intended } \\
\text { outcomes...? } \\
\text { What is your opinion of the } \\
\text { process...? } \\
\text {...have you had the } \\
\text { opportunity to discuss...? } \\
\text { How effective do you } \\
\text { feel...? }\end{array}$ & $\begin{array}{l}X \\
X\end{array}$ & & $\begin{array}{l}\text { De = Deliberate } \\
\text { Ic = Incidental }\end{array}$ & Description, commentary \\
\hline
\end{tabular}


Appendix D

Interviewee Demographics 
Interviewee Demographics

\begin{tabular}{|c|c|c|c|c|c|c|c|c|c|}
\hline County & Initials & Sex & Title & $\begin{array}{l}\text { Yrs in } \\
\text { Title }\end{array}$ & $\begin{array}{l}\text { Yrs. } \\
\text { County }\end{array}$ & $\begin{array}{l}\text { Yrs. K- } \\
12 \\
\end{array}$ & $\begin{array}{l}\text { Str Plan } \\
\text { Yrs }\end{array}$ & Cert & Degrees \\
\hline Gamble & G.S. & $\mathrm{F}$ & Asst. Supt. & 4 & 24 & 31 & 5 & $\begin{array}{l}\text { Supt. } \\
\text { Supr. } \\
\text { Princ. } \\
\text { Sp. Ed. }\end{array}$ & $\mathrm{MA}$ \\
\hline Gamble & K.M. & $\mathrm{F}$ & Sp Ed Dir & 5 & 24 & 30 & 5 & $\begin{array}{l}\text { Sp Ed } \\
\text { English } \\
\text { SLP }\end{array}$ & MA \\
\hline Gamble & A.S. & $\mathrm{F}$ & $\begin{array}{l}\text { Dir, Title } \\
\text { Services }\end{array}$ & 4 & 33 & 33 & 5 & $\begin{array}{l}\text { Supt } \\
\text { Supr } \\
\text { Princ } \\
\text { Lang Arts }\end{array}$ & MA \\
\hline Fusion & M.W. & $F$ & Sp Ed Dir & 3 & 8 & 8 & 3 & $\begin{array}{l}\text { Supt } \\
\text { Supr } \\
\text { Princ } \\
\text { Sp Ed } \\
\text { Attend } \\
\text { Pre-K }\end{array}$ & MA \\
\hline Fusion & J.D. & $M$ & Treasurer & 12 & 12 & 12 & 5 & $\begin{array}{l}\text { Supt } \\
\text { Supr } \\
\text { Princ } \\
\text { Sch B Off }\end{array}$ & MA \\
\hline Fusion & J.H. & $M$ & Supt. & 3 & 21 & 30 & 4 & $\begin{array}{l}\text { Supt } \\
\text { Supr } \\
\text { Princ } \\
\text { Soc St }\end{array}$ & MA \\
\hline Fusion & R.D. & $\mathrm{F}$ & Principal & 3 & 30 & 30 & 5 & $\begin{array}{l}\text { Supt } \\
\text { Supr } \\
\text { Princ } \\
\text { Elem } \\
\text { Math }\end{array}$ & MA \\
\hline Fusion & S.B. & $\mathrm{F}$ & Dir, C \& I & 29 & 41 & 41 & 5 & $\begin{array}{l}\text { Supt } \\
\text { Supr } \\
\text { Princ } \\
\text { Elem }\end{array}$ & MA \\
\hline Academy & D.V. & $\mathrm{F}$ & Asst.Supt. & 4 & 25 & 27 & 5 & $\begin{array}{l}\text { Supt } \\
\text { Supr } \\
\text { Princ } \\
\text { Math } \\
\text { Elem }\end{array}$ & Ed.D. \\
\hline Academy & L.S. & $\mathrm{F}$ & $\begin{array}{l}\text { Sp Ed } \\
\text { Coord }\end{array}$ & 5 & 9 & 9 & 5 & $\begin{array}{l}\text { Supt } \\
\text { Supr } \\
\text { Princ } \\
\text { Elem } \\
\text { Sp Ed }\end{array}$ & MA \\
\hline Academy & K. F. & $\mathrm{F}$ & $\begin{array}{l}\text { Dir, Hum } \\
\text { Res; } \\
\text { General } \\
\text { Counsel }\end{array}$ & 17 & 22 & 34 & 5 & $\begin{array}{l}\text { Supt } \\
\text { Supr } \\
\text { Princ } \\
\text { SLP }\end{array}$ & JD \\
\hline Heritage & T.D. & $M$ & Supt & 1 & 39 & 39 & 5 & $\begin{array}{l}\text { Supt } \\
\text { Supr } \\
\text { Princ } \\
\text { Science }\end{array}$ & MA \\
\hline Heritage & G.D. & $F$ & Sp Ed Dir & 4 & 13 & 26 & 4 & $\begin{array}{l}\text { Sp Ed } \\
\text { Home Ec }\end{array}$ & MA \\
\hline Heritage & J.N. & $\mathrm{F}$ & Curr Coord & 5 & 34 & 34 & 5 & $\begin{array}{l}\text { Supt } \\
\text { Supr } \\
\text { Princ } \\
\text { English } \\
\text { Journalism }\end{array}$ & MA \\
\hline
\end{tabular}


Appendix E

Core Strategic Plan

(format differs due to software incompatability) 


\section{FUSION COUNTY SCHOOLS CorePlan Plan June 03, 2009}

Education is about discovering in all students their special skills and talents and encouraging them to achieve to high standards. The Fusion County Board of Education supports this commitment to offer every student a high quality educational program, steeped in Global 21 instructional skills and assessments, and valuable learning experiences.

The Education Agenda for Fusion County Schools is one of quality, excellence, and hope; not only for this generation, but for all generations of students yet to come. A unique set of challenges face American students every day. It is our responsibility to prepare them, as best we can, to address these challenges in a positive and productive manner. To that end, Fusion County Schools is committed to academic excellence and strives to offer a diverse curriculum that meets societal needs.

The Fusion County Board of Education believes that student learning must be engaging, relevant, and exciting. Our teachers must actively use technology tools within their teaching. Fusion County Schools must actively engage teachers in professional development that is current and that involves emerging technologies that will facilitate them in engaging their students.

Fusion County students are most fortunate to live in a community that places a high priority on their education. Thanks to the support of Fusion County citizens, business and dedicated staffs, our students are provided with numerous opportunities to succeed.

\section{Planning Committee \\ Name Title Representation}

Student $*$ Student

Director of Nutrition, Facilities, \& Safety *Administration

LSIC *Teacher *Business Community

Bus Operator *Service Personnel *Parent

Title 1 Teacher *Title I *Teacher

RtI Teacher *Teacher

Technology Coordinator *Technology

Sp. Ed. Teacher $*$ Special Education $*$ Teacher

RESA

* Service Personnel

Director of Personnel *Title I *Title II *Title III *Title IV *Title V*RLIS

*Administration

Principal, Middle School *Administration

Student *Student

Secretary * Service Personnel

Teacher *Teacher

Treasurer *Administration

Superintendent *Administration

Sp. Ed. Teacher *Special Education *Teacher

Teacher *Teacher

Board of Education

LSIC *Business Community

Student *Student

Editor, News *Business Community

Title 1 Teacher *Title I *Teacher

Student $*$ Student

Board of Education

Principal, High *Administration

Principal, Assistant, High/Middle

*Administration

Business Partner *Business Community

Board of Education

Board of Education, President

RLIS Teacher *RLIS *Teacher *Business Community

Parent $*$ Parent

Director of Special Education *Special Education *Administration

PK Teacher *Teacher

Secretary * Service Personnel 
Board of Education

Director of Technical Education, MOVTI *Administration

Principal, Elementary *Administration

RESA

Custodian *Service Personnel *Parent

Director, Executive, of C \& I *Administration

Teacher *Teacher * Parent

Librarian *Teacher *Parent

Principal, Elementary *Administration

Transportation Director $*$ Administration *Parent

Describe how parents, community and other appropriate stakeholder members are involved in the development and/or revision of the plan.

Three full day and full membership meetings were held during the 2004-05 school year to draft this original plan. Led by WVDE administration to develop the 5-year sections, along with a membership list that was extensive. It included representation from the following groups: central office administration, principals, WVDE, RESA, higher education, local business, LSIC membership, local media, BOE members, parents, service personnel, high school and middle school students, teachers, and the technology coordinator.

Central office administration aided this effort by researching internal and external data sources. This data was presented in a manner in which trends, strengths, and weaknesses could be identified and prioritized.

Building level principals also provided school specific information for consideration.

The technology section was produced through discussions between the school technology committees and their representatives to the county technology committee. Technical help and training was provided through RESA and WVDE workshops.

Throughout the 2005-06, 06-07, 07-08, and 08-09 school years, data was collected as the administration monitored action steps implementation within their schools or their county areas of responsibility.

Beginning in April of 2006, small group meetings began being held to judge the levels of progress and to provide direction for the 2006-07, 2007-08, 2008-09, and 2009-10 annual updates. These meetings included: the county technology council, county staff development council, preschool collaboration team, and the central office administration to name a few.

In late-June, July, and August of 2006, 2007, 2008, and 2009, a large scale effort was implemented by the county office administration to review the entire plan, section by section, and update it with newly available data. Goals and objectives were first examined for accuracy. "Baseline" data and "actual" data could now be 
compared and entered. Action steps were evaluated for continuation, change of direction, or deletion.

In order to meet the 2007-08, 2008-09, and 2009-10 deadlines to submit this plan, an abbreviated committee was utilized to review and draft the new plan. Meetings of this group will be held in October, and again in April. A focus of these meetings will be to monitor the process of institutionalizing the core beliefs throughout the district.

During the 2006-07, 2007-08, and 2009-10 school year, building principals have been directed to make a review of both their school's and the county's 5-year plan, and create a permanent agenda item for every LSIC and Curriculum Team meeting. Progress will be closely and routinely monitored in this way.

Monthly review of action step initiation and completion was completed at each central office administrators' meetings and principals' meetings. Completion rates were charted as well as compared to a pacing rate as per the number of days of instruction already completed for 06-07, 07-08, and 08-09.

This process worked very well in continuously focusing all levels of administration on the completion of action steps set, and will be continued in future years.

The beginning of the 2008-09 school year saw the establishment of a large and diverse rewrite committee come together to draft the second five year cycle (2010-15) for this plan. All sections were examined, discussed and updated with what we feel is a better alignment of parts. Large amounts of Global 21 components, as well as ARRA financial opportunities were added.

\section{Core Beliefs}

1. We believe that students come first. Students learn to become analytical and independent thinkers in different ways and at different rates; therefore, learning for all is our instructional focus.

2. We believe students must be prepared. Through an instructional focus based upon curricular standards, students will be equipped with the skills and knowledge necessary to contribute to and succeed in a democratic 21st Century global community.

3. We believe that students and staff must be healthy and ethical. All students and school personnel shall develop and promote responsibility, citizenship, mutual respect, strong character, environmental awareness, and healthful living.

4. We believe in the importance of school and community interaction. Communication and a shared involvement between the school, home, and community is essential to student success.

\section{Mission Statement}

The mission of Fusion County Schools is to provide student-centered learning opportunities that ensure all students will learn to their potential and 
master the skills, ethical behaviors, and attitudes needed to be successful citizens in a 21 st Century economy.

\section{Data Analysis}

\section{Key Outcome Indicators External Trend Data}

\section{What enrollment increases or decreases have occurred in your school system? How has this impacted the system?}

In 1984 the total net enrollment for Fusion County Schools included 2348 students. Starting thereafter and ending in 2002, Fusion County Schools has experienced an eighteen-year period of steady decline that resulted in a significant loss in total net enrollment. In fact, during that eighteen-year period the end result was a loss of 818 students. Over the past five years, the schools' enrollment has leveled out, fluctuating less than one percent. In summary, there has been a thirty-two percent decline in total net enrollment in the past twenty-four years; nine percent in the past twelve years and one percent increase in the past five years. As of June 2008 the headcount enrollment consisted of 1510 students with a larger than usual graduating class of 141. A much smaller class of 74 will be entering the kindergartens for the 2008-2009 school year. The end result is a total loss of 67 students enrolled from 2007-2008 to 20082009 pending further enrollment. Implications for our system include a reduction in the number of educators and service personnel will be required.

\section{According to available data, what changes have occurred in the age, ethnic, or racial population demographics of your county? What are the implications?}

Based on the previous seven year's total net enrollment, less than one percent of the student population in Fusion County Schools falls into categories other than non-white. Statistically, comparisons based solely on race and ethnicity are insignificant in total enrollment and in relation to trend data. At this juncture, the implications are insignificant.

3. Have there been any significant changes in the socio-economic demographics of your county? If so, what are the implications?

Over the past several years, Fusion County's socio-economic population changes have shown increases in the free and reduced lunch population. In October of 2007, the Fusion County Preschool Center had a total enrollment of 44 students, and [Elementary School] had 355 students enrolled for a total of 399 students. Of these students, 191 received free meals and 33 received reduced meals which calculates to $56 \%$ of students receiving free or reduced meals. The [Elementary School] Preschool had an enrollment of 20 students while Elementary had 273 students enrolled, which totaled 293 students combined. Of these students, 142 received free meals and 22 received reduced meals which calculates to $54.1 \%$ of students receiving free or reduced meals. Fusion Middle/High School had 846 students enrolled in October 2007. Of these students, 372 received free meals and 96 received reduced meals calculating to $55.3 \%$ of students receiving free or reduced meals. According to the West Virginia Department of Education Child Nutrition Program, all Fusion County Schools qualify for Severe Need Breakfasts for 2008-2009 based on the 2007-2008 lunch participation. Also, county boards of education with $60 \%$ or more free and reduced price lunches served during the school year 2007-2008 qualify for LUNCH BONUS, which Fusion County falls just under the $60 \%$ requirement at $55.2 \%$. Implications include: Students are in more need of support systems, such as, 1) homework assistance, 2) tutoring, and 3) parental support.

4. Have there been changes in the economic stability or economic trends in your county? What are the implications? 
Residential home construction in Fusion County has increased slightly over the last eight years. However, Fusion County's population has an increasing age populous that is eligible for the homestead exemption. The Class III and Class IV property have remained constant up to the 2003- 2004 year when Witco Corporation, Fusion County's largest taxpayer became eligible for $\$ 100$ million dollar in new equipment tax exemption. This tax exemption is valid for a period of ten years. Fusion County's tax base has remained fairly constant other than the change to Class III property. Implications include: 1) with increased economic demands, families need more support systems and 2) Fusion County Schools must continue to monitor their budget to account for a lower tax base income source.

\section{What are the changes in family characteristics or background of the students served in your county? What are the implications?}

According to the West Virginia Schools Percent of Needy Students Report, which is based on the 2nd Month Report of enrollment for the 2007-2008 school year, it indicates that Fusion County Schools has a total of $53.89 \%$ of the student population in the needy range. With greatest percents being at the elmentary grades. [Elementary School] has a percent needy of $59.8 \%$ while Elementary is at $53.25 \%$. Elementary School in the past several years has seen a rise in the number of welfare families and a rise in the divorce rate that affect the students in the school. Likewise, at Elementary School, many students come from single parent homes and many are being raised by grandparents assisting parents or with the parent(s) absent. Many of the students from single parent homes also have court orders on file preventing a parent or former partner from having any contact with the students. At Fusion Middle School, many families with school-aged children are returning to Fusion County usually for financial reasons and structural support (moving in with parents). Many senior citizens are becoming surrogate parents to their own grandchildren, due to divorce, substance abuse or behavioral/criminal problems. At Fusion High School a large percentage of students are going home to an unsupervised setting. Many students come from single parent homes or with grandparents in which many report they have little or no control of the child's behavior. The number of free and reduced lunch qualifiers has increased significantly in the past several years and we are serving more students with disabilities and the number of students with severe handicaps living with foster families has increased. Implications include: 1) Students need more support structures to assist with homework and academic understanding, 2) additional guidance counseling services may be required and 3) schools need to work with community agencies to positively increase the economic conditions.

\section{What are the significant social issues in your county? Are such things as drug abuse, homelessness, poverty, juvenile delinquency rate, or crime an increasing problem?}

Use of drugs and alcohol is always a concern for parents and community members in our county. The substance abuse and drug dealing occurring in Fusion County are resulting in serious health problems for young children; financial instability of the family to provide housing, food, and clothing for their children; parental interaction with their children is not occuring; children are more and more taking care of themselves with no direct adult supervision and care. Many of our students return to homes after school, which are unsupervised. There has been an increase in juvenile hearings and the number of students on probation in each of our schools. Some of our students reside in dwellings that are too small, and in poor condition or unclean. The number of students who qualify for free and reduced meals continues to increase countywide. Implications include: 1) the school system needs to work cooperatively with community agencies to increase the economic conditions and coordinate services for families; 2) programs need to implemented programs to address students in grades kindergarten through second grade to identify deficits due to lack of support during the first years of life; and 3) additional support is needed for families and children.

\section{What are the possible implications of technological change for your students?}

All students in our county have easy access to technology during the school day and during limited afterschool hours. The appropriate use of technology as an instructional delivery strategy continues to be an area where staff members would benefit from frequent staff development, students are more computer literate than some teachers. Fusion County is presently not equipped to take full advantage of staff 
development opportunities that are available through various distance-learning initiatives. Computers are not in every household in the county and have a student population of computer "haves" and

"have-nots." Fusion County Schools has devoted local funds to the area of technology. The special levy call has a provision to allocate money to technology. Fusion County has 2.45:1 student to every computer workstation of Windows 98 or higher while the state average is 2.8:1 All of Fusion County Schools are wired with Internet connections via T-1 line for a combined total of 4 T-1 lines in the county. Implications include: 1) Availability of technology in after school tutoring or homework help and 2) staff development needs to be provided for teachers and administrators in the area of technology to meet all mandates in the delivery of the curriculum.

\title{
8. What outside student activities or commitments may be affecting student achievement? What are the implications?
}

High School students are encouraged to participate in extra-curricular activities. Teachers and administrators try to make sure that every student is involved in school activities. Parents are encouraged to support their children in these activities. Studies indicate that when the "whole child" is involved in school, they experience more academic success.

\section{Student Achievement Data}

\section{No Child Left Behind School Reports}

Three of the four county schools met Adequate Yearly Progress under WV Achieves, the state No Child Left Behind implementation plan. One hundred percent of all students in grades 3-8 and 10 took the WESTEST or Alternative Test based on the NCLB guidelines. Fusion Middle School did not meet AYP because of the "Students with Disabilities" cell size. The cell sizes in the two elementary schools and the high school were below 50 so the scores for students with disabilities do not count for adequate yearly progress. However, there was a significant gap between the disabilities students' scores and the other cell groups' scores.

\section{WESTEST Confidential Report: 2007-2008 Fusion County Assessment Proficiency Percent}

\author{
Reading/Lang. Arts \\ $\%$ Above Mastery \\ Reading/ Lang. \\ Arts \\ $\%$ Below \\ Mastery \\ Math \\ $\%$ Above \\ Mastery \\ Math \\ $\%$ Below \\ Mastery \\ Grade 3 \\ SWD 64\% 36\% 80\% 20\% \\ Low SES 75\% 25\% 82\% 18\% \\ County \\ 83\% 17\% 85\% 15\% \\ State 79\% 21\% 75\% 25\% \\ Grade 4 \\ SWD 62\% 38\% 71\% 29\% \\ Low SES 84\% 16\% 87\% 13\% \\ County 90\% 10\% 88\% 12\% \\ State $82 \% 18 \% 76 \% 24 \%$ \\ Grade 5
}


SWD 29\% 71\% 50\% 50\%

Low SES 74\% 26\% 83\% 17\%

County $81 \% 19 \% 88 \% 12 \%$

State 80\% 20\% 81\% 19\%

Grade 6

SWD 59\% 41\% 35\% 65\%

Low SES 87\% 13\% 73\% 27\%

County $92 \% 8^{\wedge} 85 \% 15 \%$

State $82 \% 18 \% 77 \% 23 \%$

Grade 7

SWD 53\% 47\% 42\% 58\%

Low SES 87\% 13\% 86\% 14\%

County $91 \%$ 9\% 90\% 10\%

State 82\% 18\% 77\% 23\%

Grade 8

Page 7 of 24

SWD 39\% 61\% 39\% 61\%

LOW SES $77 \% 23 \% 74 \% 26 \%$

County 84\% 16\% 79\% 21\%

State 81\% 19\% 73\% 27\%

Grade 10

SWD 19\% 81\% 12\% 88\%

Low SES $60 \% 40 \% 60 \% 40 \%$

County 68\% 32\% 69\% 31\%

State 74\% 26\% 68\% 32\%

\section{WV Writing Assessment}

In 2007-2008, grades 3-11 were field tested by the WVDE, and results will not be distributed to local counties. For the 2008-2009 school year, grades 3-11 will be taking the new version of the WESTEST 2 Online Writing Assessment, and the scores will then be placed on the 2008-2009 Five Year Plan.

\section{SAT/ACT Results}

Sixty-five percent of the FCHS senior class took the ACT 2007-2008. FCHS's composite score was 21.9. Overall $11^{\text {th }}$ and 12th graders with a total number 88 students tested, they scored a composite score of 22. Sub- scores indicate a consistent performance of exceeding the state and national level. Sub-scores: English=22.4, Reading=22,Science=21.6, and Math21.4. Very few FCHS seniors (Approx. .5\%) take the SAT. The composite score for the SAT was 1103.

\section{ACT Explore - Grade 8 Middle School}

Fusion County has maintained ACT Explore score above the national average over the past nine years except in one area of mathematics with a differential of one-tenth of a point. Fusion County students' performance at 15.4 exceeds the national level composite score of 14.9 by 0.5 . The subject scores comparison are as follows:

\section{Subject Local National Level}

English 15.214 .2

Mathematics 15.015 .1

Reading 14.513 .8

Science 16.415 .9

ACT Explore Comparisons

\section{ACT Plan - Grade 10 High School}


On the ACT Plan taken at the 10th grade level, it continues to show a pattern of scoring above the national average. Fusion County students' performance at 18.3 exceeds the national level composite score of 17.5 by 0.8 . The subject scores are as follows:

\section{Subject Local National Level \\ English 17.916 .9 \\ Mathematics 18.317 .4 \\ Reading 17.916 .9 \\ ACT Plan Comparisons \\ Page 8 of 24 \\ Science 18.918 .2 \\ 6. AP Testing Report/AP Rate}

For the 2007-2008 school Fusion High School had three 11th graders and eight 12th graders taking the AP tests. Some students were taking more than one test numbering a total of 17 AP tests in the areas of biology, calculus, chemistry, statistics, and studio art. Remarkably, of the 11 tested, 7 students had a score of 3 or more. The percentage of eleventh and twelth graders at FCHS taking AP tests has typically been higher than the state average.

\section{End of Course Testing Report for Career and Technical Education}

Fusion High School administered end of the course testing in the following courses: Agriculture and Natural Resources I, Agriculture and Natural Resources II, Ag. Mechanics I, Ag. Mechanics II, Agriscience 11, Animal Processing, Horticulture, Greenhouse Technology, Landscape Design and Installation, Business Computer Applications I, and Fundamentals of Drafting. The target for the year 2007-2008 of testing was set by the state at $74 \%$ of the students taking the tests scoring at the Mastery Level or above. Fusion County meets the standard in all areas with the exception of Animal Processing, Horticulture, Landscape Design, Business Computer Applications, and Fundamentals of Drafting. The percent of student passing end of year course technical skills are as follows: Ag \& Natural Resources I 96.3\%, Ag \& Natural Resources II 100\%, Ag Mechanics I 63.16\%, Ag Mechanics II 60\%, Agriscience II $82.61 \%$, and Greenhouse Technology $67.57 \%$. Scores for the two areas not meeting standard scored as follows: Animal Processing 23.53\%, Horticulture 40\%, Landscape Design 0\%, Business Computer Applications I $37.5 \%$ and Fundamentals of Drafting 38.46\%. In 2007-08, below state standard means less than $60 \%$ of testers achieved a passing score which is $74 \%$ or higher. The percentage of students taking classes at the joint Technical Center received a score of $59.07 \%$ and did not meet the state target for 2007-2008.

Priority \#1: Close the achievement gap between Students with Disabilities and all other cell sub-groups.

Priority \#2: Early intervention for students with learning problems.

Priority \#3: Continue to integrate writing across the curriculum.

Priority \#4: Staff development for all teachers in strategies to assist in learning for all students.

\section{Other Student Outcomes}

Attendance Rate: Fusion County School has always maintained a high attendance rate. The lowest attendance rate reported over the last ten years was $94.1 \%$ in 1999 . The highest attendance rate reported was $96.02 \%$ in 2006 . We may want to consider the need for a method to track student attendance by subgroups; however, attendance does not seem to be a problem.

Discipline Referral Report: Based on the WVEIS System, annual discipline referrals that warrant suspension are kept for each school. At Elementary School, 14 events required suspensions: 1 indecent acts/language toward a student; 1 derogatory racial/sexual/ethnic remarks; 2 antisocial conduct; 1 
disruptive behavior/disorderly conduct; 1 battery against student; 5 violation of school rules or policies; 1 possession of inappropriate personal property; 1 defacing school property/vandalism; 1 stolen property under 100. Four of the fourteen events involved a special needs student. Elementary School, 8 events required suspensions: 3 physical fight; 2 violation of school rules or policies; 2 indecent acts/language toward student; 1 harassment/bullying/intimidation. Four of the eight events involved a special needs student. Fusion Middle School, 31 events required suspensions: 1 disobeying staff in a willful manner; 4 indecent acts/language toward staff; 2 indecent acts/language toward student; 1 disrespectful behavior; 3 harassment/race/religious/ethnic/sexual; 8 physical fights; 1 threat of injury or injury; 1 verbal assault against student; 3 battery against student; 1 insubordinate or defiant behavior; 1 sale of an OTC/prescription medication; 2 unauthorized use of OTC/prescription medication; 1 unauthorized possession of OTC/prescription medication; 2 possession of knife or like implement under 3.5 inches. Ten of the thirty-one events involved a special needs student. Fusion High School. sixty-six events required suspensions; 2 indecent acts/language toward staff; 1 antisocial conduct; 3 disrespectful behavior; 6 harassment/bullying/intimidation; 6 disruptive behavior/diorderly conduct; 1 inciting behavior that causes disruption; 3 threat of injury or injury; 11 battery against student; 3 cheating; 2 insubordinate or defiant behavior; 2 defacing school property/vandalism; 4 stolen property under 100; 5 possession of illegal drug/substances; 12 possession of tobacco products; 3 skipping school; 1 leaving school grounds without permission; 1 skipping class. Twenty-two of the sixty-six events involved a special needs student.

Dropout Rates/Graduation Rates: Fusion County Schools has maintained a very low dropout rate. According to the West Virginia State Report Cards, Fusion County Schools' dropout rate did not exceed $2.8 \%$ and has been as low as $1.3 \%$. In 2001 and 2002 the dropout rate was at an all time low at $1.3 \%$ and $1.4 \%$ respectively. Statistically, this low percentage can be directly attributed to the county attendance policy that correlated student daily attendance and course credit. The county attendance rate during this time experienced a statistically insignificant increase. However, the unintended result of improving student attendance was academic success in the classroom resulting in a fewer dropouts. Change in state policy at the end of the 2002 school year eliminated local education agencies right to withhold student credit based on daily attendance. Although we continue to experience a low dropout rate, one student dropping out is too many. We continue to look for ways to connect students to the schools and keep them in school.

College Enrollment Rate: Fusion County has a high college enrollment rate. We continue to encourage and assist students to enroll in post high school education. Eighty-three percent of the 2008 graduating class plans to attend college ( $46 \%$ four year college and $37 \%$ two year college).

Special Education Data: Fusion County Schools' special education department was visited by the West Virginia Department of Education Office of Special Education in June 2008 to review the Continuous Improvement and Focused Monitoring data. Based on a the review of the self-assessment, no verification findings were identified. Prior to this visit, an official on-site monitoring was conducted in 1999 at which time very few finding were reported. Presently, Fusion County Schools' special education department facilitates a Continuous Improvement and Focused Monitoring Process as mandated by the West Virginia Department of Education Office of Special Education. The 2008-2009 report documented two areas of noncompliance. Improvement plans are in place that will address each issue. Annually, Fusion County Schools evaluates and reports progress to the state department as required. In addition, we will revist the Continuous Improvement and Focused Monitoring Process during the 2009-2010 school year. Below is a chart which identifies the two areas of noncompliance along with an improvement plan for each area.

\section{District Self-Assessment Workbook School Year 2008-09 Response Compliant Noncompliant Not Applicable Not Answered}




\title{
Total \\ Responses 32200 \\ Improvement Plan Info
}

\author{
\# Citation Compliance \\ Indicators \\ IP \\ Done \\ Change \\ Answer
}

1.12 Chapter 9. Section 2.B

AYP SPP Indicator 3

Students with disabilities make continuous progress within the state's system for educational accountability

(meeting AYP). YES Change

Action Step to Address Citation

Chapter 9. Section 2.B AYP SPP

Indicator 3

Evaluation

Component Begin/End Date: Person/Group Responsible Funding Sources

Funding Amount

Measurable Objective:

Increase the number of students with exceptionalities who perform at the mastery level on the WESTEST in reading and mathematics. Both school and county will achieve Adequate Yearly

Progress for students within the disability subgroup.

1. Teachers review the Individual Student

Report from the most recent WESTEST

results for whom the special education

teacher is responsible. Teachers will

identify those students who did not

achieve mastery on the most recent

WESTEST reading/language arts

and/or math.

Prescriptions

Start Date

08/21/2009

Ending Date:

08/22/2009

County Test Coordinator will ensure test

data are distributed to schools.

County Test Coordinator will ensure that all

personnel acquire the necessary skills to

analyze and utilize test data.

Principal will ensure the data reports are

distributed to the correct personnel.

Special education teachers will review

records and graph data.

None

Estimated Cost:

0.00

2. Review the Individual Right Response

Record (IRRR)to identify deficiencies

for students who did not achieve

mastery on the most recent WESTEST

reading/language arts and/or math.

Special education teachers will

compare identified deficiencies to IEP

goals and adjust goals and/or services

as appropriate.

Prescriptions

Start Date

08/21/2009

Ending Date:

10/01/2009

Special Education Teachers/IEP Team

/Principal

None

Estimated Cost:

0.00

3. Review the placement and staff

utilization of special education teachers

based on student needs. This will 
include the teacher's use of a progress monitoring cycle based on speicalized

instruction.

Master Schedule

Start Date

08/21/2009

Ending Date:

10/01/2009

Principal/Guidance Counselor

None

Estimated Cost:

0.00

4. Teacher executes academic

interventions consistent with the IEP.

Begin the cycle of interventions and

progress monitoring for non-proficient

students.

Benchmark assessment will be conducted

three times per year.

Start Date

12/01/2009

Ending Date:

04/30/2010

Special Education Teacher/Educators

designated as appropriate by school

adminstrator.

None

Estimated Cost:

0.00

5. The special education teacher uses

benchmark assessments and/or

formative assessments on a progress

monitoring schedule that documents

progress toward IEP goals. The special

education teacher consults with an

intervention team comprised of

educators also providing services to the

student to confirm the instruction

deemed necessary based on benchmark

and/or formative assessments.

Progress Monitoring Results/Benchmark

Testing/Scientific Based Research

Interventions

Start Date

12/01/2009

Ending Date:

04/30/2010

Special education teacher provides scientific

research based interventions.

Special education teacher progress monitors

unless a decision is made for another

educator on the intervention team to

complete the progress monitoring.

Special education teacher adjusts his/her

own instruction or coordinates adjustment to

instruction provided by other educators

based on progress monitoring results.

None

Estimated Cost:

0.00

3.8 Chapter 5. Section 2.F1

The percentage of youth who had IEPs, who are no longer in secondary school and who have been

competitively employed and/or enrolled in some type of post-secondary school within one year of leaving

high school will increase.

YES Change

Action Step to Address Citation

Chapter 5. Section 2.F1

Evaluation

Component

Begin/End Date: Person/Group Responsible Funding Sources

Funding Amount

Measurable Objective:

Increase the number of graduates enrolled in college, enrolled in some type of post-secondary school, and/or have been competively employed within one year of leaving school.

1. Special Education Director or designee

will complete follow-up phone calls to

the 2008-2009 graduates one year later to

obtain post school information.

Follow-up Survey 
Start Date

03/01/2010

Ending Date:

03/30/2010

Special Education Director

None

Estimated Cost:

0.00

Total Questions Needing Improvement Plan = 2

\section{Analysis of Culture, Conditions and Practices}

\section{Digital Divide Report}

(Technology)

1.

According to the 2007-2008 Digital Divide Report, Fusion County Schools has devoted local funds to the area of technology. The Special Levy Call has a provision to allocate money to technology. Fusion County has 2.45 students to every computer workstation while the state average is $2.8: 1$. All of Fusion County Schools are wired with Internet connections via T-1 lines with a total of 4 T-1 lines.

\section{Office of Performance Audits}

Compliances and Recommendations: Fusion County last visit from the Office of Performance Audits was during the 2003-2004 school year. The non-compliance and recommendations were revisited during the fall of the 2004 school year. All non-compliances were met and the recommendations acted upon. All schools received a full accreditation rating except one. Fusion Middle School received a rating of Temporary Approval due to the number of students scoring below Mastery on the WESTEST in the subgroup of Special Needs in the areas of reading/ language arts and mathematics. A corrective action plan was written by Fusion Middle School to close the achievement gap for students with disabilities during the 2005-2006 school year. Fusion Middle School met AYP for the 2006-07 school year.

\section{Highly Qualified Personnel Report}

Priority \#1: Close the achievement gap between special needs students and regular education student as tested on WESTEST.

Priority \#2: Continue to update technology to stay abreast of learning opportunities.

\footnotetext{
The OEPA Checklist should be one source of data to assess school or county needs as you prioritize your strategic issues. There are no negative consequences to checking "No" to a high quality standard since the checklist is not used for changing accreditation or approval status or selection for on-site reviews.
}

\section{OEPA Analysis}

The OEPA finding that Fusion County Schools and Fusion Middle School have not met AYP for the 2006-07 and 2007-08 school years, due to the fact that TCMS did not make AYP in the SWD subgroup, prompted an in-depth examination of that situation. One of the questions in an effort to remediate this subgroup became "what did the 4 school systems that made AYP in 07-08 do that Fusion County did not?" Upon closer scrutiny it was found that if all 55 counties had a SWD subgroup totaling at least 50 students, then 54 of the 55 county school systems would not have made AYP. Of the four that did make AYP, three had SWD subgroups smaller than 50 . As required, an Improvement Plan has been submitted to OEPA from both the county and the school. Unfortunately, Fusion County is in good company. A closer look at Fusion Middle 
School's comparative county score rankings for 07-08 for the "ALL" subgroup, paints an entirely different picture for both the school and the school system as non-AYP is considered: FCMS: the state rankings for grades 6-8 SWD subgroup ranks FCMS as 12th in reading and 24th in math. Twenty fourth is an unacceptable level. FCMS: out of the four tests (rd, mathg, sci, ss) and associated twelve AYP qualifying subgroups within the "ALL" subgroup, including the SWD subgroup, the school ranked statewide as: 1st in four of the tests 2 nd in four of the tests Top 10 in four of the tests Fusion County Schools (grades 38,\&10 combined) - Reading - 6th Math - 2nd Science - 2nd Social Studies - 1st The system will certainly continue to work hard to remediate the children and their scores, within all of the subgroups at all grade levels. Especially, those within the SWD subgroup at the middle school level and within all tested areas at the high school level. Remedial math and reading teachers will be funded to help with middle school scores. A three tired approach will be used by the middle school special education teachers as well as the remedial math and reading specialists.

\section{Prioritized Strategic Issues}

Classroom instruction preparation will be encouraged to move from "isolation to collaboration" through the expanded use of professional learning communities at all schools and the establishment of routine professional learning communitiy meeting times for informal professional discussions.

Classroom instruction will also focus on the cognitive processes demanded of students to complete given tasks. Lessons will be created that reach all levels of depth of knowledge (DOK), but will increase the number of lessons that reach the higher DOK by solving complex problems and communicating their understandings.

WESTEST Scores for students' grades 3-10 continue to show a need for improvement in the subgroups Students with Disabilities (SWD) and Economically Disadvantaged (LSES) in both Math and Reading/Language Arts.

County action steps will include: Professional Development

1. To address the area of Reading Language Arts- The county needs to provide planned sequential Staff Development in the following areas to increase Academic Literacy K-12:

a. Training in explicit instruction and supportive practices in the use of Effective Comprehension Strategies, (e.g., use of graphic and semantic organizers; question generation; summarization and paraphrasing as well as selective reading).

b. Training in increasing the amount and quality of open, sustained discussion of reading content.

c. Increase students' motivation and engagement with reading

d. Vocabulary instruction

2. Organize a committee of teachers to research effective Middle/High School Rtl programs and develop and plan to implement this process during the 2010-11 school year.

3. To address the area of Mathematics - The county needs to provide Staff Development for all teachers of Mathematics grades K-8 using strategies that address the areas of weakness noted from the results of the WESTEST. Quality strategies that address basic Numbers and Operations for grades K-8 need to be 
offered. : All students need to have an understanding of Addition/Subtraction, Multiplication, Division, and Fractions of whole numbers and decimals prior to moving to the Middle School.

4. Organize a committee of teachers to research effective Elementary and Middle School programs that address math intervention models to assist with identifying and providing additional practice for those students having difficulty in Mathematics.

Other areas of county strategic priority include:

a. Adjustments to the mentor/mentee process as well as the recruitment of quality teachers into the mentor pool.

b. Global 21 Project based instruction will be required of all core subject teachers in grades K-12.

c. Web based grading and planning software will be utilized by all teachers by the end of the 2009-10 school year, to increase parental access and academic involvement.

\section{Prioritized Strategic Issues}

Classroom instruction preparation will be encouraged to move from "isolation to collaboration" through the expanded use of professional learning communities at all schools and the establishment of routine professional learning communitiy meeting times for informal professional discussions. Classroom instruction will also focus on the cognitive processes demanded of students to complete given tasks. Lessons will be created that reach all levels of depth of knowledge (DOK), but will increase the number of lessons that reach the higher DOK by solving complex problems and communicating their

understandings. WESTEST Scores for students' grades 3-10 continue to show a need for improvement in the subgroups Students with Disabilities (SWD) and Economically Disadvantaged (LSES) in both Math and Reading/Language Arts.

County action steps will include: Professional Development

1. To address the area of Reading Language Arts- The county needs to provide planned sequential Staff Development in the following areas to increase Academic Literacy K-12:

a. Training in explicit instruction and supportive practices in the use of Effective Comprehension Strategies, (e.g., use of graphic and semantic organizers; question generation; summarization and paraphrasing as well as selective reading).

b. Training in increasing the amount and quality of open, sustained discussion of reading content.

c. Increase students' motivation and engagement with reading

d. Vocabulary instruction

2. Organize a committee of teachers to research effective Middle/High School Rtl programs and develop and plan to implement this process during the 2010-11 school year.

3. To address the area of Mathematics - The county needs to provide Staff Development for all teachers of Mathematics grades K-8 using strategies that address the areas of weakness noted from the results of the WESTEST. Quality strategies that address basic Numbers and Operations for grades K-8 need to be offered. : All students need to have an understanding of Addition/Subtraction, Multiplication, Division, and Fractions of whole numbers and decimals prior to moving to the Middle School.

4. Organize a committee of teachers to research effective Elementary and Middle School programs that address math intervention models to assist with identifying and providing additional practice for those students having difficulty in Mathematics. 
Other areas of county strategic priority include:

a. Adjustments to the mentor/mentee process as well as the recruitment of quality teachers into the mentor pool.

b. Global 21 Project based instruction will be required of all core subject teachers in grades $\mathrm{K}-12$.

c. Web based grading and planning software will be utilized by all teachers by the end of the 2009-10 school year, to increase parental access and academic involvement.

\section{Considerations from Frameworks Needs Assessment}

\section{Professional Learning Communities}

School Master Schedules Support Collaborative Planning

Collaborative/Teacher Leadership is Present

\section{Technology Data Systems}

Teacher Computers/Presentation Stations

Student Computers

Instructional Technology for Students

Technical Support/Repair

Bandwidth

\section{Development of Highly Skilled Teachers}

Professional Learning Communities Development

Core Program - Tier 1

21st Century CSO's Learning Skills; Technology Tools

Standards Based Literacy Instruction

Standards Based Numeracy Instruction

Integration of Technology

Assessments $O F$ and FOR Learning

Intervention Programs - Tiers 2 and 3

National Board Certified Teachers

\section{Support for School Improvement}

Extended Day/Year

Pre-Kindergartens

Parent and Community Involvement

Wellness

Additional Instructional Staff 
Additional Support Staff for Students

\section{Framework for Literacy PreK-12 Core Program (Tier I)}

21st CSOs, Learning Skills and Technology Tools Standards

Standards based lesson plans, units of study and project based units of instruction Literacy, informational, primary source documents and real-world materials Writing strategies explicitly taught in all content areas Vocabulary, background knowledge comprehension strategies and increasing fluency focused on 4-6 instruction Real world application apparent in all content instruction. Lexile and Quantile Measures to differentiate instruction Balance of inquiry based investigation, guided practice, independent work, skill review and homework Manipulatives and problem solving skills integral to math Language of mathematics to develop and defend mathematical conjectures, arguments, reasoning and proof Proficiency/ conceptual understanding with fractions (decimals, percents, negative fractions) established prior to Grade 8 College Transition Class for all students not meeting readiness benchmark Comprehension strategies before, during \& after reading Diverse texts (primary sources or real world materials) Discussion of what has been read (interpret, analyze, synthesize, evaluate, infer) Academic vocabulary across content areas Text structure to organize material learned Teacher-developed classroom assessments, as well as Writing Road Map 2.0, Informal Math Assessment, reading assessments, DIBELS and Creative Curriculum

\section{Framework for Literacy PreK-12 Intervention Program (Tier II and Tier III)}

Tiered instruction framework to support 21st Century CSOs in reading, writing and Tiered instruction framework to support 21 st Century CSOs in reading, writing and mathematics Increasing levels of support for at-risk students prior to referral to special education Technology that supports intervention (DIBELS, AIMSWeb, Acuity, internet resources) Tier II as a strategic intervention for students who do not meet benchmark and includes: Direct and explicit intervention strategies, materials and web-based resources Continuous assessment (benchmark, progress monitoring and diagnostic) to pinpoint problems, design targeted interventions and measure response to interventions Small group instruction delivered beyond the core reading/language arts and mathematics periods Specific targeted instruction Program-specific assessment or other assessments to pinpoint problems and design targeted interventions Continuous assessment Flexible grouping as appropriate for targeted instruction Format of WVDE online IEP Five essential components of reading Co-teaching, consultation and small group instruction Accommodations and modifications of instruction and assessment Accelerated learning strategies Instruction aligned to WVCSOs Achievement progress carefully monitored Evidence-based strategies, 
programs and materials Technology-based resources (listed Column 1) Assessment for learning (listed Column 1)

\section{Framework for Literacy PreK-12 Independent/Extension Program}

Minimum of 25 read books per year by each student Development of individualized reading lists through student choice and relevant topics \& using Lexile measures Time to read during and outside class (SSR/DEAR) K-3 Reading Calendar Parents Lexile Reading Kit at www.lexile.com Education component that addresses reading and mathematics literacy Students products and/or performance juried by audiences beyond the class Web-Based instructional programs to support reading and math skill improvement outside the school setting. (Riverdeep, Odyssey, Compass Learning, SAS, Writing Road Map, Thinkfinity, Acuity, Cognitive Tutor, etc.) Counselor support program in place

\section{Framework for Literacy PreK-12 Infrastructure}

Minimum 10 days of extended employment to support the core program, intervention program, content area applications and independent/extended learning Sustained and job-embedded professional development focused on literacy Reading and math interventionists/coaches Technology Integration Specialist Special Needs Teachers Counselors Double block Strategic tutoring Flexible grouping After school, Saturday and summer programs Bandwidth to provide high speed Internet access for instruction/learning. Hardware to provide all students sufficient access for 21 st century learning Technology work stations for all teachers Master schedule that support student learning (intervention block, flexible scheduling) Master schedule that supports teacher collaboration and embedded professional development Realistic budget that supports literacy Teacher Leader(s) Classroom teacher Special educator Technology Integration Specialist/coaches Reading and mathematics interventionists Counselor Cross-grades collaboration and/or interdisciplinary planning Literacy plan monitored annually and necessary adjustments made

Core Achievement/SBI: Fusion County Schools will provide all students with a student-centered learning environment focused on Global 21 instructional and assessment practices, supported bypersonal wellness, environmental awareness, character development, high level communication skills, and a shared community connection for the purpose of developing independent and analytical thinking citizens. 
2. Increase the number of teachers implementing subject matter standards, and Global 21 learning skills, technology tools and research-based instruction to design instructional plans promoting depth of knowledge, problem solving and oral and written communication.

3. Increase the number of teachers implementing formative assessments to adjust and improve classroom instruction.

4. Increase collaboration time during the contract day through creative release time for teachers to meet and discuss instruction and effective strategies.

5. Increase the number of classrooms routinely creating student learning opportunities tfor the purpose of fostering and assessing independent and analytical thinking.

6. Increase the number of classrooms integrating attributes of character development, physical wellness and environmental awareness into routine classroom instruction.

7. Increase the number of teachers making routine home contacts using both electronic and personal contact methods.

\section{Date Topic Audience \\ Mode \\ (Coaching, Learning Community, or \\ Trainer Led)}

6/16-17

Continuous School Improvement for

School Leadership Teams- Dr.

Larry Lezotte

Building Principals and

3 identified teachers for

each team

Trainer Led

6/17-18 Standards Based Mathematics

Workshop Teachers grades 4-5 Trainer Led

6/22-25

WV Summer Institute for World

Language Teachers - Building

Language Proficiency in the 21st

Century Through Project Based

Learning

Teachers K-12 Trainer Led

6/22-23

Project Based 21st Century

Learning and Assessment/DOKNon

core teachers:PE/Health,

Drivers Ed., Voc. Ed.

Non-Core Teachers

K-12 Teacher Leadership Team

6/24-25

Project Based Learning for

Non-Core Teachers: Music, Art,

Library/Media

Non-Core Teachers

K-12 Teacher Leadership team

6/29-30 Standards Based Math Workshop

for Grades 2-3 Gr. 2-3 2-3 Teachers

6/29-30

Project Based/techStep Learning 
for Core Teachers and Special

Educators of Reading/English \&

Social Studies 6-12

6-12 Teachers Teacher Leadership Team

$7 / 1-2$

Project Based/techStep Learning

for Core Teachers and Special

Educators of Math/Science 6-12

6-12 Teachers Teacher Leadership Team

Page 18 of 24

7/6-7

Project Based/techStep Learning

for Core Teachers and Special

Educators of Math/Reading

Language Arts 2-3

2-3 Teachers Teacher Leadership Team

7/8-9

Project Based/techStep Learning

for Core Teachers and Special

Educators of Math/Reading

Language Arts/Science/Social

Studies 4-5

4-5 Teachers Teacher Leadership Team

7/26-30 Special Education Leadership

Academy Select team Trainer Led

7/29-31 Social Studies Summer Institute K-12 Trainer Led

8/3 Quantile Workshop - Math

Teachers 3-12 3-12 Teachers Teacher Leadership Team

8/3-6 David Langford's 4-Day Quality

Learning Workshop K-12 Trainer Led

8/3-7 Technology Conference: Living and

Learning in a Digital World K-12 Trainer Led

8/4-5

Project Based Learning for Core

Teachers and Special Educators of

Math \& Reading Language Arts K-1

K-1 Teacher Leadership Team

8/6 Recipes For Fun K-2 Trainer Led

8/9-14 2009 Teacher Leadership Institute Select team Trainer Led

8/14 PK Workshop PK \& Instructional aides Trainer Led

8/17-18 Standards Based Math for K-1

Teachers K-1 Math Teachers Trainer Led

8/17-18 WESTEST II Data Analysis for All 3-11 Teachers Trainer Led

8/20 Special Education Workshop:

Monitoring

PK-12 Special Ed

Teachers Trainer Led

8/20 My Station Workshop PK-12 PE Teachers Trainer Led

8/24 Site Based Staff Development PK-12 Teachers Trainer Led

8/25 Site Based Staff Development PK-12 Teachers Trainer Led

9/1-6/2010

The Professional Staff Development Council in conjunction with Literacy Leadership teams will being planning staff development offerings for Summer 2010 in the following areas:Graphic and semantic organizers; Question Generation; summarization and paraphrasing; Comprehension strategies; Discussion strategies; Vocabulary strategies; Depth of Knowledge and Formative Assessment.

PK-12 Teachers Trainer Led 9/1-6/2010 PLC formation and protocol training PK-12 Teachers Trainer Led 
7/1-9/1/09

Administrative training in the areas of:

1. Understanding of depth of knowledge to monitor the design and delivery of a standards-based 21st Century lesson. Administrators Trainer Led

2. Understanding of a 21st Century "balanced assessment" in order to use data/results from it to adjust instruction. A county-wide effort will be made to enhance the mentor/mentee and new teacher induction programs.

Core Plan

a. Creative approaches for making weekly mentor/mentee planning time together.

b. Increased release time for multiple mentor observations of assigned mentee.

c. Increased release time for multiple mentee observations on assigned mentor.

d. Direct principals to routinely meet with mentors, mentees, central office adminsitration, and/or team leaders within

their buildings for the purpose of mentee professional growth.

Fusion County Schools will provide technical assistance, time, training, materials, and personnel in order to bring about improvement in all core subjects.

Core Plan Technology SBI

1 Fusion County Schools will use ACUITY for student benchmark testing in grades 3-11in all core subjects; and be given 3 times per year. K-2 will use the Informal Math and Informal Reading Assessments as benchmarks throughout the school year.

2. Fusion County will develop a 3 Tier Intervention Model that will be used to target interventions for at risk students grades K-5

3. Fusion County will administer DIBELS Assessments in September, January and March. In addition, monitoring assessments will be administered for students who have been placed in Tier 1, 2, or 3.

4. Fusion County will provide funding for MOVTI Adult Literacy program.

5. Fusion County will provide opportunities for teachers to become part of Professional Learning Communities.

6. Fusion County will provide all students with the opportunity to use up-to-date technology to access informtion, solve problems and communicate grades K-12.

A county-wide focus of PLC's during the 2009-10 school year will be a system-wide review of the new CSOs for the purpose of teacher awareness and understanding of the increased rigor and depth of knowledge within the new content standards and objectives. 
By June 2012, 100\% of the graduating 8th grade students at Fusion Middle School will be deemed 'tech literate', with a techStep personal profile that reflects participation in at least fifteen technology-rich curriculum projects.

Core Plan

Planning for Summer 2010 Staff Development Offerings will begin in September with the Professonal Staff Development Council along with members of the Teacher Leadership Teams.

Core Plan

Areas needing to be addressed are:

1. Graphic and semantic organizers;

2. Question Generation: summarization and paraphrasing;

3. Comprehension strategies that are content specific;

4 Importance of increasing the amount and quality of open, sustained discussion of reading content;

5. Improve Vocabulary Knowledge: Wide reading, direct teaching of indvidual, high utility words, instruction in how to learn words independently during reading; and instruction and activities that increase work consciousness.

The C \& I/Professional Staff Development Council Director will organize a committee of teachers to research effective middle/high school Rtl reading programs.

Core Plan

These teams will become the Middle and High School Literacy Teams which will recommend a plan for implementation. The C \& I/Professional Staff Development Council Director will organize a committee of teachers to research elementary and middle school programs that address math intervention models to assist with identifying and providing additional practice for those students having difficulties in math.

Core Plan

The Superintendent and C \& I Director will verify, that each principal will oversee and verify all teachers in their school present at least one project based unit with a culminating authentic assessment that reaches depth of knowledge levels 3 and/or 4, during the 2009-2010 school year.

Core Plan SBI

The Superintendent will disaggregate data from the Self-Assessment Statistical Analysis completed by district personnel for the purpose of evaluating current staff development offerings and determining future trainings for Fusion County staff to meet 21st Century instructional and assessment expectations.

Core Plan SBI

a. Administrative training weaknesses will be identified through data review, and trainings will be offered to remediate the weakness. 
b. Principals will be directed to include in their school's plan, a similar review of teacher weaknesses for the purpose of developing site based professional development.

Fusion County Schools central office administration will work with principals, LSICs, and Curriculum Teams to assist them in developing plans to improve instructional opportunities.

Core Plan Technology

Fusion County Schools will increase opportunities for credit recovery for high school students. This will be accomplished through a recomendation from the High School curriculum team working with the Principal and C \& I Director.

Core Plan

Make available to high school students, summer school and virtual school opportunities for the purpose of credit recovery

Fusion County Schools will provide flash drives for each school to begin a library of SBI projects to be shared county-wide.

Core Plan Technology SBI

Fusion County Schools will purchase a self-paced core software package such as ODESSEY to be used by students assigned to the after-school alternative educational program.

Core Plan

Fusion County Schools will use the web based program EDLINE and GradeQuick, in an effort to permit parental access to electronic assignments, grades, and teacher communication.

Core Plan Technology

The 2009-10 action will be to continue the use of the electronic grade book, begin posting assignments on-line, and use of the Edline calendar.

Fusion County will direct and oversee the refinement of curriculum maps in the areas of reading and math. Teachers will be meeting during the school year to discuss progress to date and to make adjustments.

Core Plan

Fusion County will provide a certified after school tutoring teacher to provide academic instruction in core curriculum areas based on students area of weaknesses as identified on WESTEST 2 data and classroom performance.

Core Plan Title V

Fusion County will provide opportunities and training for teachers to become part of 3-6 member professional learning communities/teams, as well as collaboration time to meet.

Core Plan SBI

1. The Superintendent and C \& I Executive Director will form a "back porch" PLC between themselves and all principals for the purpose of discussing and determining the concepts that will be explored at each school's faculty PLCs which will be held during two hour early release days (12 hours of accrued 
instructional time) during the months of : September, October, January, February, March, and April.

2. Training of PLC school level facilitators will be held during the summer of 2009.

3. SES and AIB will attempt to begin a joint collaboration with their PLCs before the end of the 09-10 school year.

Fusion County will provide technical assistance, time, training, materials and personnel in order to bring about improvement in Mathematics:

Core Plan

\section{Special Education: Fusion County Schools will provide a free and appropriate education to students with exceptionalities to increase achievement and performance.}

1.1 To provide personnel to meet the needs documented in IEPs for students with special needs in Fusion County Schools

1.2 To provide adequate training for special education teachers to facilitate 21 st Century Skills and implement technology tools into all classrooms.

1.3 To increase the number of special education students scoring at or above mastery in all area on the WESTEST

\section{Date Topic Audience \\ Mode \\ (Coaching, \\ Learning \\ Community, \\ or Trainer \\ Led) \\ Funding \\ Source}

8/09-6/10 Positive Behavior Support

professional and service employees at Elementary School and Elementary School Trainer Led WVDE

$8 / 09-6 / 10$ 
Professional Learning Community -Universal PK professional and service employees at the Fusion Preschool Center Learning Community NA 8/09 SLD Eligibility professional employees at Elementary School and Elementary School Trainer Led WVDE

$8 / 09$

Alternate Identification and Report Pilot

Professional employees and administrators at Elementary School and Elementary School Trainer Led WVDE

8/09

Response to Intervention/Progress Monitoring new elementary professional employees Trainer Led C\&I

$8 / 09$

Student Assistance Team and Team Coordinator Updates Student Assistance Team and Special Education Team Coordinators at each school Trainer Led NA

$8 / 09$

Special Education Compliance and Monitoring special education professional employees Trainer Led C\&I

8/09 Special Education Annual Updates special education professional employees Trainer Led NA

3/10 IEP Development

special education professional employees Trainer Led

\section{Action 02/Special Education-Contracted Services:}

Obtain services needed to provide free appropriate public education to students with exceptionalities.

Special Education ARRA-IDEA

2.1: Provide special education contracted services specifically occupational therapy, physical therapy, psychological services, case management, child find, parent workshops, classroom behavior interventionist and extended school year services

Action 03/Special Education-Materials, Supplies and Equipment: 
Purchase materials, supplies, and equipment to support free appropriate public education for students with exceptionalities.

Special Education ARRA-IDEA

3.1: Provide materials, supplies and equipment for special education teachers and/or special education students

\section{Action 04/Special Education-Other:}

Provide other activities to ensure provision of free appropriate public education for eligible student with disabilities and exceptionalities.

Special Education ARRA-IDEA

\section{1: Provide travel expenses for itinerant teachers/bus transportation instructional aides/director of special education and teachers to attend conferences}

4.2: Provide substitute teachers for coverage of special education teachers

\section{3: Provide indirect costs}




\section{Appendix F}

WVDE Five-Year Online Strategic Plan Text Box 


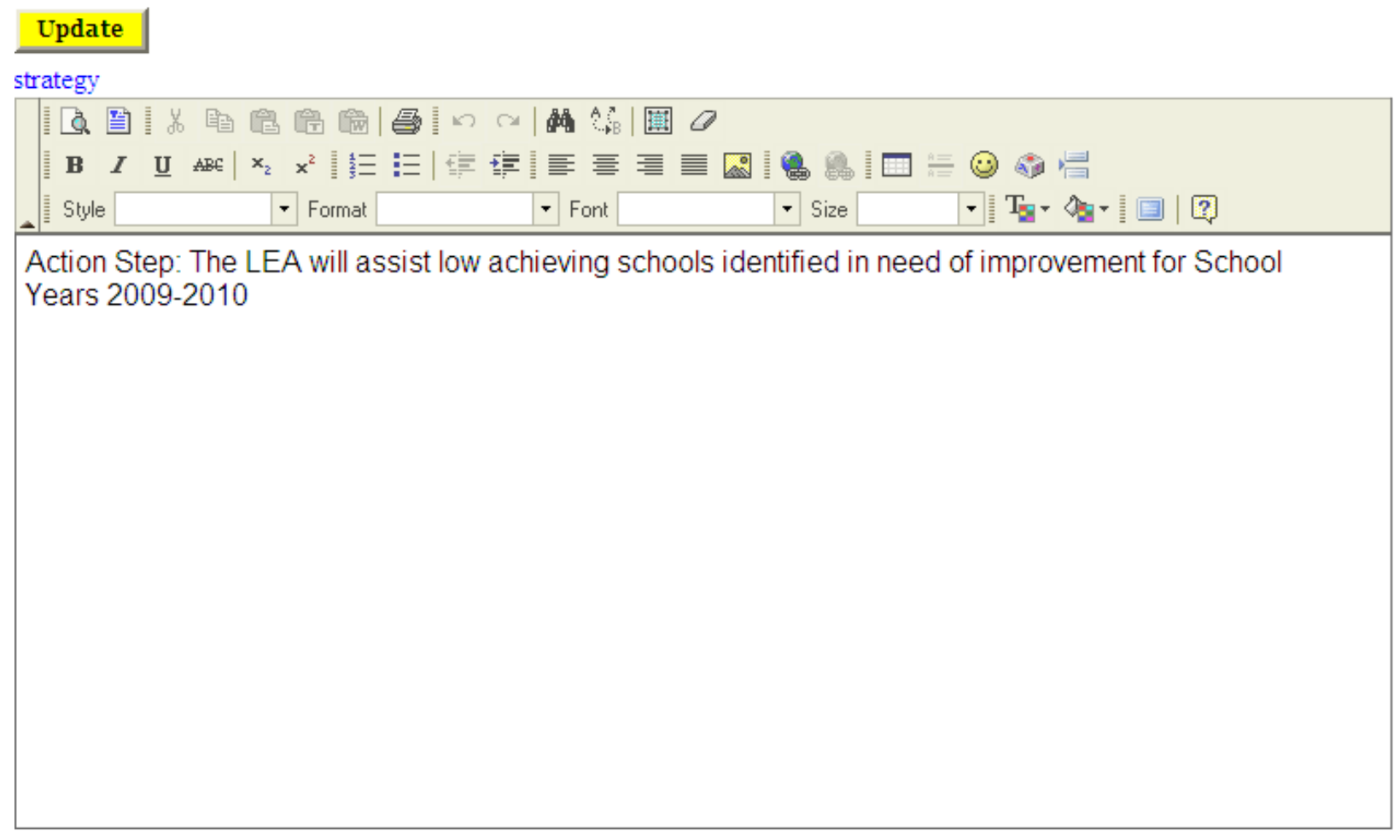

John 